\title{
High fat diet disrupts diurnal interactions between REG3y and small intestinal gut microbes resulting in metabolic dysfunction
}

\section{Authors}

Katya Frazier ${ }^{1 *}$, Amal Kambal ${ }^{1 *}$, Elizabeth A. Zale ${ }^{2}$, Joseph F. Pierre ${ }^{3}$, Nathaniel Hubert ${ }^{1}$, Sawako Miyoshi $^{4}$, Jun Miyoshi ${ }^{5}$, Daina Ringus ${ }^{6}$, Dylan Harris ${ }^{1}$, Karen Yang ${ }^{1}$, Candace Cham ${ }^{1}$, Mark W. Musch $^{1}$, Eugene B. Chang ${ }^{1}$, \& Vanessa Leone ${ }^{1 \#}$

\section{Affiliations \\ *1Department of Medicine, The University of Chicago, Chicago, IL 60637. \\ ${ }^{2}$ Infectious Diseases Division, Weill Cornell Medicine, New York, NY, 10065. \\ ${ }^{3}$ Department of Pediatrics, University of Tennessee Health Science Center, Memphis, TN 38163.}

${ }^{4}$ Department of General Medicine, Kyorin University School of Medicine, Tokyo, Japan 1818611. ${ }^{5}$ Department of Gastroenterology and Hepatology, Kyorin University School of Medicine, Tokyo, Japan 1818611.

${ }^{6}$ Northwestern University Feinberg School of Medicine, Northwestern University, Chicago, IL 60611.

\section{Author List Footnotes}

* These authors contributed equally

\# Lead Contact

\section{Contact Info}

Vanessa Leone, PhD

University of Chicago

Knapp Center for Biomedical Discovery, Rm 9134

900 E. $57^{\text {th }}$ St. Chicago, IL 60637

Email: vleone@bsd.uchicago.edu

Telephone: 773-702-2283

Fax: 773-702-2281 
bioRxiv preprint doi: https://doi.org/10.1101/2020.06.17.130393; this version posted June 18, 2020. The copyright holder for this preprint (which was not certified by peer review) is the author/funder. All rights reserved. No reuse allowed without permission.

\section{Highlights:}

1. Small bowel diurnal Reg3y expression is independent of the core circadian clock

2. Diurnal Reg3y expression requires low fat, high fiber diet-induced gut microbes

3. Western diet disrupts microbial rhythms that suppress diurnal Reg3y expression

4. Western diet in absence of Reg3y permits microbial rhythms promoting dysmetabolism 


\section{Summary}

Gut microbial diurnal oscillations are important diet-dependent drivers of host circadian rhythms and metabolism that ensure optimal energy balance. Yet, the interplay between diet, microbes, and host factors that sustain intestinal oscillations is complex and poorly understood. Here, we report the host C-type lectin antimicrobial peptide Reg3y works with key ileal microbes to orchestrate these interactions in a bi-directional manner, independent from the intestinal core circadian clock. High fat diet diminishes physiologically relevant microbial oscillators essential for host metabolic homeostasis, resulting in arrhythmic host Reg3y expression and increased abundance and oscillation of Reg3y-independent gut microbes. This illustrates a transkingdom co-evolved biological rhythm involving reciprocating, sensor-effector signals between key host and microbial components that ultimately drive metabolism, but are also heavily influenced by diet. Restoring the gut microbiota's capacity to sense and transduce dietary signals mediated by specific host factors such as Reg3y could be harnessed to improve metabolic dysfunction.

Keywords: Circadian rhythms; Innate immunity; Reg3y; Gut microbiota; Small intestine; High-fat diet; Diurnal oscillation; Organoid; Germ-free; Host-microbe interactions 


\section{Introduction}

Disruption of circadian rhythms (CRs) in modern society has contributed to the rise in incidence of metabolic diseases (Turek et al., 2005). CRs are 24-hr oscillations in behavioral and biological processes driven in part by a core circadian clock (CC) transcriptional-translational feedback loop found in nearly all cells within the body (Dibner et al., 2010). These rhythms are crucial to regulation of major metabolic and immune pathways, where nearly half the murine transcriptome is under CC control (Zhang et al., 2014). When CRs are altered or non-functional, adverse metabolic consequences emerge, including increased adiposity and impaired insulin sensitivity (Turek et al., 2005; Jacobi et al., 2015; Karlsson et al., 2003).

Recent work shows the trillions of gut microbes not only influence host digestion, absorption, and energy balance, but are intricately intertwined with the host CC, where disruption either via environmental manipulations, (Thaiss et al., 2014), high fat diet (Leone et al., 2015; Zarrinpar et al., 2014) or via genetic mutation (Liang et al., 2015; Thaiss et al., 2016), results in loss of gut microbiome oscillations. Diurnal microbiome oscillations in cecum, colon, and stool are driven, in part, by time of feeding and nutrient delivery to the gut over $24 \mathrm{hrs}$. However, we previously revealed mice fed via continuous parenteral nutrition (PN) drives unique gut microbial community membership, yet PN microbiota still exhibited diurnal oscillations (Leone et al., 2015). This suggests additional gut signals, whether host-derived, microbially-derived, or both, can play a role in gut microbial rhythmicity.

While host factors drive microbial rhythms, microbes provide feedback that influence host diurnal patterns both locally and peripherally. In mice, gut microbes drive rhythmicity and amplitude of CC and innate immune factors in intestinal epithelial cells (IEC) that influence host lipid metabolism (Wang et al., 2017). Gut microbe antibiotic depletion or their complete absence, i.e. germ-free (GF), significantly impairs circadian dynamics of IEC Toll-like receptor (TLR) expression and downstream gene that drive intestinal antimicrobial peptide (AMP) synthesis, a group of host-derived molecules that target specific microorganisms to aid in maintaining gut homeostasis (Mukherjee and Hooper, 2015).

One particular AMP associated with host-microbe diurnal patterns is Regenerating isletderived protein 3 gamma (Reg3y). REG3y is a Myeloid differentiation primary response 88 (MyD88)-dependent C-type lectin made by IECs throughout the GI tract, and highly expressed in the distal small intestine (SI) (Narushima et al., 1997; Nata et al., 2004; Vaishnava et al., 2008) that targets Gram-positive bacteria (Cash et al., 2006a; Mukherjee et al., 2014). REG3y aids in separating IECs from mucosa-associated microbes, while diet-induced obesity (DIO) ablates Reg3y expression (Everard et al., 2014; Loonen et al., 2014). Antibiotic depletion of gut microbes 
significantly impairs diurnal Reg3y expression in colon and ileum (Mukherji et al., 2013). Reg3ydeficient mice exhibit loss of host-microbial separation (Vaishnava et al., 2011; Wang et al., 2016) and disrupted diurnal rhythms of mucosa-associated microbial abundance within the colon (Thaiss et al., 2016). How diurnal Reg3y expression aids in maintaining normal gut microbial oscillations and the implications for host metabolic health remain unexplored.

We investigated whether signals derived from specific gut bacteria are required to drive host diurnal expression patterns of Reg3y, and if these endogenous cues can "reset" bacterial oscillations. We aimed to identify whether microbial signals were lost in high fat diet (HF)-induced gut dysbiosis, further exacerbating host metabolic disruption. Using both in vivo and in vitro approaches, we show distal SI Reg3y diurnal expression is not under CC control, but is regulated locally by specific, diet-dependent oscillating bacteria. We reveal small molecules derived from bacteria promoted by regular chow diet (RC), but not HF, induce Reg3y expression in vitro, and these bacteria exhibit unique susceptibility to REG3y's antimicrobial action. Finally, we reveal $R e g 3 y$ deficiency coupled with HF permits a gain in oscillation in relative abundances of specific gut microbes normally susceptible to REG3y. Together, our data demonstrate a reciprocating, synchronized relationship between rhythmic, diet-selected SI gut microbes and REG3y, where desynchronization of these local interactions can result in metabolic disruption and perhaps DIO.

\section{Results}

\section{Diurnal expression of SI Reg3y is independent from the core CC gene network and requires diet-induced gut microbiota}

We first examined impact of diet and microbe status on core CC genes within distal ileum mucosal scrapings (DIMS) obtained from GF and SPF mice fed RC or HF. We observed some significant, yet modest core CC gene expression changes within specific Zeitgeber time points (ZT), i.e., Bmal1, Clock, and Cry1 over a 12:12 LD cycle (Figure 1A, Figure S1A). Despite changes within $\mathrm{ZT}$, neither RC, HF, or gut microbe status impacted diurnal rhythmicity and amplitude of core CC genes in DIMS (Table S1).

We next examined diurnal transcript levels of several highly expressed AMPs in DIMS of RC or HF-fed SPF and GF mice. RC-fed SPF mice exhibited significantly increased transcript levels within specific ZTs relative to all other groups, particularly Reg3y (Figure 1B). Additional AMPs, including $\beta$-1,4-glycosidase Lysozyme1 (Lyz1), ribonuclease Angiogenin4 (Ang4), and a-defensin Cryptidin4 (Crypt4) did not exhibit significant differences between groups. Only Reg3y exhibited diurnal rhythmicity in SPF and GF RC-fed mice, despite significantly reduced overall expression and amplitude in GF animals (Table S1). Peak Reg3y expression in SPF RC-fed mice was 
observed at ZT10, 2hrs prior to lights off and presumably prior to onset of feeding. Mucin-2 (Muc2) expression, which has been previously associated with Reg3y (Huang et al., 2017), was also significantly elevated in RC-fed SPF mice at ZT10 (Figure 1C). Only RC-fed GF mice exhibited diurnal Muc2 expression, although overall levels were not changed relative to SPF RC-fed mice.

We confirmed Reg3y diurnal patterns were also evident at the translational level. Similar REG3y diurnal patterns were observed in SPF RC-fed, but not in SPF HF-fed counterparts via immunostaining (Figure 1D,E). Further analysis of DIMS from SPF RC and HF-fed mice via Western blot (Figure 1F) revealed both diet and ZT-dependent REG3y oscillations. Since Reg3y is expressed by both absorptive enterocytes and Paneth cells (Cash et al., 2006a; Narushima et al., 1997; Nata et al., 2004), we next determined if diurnal and diet-dependent Reg3y expression was lost in all compartments following HF. We performed mucosal villus to crypt cell fractionation using timed EDTA exposure of the gut epithelium, followed by qPCR for Reg3y at ZT2 and 10, the nadir and peak of expression. Pooled fractions 1-8 contained absorptive enterocytes and fraction 9 contained crypts (including Paneth cells). We first confirmed cell fraction composition via marker genes sucrase-isomaltase (villus epithelial marker) and Lyz1 (Paneth cell marker) (Figure S1B). Only fractions 1-8 from RC-fed mice exhibited ZT-dependent Reg3y expression, while crypt expression was not different between ZT2 and 10 in RC or HF-fed mice. Together, these data show the core CC gene network is stable regardless of microbe status or diet; however, diurnal rhythms of host $R e g 3 y$ expression within the villous epithelium are driven by both presence of gut microbes and those selected by diet.

\section{HF alters ileal microbiota community membership and dampens microbial diurnal oscillations relative to RC}

We examined microbial community membership within distal ileal luminal contents (DILC) collected every $4 \mathrm{hrs}$ from RC or HF-fed SPF mice via 16S rRNA gene amplicon sequencing and QIIME. HF significantly increased relative abundance of Operational Taxonomic Units (OTUs) belonging to phyla Firmicutes and decreased Bacteroidetes (Figure 2A). No differences were detected in less abundant phyla (Figure S2A). Beta-diversity analysis using Bray-Curtis (Figure 2B, Principal Coordinate Analysis (PCoA)) and Canberra distances (Figure S2B) revealed significant differences between RC and HF DILC microbial communities (Table S3).

Absolute 16S rRNA gene copy number determined via qPCR averaged across ZT in DILC was not different between RC and HF (Figure S2C). Significant differences were only observed between RC and HF-fed mice at ZT6, while diurnal rhythmicity was not detected in RC or HF-fed mice. However, while 16S rRNA gene copy number exhibited a similar amplitude in RC and HF- 
fed mice, HF elicited a phase-shift relative to RC (Figure 2C). Distinct DILC OTU differences were observed between RC and HF-fed mice (Figure 2D), where HF significantly increased Clostridiales and decreased Bacteroidales relative to RC (Table S2).

To determine whether RC or HF impacted DILC diurnal oscillations, we applied empirical JTKCycle (eJTK) to relative abundance data as previously described (Leone et al., 2015). Similar to cecum and feces, $\sim 15 \%$ of DILC taxa oscillated under RC and was dramatically reduced by HF (Figure 2E). 81 unique oscillating OTUs were observed in DILC of RC-fed mice, while 14 unique OTUs were present in HF-fed mice; only two oscillating OTUs overlapped in RC and HF (Table S4). Oscillating RC OTUs annotated to genus were absent, decreased in overall abundance, or lost oscillation under HF (Figure 2F). Despite decreased percentage of oscillating OTUs in HF, several gained oscillations (Figure S2D). Two OTUs exhibiting oscillations under both RC and HF were annotated to genera Ruminococcus and Oscillospira, exhibiting diet-dependent effects on their overall abundances (Figure S2E, Table S4). Together, these data reveal HF dramatically alters distal ileum microbial membership that corresponds to an overall decrease as well as a unique set of oscillating taxa relative to $\mathrm{RC}$.

\section{Specific taxa promoted by RC or HF correlate with distal SI diurnal Reg3y expression}

Using Pearson correlation analysis, we determined only 3 OTUs in DILC of RC and HF-fed mice significantly correlated with Reg3y expression. A Lactobacillus OTU positively correlated with Reg3y expression, while Clostridiaceae and Peptostreptococcaceae OTUs negatively correlated (Figure 2G). Lactobacillus OTU exhibited oscillation only in RC, with dramatically reduced overall levels in HF-fed counterparts at all ZTs (Figure 2F, top left panel). Surprisingly, while OTUs negatively correlated with Reg3y did not exhibit significant oscillations in either RCor HF-fed mice, their relative abundances were significantly increased across all ZT in HF relative to $\mathrm{RC}$ (Figure $\mathbf{2 H}$ ). These associations were also apparent at a higher taxonomic classification level, where relative abundances of families Clostridiaceae, Lactobacillaceae, and Peptostreptococcaceae exhibited nearly identical positive and negative correlations with Reg $3 \mathrm{~V}$ expression (Figure 2I). Lactobacillaceae was increased during the mid to late dark cycle only in RC, while Clostridiaceae and Peptostreptococcaceae were significantly increased at several ZTs in HF-fed counterparts (Figure S2F). These data reveal diet drives unique SI microbiota membership, serving as the primary driver of microbial oscillations. Lactobacillaceae are enriched by $\mathrm{RC}$ and exhibit oscillations, while certain OTUs positively correlate with host diurnal $\operatorname{Reg} 3 \mathrm{Y}$ expression. Conversely, HF diminishes microbial oscillations and promotes Clostridiaceae and Peptostreptococcaceae overall expansion, which negatively correlate with Reg3y expression. 


\section{Complex gut microbiota or individual bacterial strains induced by diet directly influence Reg3y expression in vitro}

We examined the direct impact of diet-induced microbial communities on Reg $3 y$ mRNA in vitro using 3-dimensional intestinal enteroids derived from distal SI of GF or SPF WT mice. We first used enteroids derived from GF WT mice due to their naïve state and nearly undetectable $R e g 3 y$ in vivo. DILC lysate derived from RC-fed SPF mice harvested at ZT10 (peak of host Reg3y expression, Figure 1B) significantly induced Reg3y expression in GF enteroids compared to HF DILC lysate $(p<0.05$, Figure $3 A$ ) after $24 \mathrm{hr}$ exposure, indicating diet-induced gut microbiota directly and differentially impact $R e g 3 \gamma$.

Next, we determined if bacteria type strains belonging to families significantly correlated with Reg3y in vivo (Figure 2G,H) could directly influence expression in vitro. Conditioned media (CM) or bacterial lysates were prepared from Lactobacillus rhamnosus GG (LGG, Lactobacillaceae), Peptostreptococcus anaerobius (Clostridiaceae), and Peptoanaerobacter stomatis Sizova ( $P$. stomatis, Peptostreptococcaceae,). Enteroids derived from GF WT mice exhibited significant induction of Reg $3 y$ expression following $12 \mathrm{hr}$ exposure to either LGG-derived CM or lysate (Figure 3B, S3A). Neither $P$. anaerobius nor $P$. stomatis $C M$ or lysate significantly induced $R e g 3 \gamma$ expression. LGG CM similarly induced $R e g 3 \gamma$ in enteroids derived from SPF WT mice, albeit with a $12 \mathrm{hr}$ delay after $24 \mathrm{hr}$ exposure (Figure $3 \mathrm{C}$ ). These results indicate that CM is equally capable of Reg3y upregulation on GF or SPF-derived enteroids; therefore, we used SPF-derived enteroids going forward.

We next tested if CM from a non-inducer could inhibit inductive influences of LGG on Reg3y expression. We observed LGG alone induced Reg3y expression, while $P$. stomatis alone resulted in no induction (Figure 3D). However, even in the presence of LGG CM, co-exposure to $P$. stomatis $\mathrm{CM}$ at any time point suppressed induction of Reg3y expression. These data suggest small molecules or components derived from bacteria exhibiting correlations with Reg $3 y$ in vivo directly influence expression in a bacteria species-specific manner.

To test whether CM from LGG or $P$. stomatis requires MyD88 for Reg3y induction as previously shown (Natividad et al., 2013; Vaishnava et al., 2008), enteroids were derived from SPF MyD88 ${ }^{+-}$or MyD88 ${ }^{-/-}$littermate mice. LGG CM significantly induced Reg $3 y$ in $\mathrm{MyD}^{-1 / 8^{+-}}$, but not $M y D 88^{-/-}$enteroids, implying LGG requires MyD88, while no induction was observed with $P$. stomatis CM regardless of MyD88 status (Figure S3B). CM size fractionation revealed small molecules less than 3kDa derived from LGG were sufficient to induce Reg3y expression, while the suppressive effect of $P$. stomatis was lost in all fractions containing small molecules less than 
30kDa (Figure S3C). This suggests LGG-derived small molecules and components induce, while $P$. stomatis-derived large molecules and components suppress Reg3y expression in a MyD88dependent manner.

\section{Lactobacillus ZT-dependent distal SI Reg3y expression is mediated by diet composition}

To determine whether our in vitro findings translated in vivo, we monoassociated GF mice fed either RC or HF with LGG. HF+LGG resulted in a modest, yet significant, body weight increase compared to RC+LGG at 3 and 4 wks post-association (Figure 3E). Liver weights were not different, however both GF HF and RC + LGG mice exhibited significantly increased gonadal fat relative to GF RC (Figure S3D, top/middle panels). GF HF and HF+LGG exhibited significantly increased mesenteric fat weight relative to GF RC and RC+LGG (Figure S3D, bottom panel). Reg3y expression was significantly increased in DIMS only from RC+LGG, but not HF+LGG mice harvested at ZT2 and 10 (nadir and peak expression in RC SPF mice), where ZT10 tended to be higher (Figure 3F). Lyz1 expression was increased only in RC+LGG mice (Figure S3E). Together, these data suggest microbes and diet combined impact distal ileal Reg $3 y$ with corresponding changes in host metabolic outcomes.

\section{Diet-induced Gram-positive bacteria are uniquely susceptible to REG3y}

Our observations revealed specific Gram-positive bacteria directly induce or suppress ileal $R e g 3 y$ expression. To elucidate bidirectionality of this dynamic, we determined if REG3y exhibited differential bactericidal action against these strains using murine recombinant REG3y (rREG3y). We recapitulated previous findings showing Gram-negative bacteria were not susceptible to rREG3y, whereas only $\sim 30 \%$ of Gram-positive Enterococcus faecalis Portland CFUs remained at

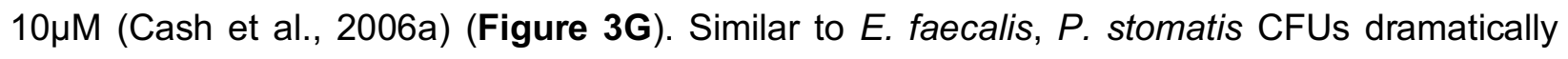

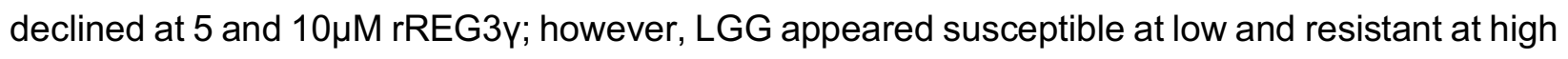
concentrations, suggesting unique susceptibility of representative diet-induced gut bacteria correlating with host $\operatorname{Reg} 3 y$.

We next determined if LGG's lack of susceptibility to high rREG3y concentrations was due to the bactericidal assay's nutrient-limited conditions and identified rREG3y's minimal inhibitory concentration (MIC) in actively dividing bacteria. Following an overnight exposure of Grampositive and -negative bacteria to rREG3y concentrations ranging from 15uM to 0.01uM optical density was measured (Figure $\mathbf{3 H}$ ). Relative to vehicle control, E. coli $K 12$ was unaffected by rREG3y ( $0 \%$ inhibition), while Listeria monocytogenes growth was inhibited by $\sim 80 \%$ or greater at 7.5 and $15 \mu \mathrm{M}$ rREG3y. E. faecalis growth was inhibited by $\sim 40 \%$ at $15 \mu \mathrm{M}$ rREG3y and 
decreased in a dose-dependent manner. LGG growth was not inhibited and appeared to be enhanced at nearly all rREG3y concentrations. Together, these data suggest Lactobacillus may be resistant to REG3y's antimicrobial properties relative to other Gram-positive bacteria.

\section{Murine indigenous distal SI Lactobacillus species are uniquely resistant to REG3y}

To this point, our in vitro studies utilized bacteria type strains which may not fully recapitulate those found in the murine gut, i.e., LGG was originally isolated from human GI tract. We tested whether our observation regarding LGG was generalizable across Lactobacillus in murine-derived strains. We isolated four indigenous Lactobacillus strains from DILC of RC-fed WT mice. We revealed $L$. johnsonii MRS4 and L. intestinalis BBA5 behaved similar to LGG following rREG3y

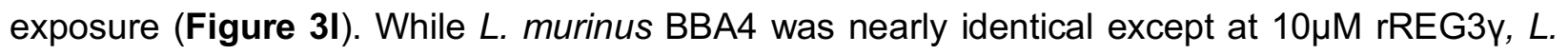
reuteri BBA15 displayed similar susceptibility as $E$. faecalis and $P$. stomatis. The MIC assay also showed L. johnsonii, L. intestinalis, and L. murinus were comparable to LGG, while L. reuteri growth was inhibited by $\sim 70 \%$ at high rREG3y concentrations (Figure $3 \mathbf{J}$ ). These data show some, but not all, RC-promoted Lactobacillus can resist or evade REG3y, which could impact their ability to thrive under fluctuating diurnal intestinal conditions.

\section{REG3y deficiency promotes diet-independent glucose intolerance and does not impact core CC gene expression in distal SI}

We next examined how host REG3y deficiency impacts host and microbial dynamics in RC and HF-fed SPF global Reg3y knockout $\left(\operatorname{Reg} 3 \gamma^{-/}\right)$and heterozygote littermate control $\left(\operatorname{Reg} 3 \gamma^{+/}\right)$ mice. Reg $3 \gamma^{-/}$mice were equally susceptible to HF DIO relative to $R e g 3 \gamma^{+/}$littermates, where body weight increased $\sim 12 \%$ relative to RC-fed counterparts over 4 weeks (Figure 4A). Liver weights were not different while HF significantly increased gonadal and mesenteric fat relative to $\mathrm{RC}$ regardless of genetic background (Figure S4A). RC-fed $R e g 3 \gamma^{-/}$mice exhibited significantly worse glucose tolerance, with slower glucose clearance rates and increased area under the curve (AUC) compared to RC-fed $R e g 3 \gamma^{+/}$controls while HF decreased blood glucose clearance rate regardless of genetic background relative to $\mathrm{RC}$-fed $R e g 3 \gamma^{+/-}$mice (Figure 4B). These data suggest REG3y does not alter HF DIO, but rather plays a functional role in how diet impacts glucose tolerance, where REG3y deficiency impairs glucose clearance rates regardless of diet.

We explored diet vs. REG3y influences on distal ileum core CC gene expression. Diet or genetic background did not affect overall and diurnal CC expression, further supporting core CC gene network and Reg3y independence (Figure 4C, S4B; Table S1). Significantly elevated and diurnal Reg3y expression were evident in RC Reg $3 \gamma^{+/-}$mice, peaking at ZT10, with no detectable 
transcript in Reg3 $\gamma^{-/}$mice (Figure 4D). Diet or genotype had no effect on levels, diurnal rhythms, or amplitude of Crypt4, Lyz1, Ang4, and TIr expression (Figure S4C, Table S1). RC-fed Reg $3 \gamma^{+/}$ mice exhibited increased overall levels and diurnal patterns of Muc2 expression, which peaked at ZT10 mirroring Reg3y; however, Muc2 expression was reduced and arrhythmic in HF-fed Reg $3 \gamma^{+/-}$ as well as RC and HF-fed Reg $3 \gamma^{-/}$mice (Figure 4E). These data suggest independence of Reg $3 \gamma$ and other AMPs from the core CC, while Reg3y appears to mediate diet effects on Muc2 expression and rhythmicity, which may impact diurnal rhythms in distal ileum mucosal barrier function.

\section{HF overwhelms the modest influence of REG3y on ileal microbiota and shifts specific bacterial families correlated with Reg $3 y$ expression}

We determined the influence of diet vs. Reg3y status on DILC and DIMS gut microbial community membership and oscillations via 16S rRNA gene amplicon sequencing in samples from $R e g 3 \gamma^{+-}$and $R e g 3 \gamma^{-/-}$mice. Regardless of genotype, HF significantly increased relative abundance of Firmicutes with corresponding decrease in Bacteroidetes (Figure 5A). Less dominant phyla exhibited modest or no significant change in HF groups (Figure S5A). HF also shifted community membership regardless of genotype in both DILC and DIMS assessed via Beta-diversity analyses using Bray Curtis distances (Figure 5B, S5B; Table S3). This was confirmed via independent comparison of dietary conditions within genotype (Figure S5C; DIMS data not shown). Significant differences in DILC community membership were observe between genotypes, but only on RC which indicated a diet-dependent genotype effect (Figure 5C, left panel), which was ablated by HF (Figure 5C, right panel). No difference in DIMS was observed (data not shown). These data suggest REG3y exerts a modest but significant influence on community membership under RC, which is overwhelmed by $\mathrm{HF}$.

16S rRNA gene copy number in DILC was not different between any group (one-way ANOVA, $\mathrm{p}>0.05$; Figure S5D), while diurnal rhythmicity was only apparent in RC-fed Reg $3 \gamma^{-/}$mice (Figure 5D, Table S1). Regardless of genotype, HF significantly altered DILC relative abundances (ANOVA Bonferroni $\mathrm{p}<0.05$, Table S5), while diet-dependent differences in oscillation were observed between genotypes (Figure S2E). We further explored the impact of diet vs. REG3y on microbial community membership at the family level. HF resulted in decreased relative abundance of Lactobacillaceae and increased Peptostreptococcaceae and Clostridiaceae regardless of genotype (Figure 5E). DIMS were nearly identical, except relative abundance of Clostridiaceae was decreased by HF (Figure S5F). DILC Lactobacillaceae relative abundance was decreased in HF-fed $R e g 3 \gamma^{-/}$at ZT14 relative to RC-fed $R e g 3 \gamma^{+/-}$mice, while both Peptostreptococcaceae 
and Clostridiaceae tended to be lower at nearly all ZTs in RC-fed mice regardless of genotype (Figure 5F). Although diurnal patterns were similar, Clostridiaceae was less abundant in DIMS at nearly all ZTs (Figure S5G). These data confirm that diet broadly reshapes distal ileum microbes with a modest, and diet-dependent effect of REG3y.

\section{Reg3y deficiency coupled with HF promotes gain of oscillation in Clostridiales and bacteria that are susceptible to REG3y's bactericidal action}

Examination of $16 \mathrm{~S}$ rRNA amplicon sequences from DILC via eJTK revealed RC-fed Reg $3 \gamma^{+/-}$ mice displayed significantly more oscillating OTUs than HF-fed counterparts, while both $\operatorname{Reg} 3 \gamma^{-/-}$ groups exhibited nearly identical numbers (Figure 6A, Table S6). DIMS exhibited opposite patterns; regardless of diet, Reg3 $\gamma^{-/}$mice exhibited the greatest oscillating OTUs (Figure 6B). Further, RC-fed $R e g 3 \gamma^{+/}$mice exhibited the highest diversity of oscillating DILC OTUs at the taxonomic level of order (Figure 6C, left panel). In Reg $3 \gamma^{+/-}$mice, HF induced more oscillating Bacteroidales, fewer Lactobacillales, and no major change in Clostridiales. In Reg $3 \gamma^{-/-}$mice, HF induced fewer oscillating Bacteroidales, more Lactobacillales, and significantly more Clostridiales. DIMS exhibited an inverse microbial oscillator phenotype (Figure 6C, right panel). Both RC-fed groups exhibited decreased diversity in taxonomic order of oscillating OTUs and more oscillating Lactobacillales relative to HF (Table S7). Reg $3 \gamma^{-/}$mice also hosted the highest number of oscillating Bacteroidales and Clostridiales relative to $R e g 3 \gamma^{+/-}$counterparts.

We next examined oscillations of Lactobacillaceae, Clostridiaceae, and Peptostreptococcaceae (Figure 6D). Many oscillating Lactobacillus OTUs exhibited increased relative abundance in RC-fed mice, regardless of genotype. $60 \%$ of these OTUs oscillated only in RC-fed mice, indicating Lactobacillus diurnal rhythms are dependent on RC. Despite an overall lack of species-level annotation, two Lactobacillus OTUs were classified as $L$. reuteri. Although the relative abundance of $L$. reuteri was increased in RC, these OTUs only oscillated in HF when diurnal Reg3y expression was impaired. Similarly, nearly all oscillating Clostridiaceae and Peptostreptococcaceae OTUs were only observed when diurnal Reg3y expression patterns were impaired or completely absent. This expands our findings from SPF WT mice, in which HF only impacted relative abundance patterns and overall number of oscillating microbiota (Figure 2). This suggests bacteria that are normally susceptible to REG3y, i.e., L. reuteri, Clostridiaceae, and Peptostreptococcaceae, only gain rhythmicity following HF-diet induced reshaping of distal ileum microbiota coupled with absence of host REG3y.

\section{Discussion}


Biological rhythms are essential to all life forms for coordination of internal events with the environment to maximize efficiency in metabolic, neural, immune, and other critical functions. CRs consist of a feedback loop of transcription factors that induce rhythmic gene expression patterns to orchestrate a hierarchy of downstream events to achieve this efficiency. However, the gut microbiome, which also exhibits rhythms, cannot entrain to photic environmental cues, instead responding to signals such as meal timing, content, and amount. Three major findings of our study underscore the uniqueness of gut microbial rhythms, as well as provide insight into a dynamic, transkingdom interaction between microbes and local host factors. First, we define a temporal push-pull relationship between specific microbial oscillators and the innate AMP Reg $3 y$, which exhibits diurnal rhythmicity but is independent of the core CC. Second, relevant to human metabolic disorders, we demonstrate HF, low-fiber diet results in loss of functional microbial oscillators and gain of populations that no longer engage with and suppress Reg3y. Third, the combination of HF and loss of Reg $3 y$ allows specific microbial oscillators to emerge, which could contribute to metabolic imbalances such as DIO. While an essential role of SI microbes in regulating circadian networks and metabolism has been previously demonstrated, these studies focused on host parameters and outcomes without examining gut microbe membership, function, and rhythmicity. Here, we demonstrate a dynamic, bidirectional interaction between diet-induced gut microbes and Reg $3 y$ through the lens of CRs and metabolic homeostasis.

In our model system, we demonstrate the SI core CC gene network exhibits remarkable autonomy from both diet- and microbe-derived cues (Figure 1A), confirming previous work (Wang et al., 2017). These results underscore uniqueness of the gut relative to other peripheral tissues; we previously showed rhythmicity of hepatic core CC genes is exquisitely sensitive to diet-induced microbial cues (Leone et al., 2015). Importantly, we show distal SI diurnal Reg3y regulation is instead driven by microbial diurnal cues under RC (Figure 1B). HF-induced gut dysbiosis results in arrhythmic Reg3y, underscoring the importance of microbes as key drivers of this phenomenon. The reason for decoupled diurnal regulation of these two systems is unclear; however, it could indicate autonomy of the gut is required to maintain proper timing of essential digestive functions where perturbing rhythmicity of the CC could ultimately compromise host fitness.

Our results clearly demonstrate RC promotes specific microbes that are essential to drive host diurnal SI Reg3y expression. While Lactobacillus is known to correlate with Reg3y (Huang et al., 2017), we reveal their diurnal dynamics are intricately intertwined with this phenomenon (Figure 2F). In the SI, approximately $15 \%$ of microbes oscillate on RC and HF eliminates the majority of oscillators (Figure 2E), corroborating previous findings in the distal GI tract (Leone et al., 2015; Thaiss et al., 2014; Zarrinpar et al., 2014). We reveal DIO is not only associated with decreased 
SI Reg3y expression (Everard et al., 2013, 2014; Vaishnava et al., 2011), but also HF-induced gut dysbiosis is essential to suppress rhythmic Reg3y expression (Figure 1B). Our work supports diet overwhelms genetics in shaping microbial SI membership, where HF elicits greater influence than Reg3y genetic deletion (Figures 2, 5, 6), confirming previous studies in the distal GI tract (Carmody et al., 2015; Devkota et al., 2012). Interestingly, HF coupled with global REG3y deficiency permits diet-induced gut microbes to increase proportionally and gain oscillations within the community (Figure 6D). Together, this reveals diet is the main driver of gut microbiota membership and oscillations, while Reg $3 y$ serves a secondary role in shaping rhythmicity of key Sl gut microbes.

We provide direct evidence that diet-induced representative and indigenous SI bacteria associate with and directly induce diurnal Reg3y expression requiring MyD88 (Natividad et al., 2013; Vaishnava et al., 2008). While Lactobacillus correlate with diurnal Reg3y expression, the precise factor they secrete or produce in vivo to drive this is not clear. However, we show small molecules derived only from specific Lactobacillus can induce Reg3y in vitro (Figure S3C), and may involve direct activation of IEC TLRs. Whether Lactobacillus-mediated diurnal Reg $3 \mathrm{Y}$ expression also requires interleukin-22/STAT3-mediated induction is unclear and requires further exploration. Functionally, previous work showed bacteria expressing Bile Salt Hydrolase (BSH), such as Lactobacillus, are associated with Reg3y expression (Joyce et al., 2014; O'Flaherty et al., 2018). Whether BSH mediates production of small molecules that directly induce Reg $3 \mathrm{~V}$ expression is unknown. However, the ability of Lactobacillus species to express BSH could influence their diurnal oscillations, which may relate to food intake timing and bile acid delivery/reuptake in the ileum (Zarrinpar et al., 2014).

To our knowledge, negative associations between SI Reg3y expression and specific gut microbes have not been well established. We show Clostridiaceae and Peptostreptococcaceae family members do not induce, and may even suppress Reg $3 y$ expression in vitro in certain instances (Figures 3G,H). Whether this occurs in vivo remains to be determined. We were unable to successfully monoassociate RC or HF-fed GF mice with $P$. stomatis despite several attempts. Since $P$. stomatis was isolated from human oral cavity, it is possible that murine gut is not a suitable environment and indigenous Peptostreptococcaceae strains could be used in future studies to explore their influence on host Reg $3 \gamma$.

While REG3y's ability to target commensal vs. pathogenic bacteria has been shown (Cash et al., 2006a), we also reveal its antimicrobial action may be more targeted. While some Lactobacillus species evade REG3y, L. reuteri is quite susceptible (Figure 3I-K), more closely aligning with $P$. stomatis and E. faecalis (Figure $\mathbf{3 G}, \mathbf{H}$ ). This is in line with work showing Reg $3 y$ 
overexpression in murine IECs led to expansion of Lactobacillus abundance in general, while certain species such as L. reuteri, were reduced (Huang et al., 2017). The reason for Lactobacillus species differential sensitivity is unclear, however we posit diurnal induction of and resistance to REG3y may aid in niche maintenance within the community while contributing to host intestinal health. Given the heterotrophic nature and heterogeneous proteolytic capacity of Lactobacillus, it is possible certain species are able to utilize host-derived peptides, including AMPs, as a novel fuel source under nutrient-limiting conditions.

The dual function of REG3y as both an AMP and hormonal signal remains poorly defined, particularly in HF DIO. We show that global Reg $3 y$ deficiency worsens glucose sensitivity under $\mathrm{RC}$ feeding conditions and is not exacerbated by HF (Figure 4B), which is unique relative to a previous report (Bluemel et al., 2018). While compelling, we cannot establish which tissue compartment drives glucose tolerance and whether diurnal Reg3y expression is important since we employed a global knockout. Further investigation is required to elucidate the direct diurnal signaling influence of $R e g 3 \gamma$, locally and globally, and its impact on metabolism. Further, we identified modest differences in luminal SI microbes between RC-fed $R e g 3 \gamma^{+/-}$and $R e g 3 \gamma^{-/-}$mice, while others have not observed this (Vaishnava et al., 2011). This could be due to microbiome differences between animal vivaria, housing conditions (individual vs. group), our use of heterozygote mice as controls.

Together, we show diet coupled with REG3y, through their actions on gut microbial populations, are essential components for regulating rhythmicity of specific bacteria, independent of archetypal CC gene networks. These microbial rhythms depend on dynamic diet-host-microbe interactions. We speculate specific bacteria either flourish or are lost as a result of altered dietary intake leading to $R e g 3 y$ induction or suppression at crucial times. If improper timing or loss of diurnal Reg3y persists, it could render the host more susceptible to infection or worse pathogenesis of chronic diseases, such as DIO. These interactions are a prime example of transkingdom co-evolution that is essential for the mammalian host to adapt to changes in daily dietary intake. The knowledge gained here provides a framework for identification of interventions that restore diurnal host-microbe interactions to alleviate metabolic diseases associated with Western diet.

Acknowledgements: The present research was supported by NIH NIDDK K01 DK111785 (VL); NIDDK Digestive Diseases Research Core Center (NIH P30 DK42086); NIDDK F31 DK122714 (KF) and the University of Chicago GI Research Foundation. We thank the UChicago Human Tissue Resource Center for histological processing and Gnotobiotic Research Animal Facility staff 
for animal husbandry. We are indebted to Dr. Lora Hooper for thoughtful discussions regarding experiments and data.

Author Contributions: KF, EZ, EBC, and VL conceptualized experiments. AK, EZ, JFP, SM, JM, $\mathrm{DR}, \mathrm{DH}, \mathrm{KY}, \mathrm{CC}, \mathrm{MWM}$, and VL performed experiments. VL, AK, EZ, KF, and NH analyzed data. $\mathrm{KF}, \mathrm{EBC}$, and $\mathrm{VL}$ wrote the manuscript. VL oversaw the entire project.

\section{Declaration of Interests}

The authors declare no competing interests.

\section{Main figure titles and legends:}

Figure 1. Diurnal patterns of SI Reg $3 y$ expression is independent of the core CC network and requires presence of diet-induced gut microbes

(A - C) Circadian (A), anti-microbial peptide (B), and Mucin2 (C) gene expression in DIMS collected every $4 \mathrm{hrs}$ from RC or HF-fed GF and SPF mice maintained in 12:12 LD (indicated by open and closed bars on the X-axis). ${ }^{*} \mathrm{p}<0.05 ;{ }^{* *} \mathrm{p}<0.01 ;{ }^{* *} \mathrm{p}<0.001$ via Brown-Forsythe and Welch ANOVA followed by Dunnett's test as compared to SPF-RC control—star color indicates treatment exhibiting significance within $\mathrm{ZT}$. $\xi$ indicates significant $(p<0.05)$ co-sinor expression patterns detected via CircWave.

(D) Representative immunostaining images for REG3y in distal ileum sections from RC and HFfed SPF mice at ZT 2, 10, and 18, with corresponding fluorescence intensity quantification. Welch's t test was performed within ZT.

(E) REG3y Western blot in DIMS from RC and HF-fed SPF mice at ZT2, 10, and 18.

(F) Reg3y expression in distal ileum epithelial fractions from RC or HF-fed SPF mice at ZT2 and 10. Fractions $1-4$ and 5-8 = absorptive enterocytes, fraction $9=$ crypts harboring stem cells and Paneth cells. ${ }^{* * *} p<0.001 ;{ }^{* * *} p<0.0001$ via two-way ANOVA followed by Tukey's test.

\section{Figure 2. Diet shapes distal SI gut microbe community membership and oscillations that} correlate with Reg3y expression

(A) Relative abundances of dominant phyla in DILC from RC or HF-fed SPF mice via 16S rRNA gene amplicon sequencing averaged across all timepoints within diet treatment. Box-whisker plots represent mean $\pm \min / \max .{ }^{* * *} p<0.001$ via Welch's t test.

(B) Bray-Curtis PCoA of 16S rRNA amplicon sequences from RC (blue) and HF (red)-fed mice. 
(C) Absolute 16S rRNA gene copy number determined via qPCR in RC or HF-fed mice. Data represent mean \pm SEM. * $\mathrm{p}<0.05$ via Welch's $\mathrm{t}$ test.

(D) anvi'o heatmap of $16 \mathrm{~S}$ rRNA relative abundances in DILC from RC or HF-fed mice ( $n=2-3$ mice/ZT). Columns = OTUs, rows = samples. Colored bars at the bottom represent taxonomy. Blue and red bars to the right represent diet, gray bars represent $\mathrm{ZT}$.

(E) Percentage (pie charts) of oscillating and non-oscillating OTUs determined via eJTK and numbers (venn diagram) of unique and shared oscillators in DILC from mice fed RC or HF.

(F) Relative abundances of significantly oscillating OTUs annotated to genus only in RC-fed mice. Data represent mean \pm SEM. *indicates significant oscillation $(p<0.05)$; $\xi_{\text {indicates significant }}$ oscillation ( $p=0.05-0.1)$ detected via eJTK.

(G) Reg3y expression vs. relative abundances of OTUs exhibiting significant Pearson correlations (Bonferroni $\mathrm{p}<0.05$ ) in RC and HF-fed mice. Linear regression lines with $95 \%$ confidence bands shown.

(H) Relative abundance of OTUs exhibiting significant negative correlation with Reg3y expression in RC and HF-fed mice.

(I) Reg $3 y$ expression vs. relative abundances of OTUs at the family level that exhibit significant Pearson correlations in RC and HF-fed mice. Linear regression lines with 95\% confidence bands shown.

Figure 3. Diet-induced Gram-positive bacteria drive host Reg3y expression and exhibit unique susceptibility to REG3y's antimicrobial properties

(A) Reg3y expression in GF WT enteroids following 24hr exposure to DILC lysate obtained from RC or HF-fed SPF WT mice at ZT10 relative to PBS vehicle control. $n=6$ technical replicates/treatment. Data representative of 3 independent experiments. Data represent mean \pm SEM. ${ }^{*} \mathrm{p}<0.05$ via Welch's $t$ test.

$(B, C)$ Reg3y expression in GF (B) or SPF (C) WT enteroids following 12 or $24 \mathrm{hr}$ exposure to conditioned media (CM) from cultured bacteria strains relative to blank media. $n=3-6$ technical replicates/treatment. Box-whisker plots represent mean $\pm \mathrm{min} / \mathrm{max}$, representative of 3 independent experiments. ${ }^{* * *} p<0.0001,{ }^{* *} p<0.01,{ }^{*} p<0.05$ via Brown-Forsythe and Welch ANOVA followed by Dunnett's test within timepoint; n.s.=not significant.

(D) Reg3y expression in SPF WT enteroids following 6, 12 or $24 \mathrm{hr}$ exposure to CM from cultured bacteria strains relative to blank media. After 6hrs, enteroids were either collected or exposed to second $\mathrm{CM}$ treatment. $n=3$ technical replicates/treatment. Data represent mean $\pm S E M$, representative of 2 independent experiments. Symbols indicate significant differences relative to: 
\#-12hr LGG; @-6hr P. stomatis; \$-12hr P. stomatis $\rightarrow$ LGG. p<0.05 via 2-way ANOVA followed by Tukey's test.

(E) Percent weight change relative to baseline of RC or HF-fed GF or LGG-monoassociated WT mice. $n=6-8$ mice/treatment. Data represent mean \pm SEM. ${ }^{*} p<0.05$ via Brown-Forsythe and Welch ANOVA followed by Dunnett's test.

(F) Reg3y expression in DIMS of RC or HF-fed GF or LGG-monoassociated WT mice collected at ZT2 and 10. Data represent mean \pm SEM, representative of 2 independent experiments. Bars with different letters are significantly different $(p>0.05)$ via two-way ANOVA followed by Tukey's test.

$(G, I)$ Percent remaining CFUs of representative $(G)$ or indigenous Lactobacillus strains (I) following $2 \mathrm{hr}$ exposure to $\mathrm{rREG} 3 \mathrm{y}$ relative to vehicle control. $n=2$ replicates/bacteria strain. Data represent mean \pm stdev, representative of 3 independent experiments. Symbols indicate significant differences relative to vehicle control; 1 symbol $=p<0.05 ; 2$ symbols $=p<0.01 ; 3$ symbols $=p<0.001$; four symbols $=p<0.0001$, via one-way ANOVA followed by uncorrected Fisher's LSD.

$(\mathbf{H}, \mathbf{J})$ Minimum inhibitory concentration (MIC) assay of representative $(\mathrm{H})$ or indigenous Lactobacillus strains $(\mathrm{J})$ exposed to varying concentrations of $\mathrm{rREG} 3 \mathrm{y} . n=2$ replicates/strain. Data represent mean \pm stdev, representative of 3 independent experiments. *represents $80 \%$ growth inhibition ( $\mathrm{MIC}_{80}$ ); ${ }^{*}$ represents $50 \%$ growth inhibition ( $\mathrm{MIC}_{50}$ ).

(K) Reg $3 y$ expression in enteroids derived from SPF WT mice following 12 or $24 \mathrm{hr}$ exposure to CM from L. murinis BBA4 and $L$. reuteri BBA15. $n=6$ technical replicates/treatment. Data representative of 1 independent experiment. Box-whisker plots represent mean \pm min/max. ${ }^{*} p<0.05$ via Welch's t test.

Figure 4. Reg3y deficiency impacts glucose homeostasis in a diet-dependent manner independent from the core $\mathrm{CC}$ network

(A) Percent weight change from baseline in RC or HF-fed Reg $3 \gamma^{+/-}$or Reg $3 \gamma^{-/}$mice fed. $n=23-25$ mice/treatment. Data represent mean \pm SEM. ${ }^{*} \mathrm{p}<0.05$; ${ }^{* *} \mathrm{p}<0.01 ;{ }^{* *} \mathrm{p}<0.001$ via Brown-Forsythe and Welch ANOVA followed by Dunnett's test as compared to RC-fed Reg $3 \gamma^{+/-}$control—star color indicates treatment exhibiting significance within time point.

(B) Glucose tolerance test in Reg3 $3 \gamma^{+/-}$or Reg $3 \gamma^{-/-}$mice fed RC or HF. $n=8-9$ mice/treatment. Data represent mean \pm SEM. ${ }^{*} p<0.05 ;{ }^{* *} p<0.01 ;{ }^{* *} p<0.001 ;{ }^{* * *} p<0.0001$ via Brown-Forsythe and Welch ANOVA followed by Dunnett's test relative to Reg $3 \gamma^{+/} \mathrm{RC}$ control—star color indicates treatment exhibiting significance within time point. Inset graph represents Area Under the Curve. 
(AUC). Box-whisker plots represent mean \pm min/max. Bars with the same letter are not significantly different $(p>0.05)$ via two-way ANOVA followed by Tukey's test.

(C-E) Circadian (C), anti-microbial peptide (D), and Muc2 (E) gene expression in DIMS from RC or HF-fed SPF Reg $3 y^{+/}$or Reg $3 \gamma^{-/}$mice harvested every 4 hrs over a 12:12 LD. ${ }^{*} p<0.05 ;{ }^{* *} p<0.01$; ${ }^{* * *} p<0.001 ;{ }^{* * *} p<0.0001$ via Brown-Forsythe and Welch ANOVA followed by Dunnett's test relative to $R e g 3 y^{+/} \mathrm{RC}$ control-star color indicates treatment exhibiting significance within ZT time point. $\xi$ indicates significant $(p<0.05)$ co-sinor expression patterns detected via CircWave.

\section{Figure 5. REG3y deficiency modestly impacts distal SI gut microbe community membership in a diet-dependent manner}

(A) Relative abundances of dominant bacterial phyla in DIMS from RC or HF-fed SPF Reg3Y ${ }^{+/}$or $R e g 3 \gamma^{-/}$mice, determined via 16S rRNA gene amplicon sequencing. Box-whisker plots represent mean $\pm \min / \max .{ }^{*} p<0.05 ;{ }^{* *} p<0.01 ;{ }^{* * *} p<0.001$ via Brown-Forsythe and Welch ANOVA followed by Dunnett's test.

(B,C) Bray-Curtis PCoA of 16S rRNA amplicon sequencing in DILC from both $R e g 3 \gamma^{+/-}$or $\operatorname{Reg} 3 \gamma^{-}$ / mice fed RC or HF (B) and separated by RC or HF (C).

(D) $16 \mathrm{~S}$ rRNA gene copy number in DILC from RC or HF-fed Reg $3 \gamma^{+/}$or Reg $3 \gamma^{-/}$mice. Data represent mean \pm SEM. Statistics via Brown-Forsythe and Welch ANOVA followed by Dunnett's test relative to $R e g 3 \gamma^{+/} \mathrm{RC}$ control. $\xi$ indicates significant $(p<0.05)$ co-sinor expression patterns detected via CircWave.

(E) Average family relative abundances in DILC from RC or HF-fed $R e g 3 \gamma^{+/-}$or $R e g 3 \gamma^{-/}$mice. Data represent mean \pm SEM. ${ }^{*} p<0.05 ;{ }^{* *} p<0.01$; ${ }^{* * *} p<0.001 ;{ }^{* * *} p<0.0001$ via Brown-Forsythe and Welch ANOVA followed by Dunnett's test.

(F) Relative abundance of bacteria families in DILC from RC or HF-fed Reg $3 \gamma^{+/-}$or Reg $3 \gamma^{-/-}$mice. Data represent mean \pm SEM. ${ }^{*} p<0.05$ via Brown-Forsythe and Welch ANOVA followed by Dunnett's test relative to $R e g 3 y^{+-} \mathrm{RC}$ control-star color indicates treatment exhibiting significance within ZT.

Figure 6. Diet coupled with Reg3y deficiency induces unique microbial community member specific diurnal oscillations

$(A, B)$ Number of significantly oscillating OTUs detected via eJTK in DILC (A) and DIMS (B) from $\mathrm{RC}$ or HF-fed Reg $3 \gamma^{+/}$or Reg $3 \gamma^{-/}$mice. 
(C) Proportion of significantly oscillating OTUs detected via eJTK divided by order in DILC (left) and mucosal scrapings (right) from RC or HF-fed Reg $3 \gamma^{+/-}$or Reg $3 \gamma^{-/-}$mice. Pie charts indicate number of significantly oscillating OTUs.

(D) Relative abundances of OTUs (Log10 of counts) of bacterial families that exhibit significant oscillations detected via eJTK in DILC and DIMS from RC or HF-fed Reg $3 \gamma^{+/-}$or Reg $3 \gamma^{-/-}$mice. Symbols represent significant oscillations within a group.

\section{Supplemental Tables and Figure Titles and legends:}

Supplementary Table S1, related to Figure 1, 2, 4, 5, S1, S2, S4

Supplementary Table S2, related to Figure 2, S2

Supplementary Table S3, related to Figure 2, 5, S2, S5

Supplementary Table S4, related to Figure 2, S2

Supplementary Table S5, related to Figure 5, S5

Supplementary Table S6, related to Figure 5, 6, S5

Supplementary Table S7, related to Figure 6

Figure S1, related to Figure 1. Core CC gene expression is not influenced by diet or gut microbes.

(A) Diurnal circadian gene expression from DIMS collected every $4 \mathrm{hrs}$ from GF and SPF mice fed $\mathrm{RC}$ or HF. ${ }^{*} \mathrm{p}<0.05,{ }^{* *} \mathrm{p}<0.01,{ }^{* *} \mathrm{p}<0.001$ via Brown-Forsythe and Welch ANOVA followed by Dunnett's test as compared to SPF-RC control-star color indicates treatment exhibiting significance within ZT time point. $\xi_{\text {in }}$ figure legends indicate significant $(p<0.05)$ co-sinor expression patterns detected via CircWave.

(B) $L y z 1$ and Sucrase-Isomaltase expression relative to Gapdh in distal ileum epithelial fractions from SPF RC or HF-fed mice. Fractions 1-4 and 5-8 contain absorptive enterocytes, fraction 9 contains intestinal crypts harboring stem cells and Paneth cells. ${ }^{* *} \mathrm{p}<0.01$ via Brown-Forsythe and Welch ANOVA followed by Dunnett's test.

Figure S2, related to Figure 2. Diet drives differential community membership in nondominant phyla and at the family level across all time points.

(A) Relative abundance of less dominant bacterial phyla of DILC from RC or HF-fed SPF mice determined via 16S rRNA amplicon sequencing. Box-whisker plots represent mean $\pm \min / \max$. Statistics via Welch's t test.

(B) PCoA of Canberra distances from 16S rRNA amplicon sequences indicated by diet in DILC. 
(C) 16S rRNA gene copy number in DILC from RC or HF-fed mice. Data represent mean \pm SEM. n.s.=not significant via Welch's t test.

(D) Relative abundances of OTUs mapped to the level of genus that significantly oscillate only in DILC of HF-fed mice. Relative abundances of these OTUs are also shown for RC-fed mice as a comparison. Data represent mean \pm SEM. * indicates significant oscillation $(p<0.05)$, while $\xi$ indicates significant oscillation $(p=0.05-0.1)$ detected via eJTK.

(E) Relative abundances of OTUs mapped to the level of genus that significantly oscillate in DILC of RC and HF-fed mice. Data represent mean \pm SEM. * indicates significant oscillation $(p<0.05)$, while $\xi$ indicates significant oscillation $(p=0.05-0.1)$ detected via eJTK.

(F) Relative abundance of indicated bacterial family in DILC from RC and HF-fed mice that include OTUs that positively or negatively correlate with Reg3y expression. Data represent mean \pm SEM. ${ }^{*} p<0.05 ;{ }^{* *} p<0.01 ;{ }^{* * *} p<0.001$ via Welch's t test.

Figure S3, related to Figure 3. Gram-positive bacteria drive host Reg $3 y$ expression in a MyD88-dependent manner in vitro and in vivo.

(A) Percent induction of Reg3y expression in enteroids derived from RC-fed GF WT mice following 12 or $24-\mathrm{hr}$ exposure to bacterial lysate from cultured strains LGG, $P$. stomatis, or $P$. anaerobius relative to their respective blank media controls. $n=3-6$ technical replicates/treatment, representative of 3 independent experiments. Box-whisker plots represent mean $\pm \min / \max$. ${ }^{*} p<0.05$ via Brown-Forsythe and Welch ANOVA followed by Dunnett's test; $n . s .=$ not significant.

(B) Percent induction of Reg3y expression of enteroids derived from SPF MyD88 ${ }^{+/-}$or MyD88 ${ }^{-/-}$ RC-fed mice. Enteroids were treated with CM from LGG or $P$. stomatis for 6 , 12 , or $24 \mathrm{hrs}$. $n=3$ technical replicates/treatment. Data presented as mean \pm SEM, representative of 2 independent experiments. Columns with the same letter are not significantly different $(p>0.05)$ as determined via two-way ANOVA followed by Tukey's test.

(C) Percent induction of Reg3y expression in enteroids derived from RC-fed SPF WT mice following exposure to size fractionated CM from LGG or $P$. stomatis for 6,12 , or $24 \mathrm{hrs.} n=3$ technical replicates/treatment. Data are presented as mean \pm SEM and are representative of 2 independent experiments. Columns with the same letter are not significantly different $(p>0.05)$ via two-way ANOVA followed by Tukey's test.

(D) Liver, gonadal fat pad, and mesenteric fat pad weight expressed as a percent of body weight of GF or LGG-monoassociated mice fed RC or HF. Box-whisker plots represent mean \pm min/max. $n=6-8$ mice/treatment. ${ }^{*} p<0.05,{ }^{* * *} p<0.001,{ }^{* * *} p<0.0001$ via Brown-Forsythe and Welch ANOVA followed by Dunnett's test. 
(E) Lyz1 expression in DIMS of GF or LGG-monoassociated WT mice fed RC or HF. Data presented by mean \pm SEM, representative of 2 independent experiments. Bars with the same letter are not significantly different $(p>0.05)$ via two-way ANOVA followed by Tukey's test.

Figure S4, related to Figure 4. Reg3y deficient mice are equally susceptible to HF dietinduced body composition changes with no changes in core CC or TLR expression.

(A) Liver, gonadal fat pad, and mesenteric fat pad weight expressed as a percent of body weight of $R e g 3 \gamma^{+/}$or $R e g 3 \gamma^{--}$mice fed RC or HF. Box-whisker plots represent mean \pm min/max. $n=24-25$ mice/treatment. " $p<0.05$; ${ }^{* * * *} p<0.0001$ via two-way ANOVA followed by Tukey's test.

(B-C) Diurnal circadian (B) and TLR (C) gene expression in DIMS from Reg $3 \gamma^{+/-}$or Reg $3 \gamma^{-/-}$mice fed RC or HF. Statistics via Brown-Forsythe and Welch ANOVA followed by Dunnett's test relative to $R e g 3 y^{+/-}$RC control—star color indicates treatment exhibiting significance within timepoint. $\xi$ indicate significant $(p<0.05)$ co-sinor expression patterns detected via CircWave.

Figure S5, related to Figure 5. Diet is the primary driver of overall microbial community membership regardless of host Reg3y status.

(A) Relative abundances of less dominant bacterial phyla of DILC from RC or HF-fed Reg $3 \gamma^{+/}$or $R e g 3 \gamma^{-/}$mice via $16 \mathrm{~S}$ rRNA amplicon sequencing. Box-whisker plots represent mean \pm min/max. ${ }^{*} p<0.05$ via Brown-Forsythe and Welch ANOVA followed by Dunnett's test.

(B) Bray-Curtis PCoA of $16 \mathrm{~S}$ rRNA amplicon sequencing of DIMS from Reg $3 \gamma^{+/-}$or Reg $3 \gamma^{-/-}$mice fed RC or HF.

(C) Bray-Curtis PCoA of $16 \mathrm{~S}$ rRNA amplicon sequencing of DILC from RC- and HF-fed mice, separated by $\operatorname{Reg} 3 \gamma^{+/-}$or $\operatorname{Reg} 3 \gamma^{-/}$.

(D) $16 \mathrm{~S}$ rRNA gene copy number in DILC from $R e g 3 \gamma^{+/-}$or Reg3$\gamma^{-/-}$mice fed RC of HF. Data represent mean \pm SEM. n.s.=not significant via Brown-Forsythe and Welch ANOVA followed by Dunnett's test.

(E) OTU 16S rRNA relative abundances in DILC from $R e g 3 \gamma^{+/-}$or $R e g 3 \gamma^{-/}$mice fed RC or HF ( $n=3-4$ mice/timepoint) using anvi'o. Columns represent OTUs, rows represent samples. Colored bars at bottom represent taxonomic assignment. Colored bars at right represent diet, gray bars represent $\mathrm{ZT}$.

(F) Average relative abundance of indicated bacterial family in DIMS from $\operatorname{Reg} 3 \gamma^{+/-}$or $\operatorname{Reg} 3 \gamma^{-/-}$ mice fed RC or HF. Data represent mean \pm SEM. ${ }^{*} p<0.05 ;{ }^{* *} p<0.01$ via Brown-Forsythe and Welch ANOVA followed by Dunnett's test. 
(G) Relative abundance of indicated bacterial family in DIMS from $R e g 3 \gamma^{+/-}$or Reg $3 \gamma^{-/}$mice fed $\mathrm{RC}$ or HF. Data represent mean \pm SEM. Statistics via Brown-Forsythe and Welch ANOVA followed by Dunnett's test relative to $R e g 3 \gamma^{+/} \mathrm{RC}$ control.

\section{Experimental procedures (STAR Methods)}

Lead contact

Further information and requests for resources and reagents should be directed to and will be fulfilled by the Lead Contact, Vanessa Leone (vleone@bsd.uchicago.edu).

\section{Materials Availability}

Frozen stocks of Lactobacillus species isolated and cultivated in the present study are stored in the facility of the Lead Contact.

\section{Experimental Model and Subject Details}

Mice

All animal protocols and experimental procedures were approved by the University of Chicago Institutional Animal Care and Use Committee (IACUC). Specific pathogen-free (SPF) C57BI/6 male mice, aged 8-10 weeks, were purchased from Jackson Laboratories (Bar Harbor, ME, USA).

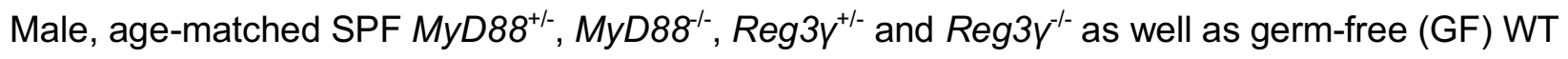
mice on a C57BI/6 background were bred in the University of Chicago animal vivarium. GF mice were maintained in plastic flexible film isolators (CBC Ltd. Madison, WI, USA). All mice were held under standard 12:12 light/dark conditions (lights on beginning at 6am, Zeitgeber (ZT) 0) and individually housed. After two weeks acclimatization, mice were allotted to one of two dietary treatments: regular, low-fat (RC) chow (10\% dietary fat, TD.2018S, Envigo, Madison, WI, USA) or high fat (HF) diet (37.4\% dietary fat, TD.97222, custom diet, Envigo, Madison, WI, USA) (see supplemental information in Leone et al., 2015 for detailed dietary components). GF diets were irradiated and tested before and after experiments for sterility. Macronutrient distribution of experimental diets is listed in Table S11. All mice were fed ad libitum. Body weights and food consumption were monitored weekly throughout the study. After 4 weeks, mice were sacrificed via $\mathrm{CO}_{2}$ asphyxiation followed by cervical dislocation over $24 \mathrm{hrs}$ at six ZT time points: ZT 2=8 AM, ZT 6=12 PM, ZT 10=4 PM, ZT 14=8 PM, ZT 18=12 AM, and ZT 22=4 AM. DILC and DIMS were snap frozen in liquid nitrogen and stored at $-80 \mathrm{C}$ until further analyses.

\section{Preparation of isolated epithelial cells}


A modified version of the Weiser method was utilized to isolate epithelium from the villus-crypt axis (Weiser, 1973). Briefly, the distal $11 \mathrm{~cm}$ of the ileum was isolated from RC or HF-fed mice at ZT2 or 10. Sections were perfused with ice cold PBS plus $1 \mathrm{mM}$ DTT, followed by eversion, tied at one end, and filled to distension with ice cold PBS. Ileal segments were then incubated at 37C for $15 \mathrm{~min}$ in $15 \mathrm{~mL}$ citrate buffer, followed by transfer to a PBS buffer containing 1.5mM EDTA, $0.5 \mathrm{mM}$ DTT, and $1 \mathrm{mg} / \mathrm{mL}$ bovine serum albumen and shaken at $175 \mathrm{RPM}$ at $37^{\circ} \mathrm{C}$ for $10 \mathrm{~min}$. Intestinal segments were then transferred to fresh PBS buffer solution and incubated nine consecutive times for $10,6,5,5,9,10,15,25$, and $30 \mathrm{~min}$., respectively as previously described (Ferraris et al., 1992). Fractions 1-4 and 5-8 were pooled and considered villi while fraction 9 was considered crypt, containing Paneth cells. Combined fractions were spun for one minute at 13,000G and resuspended in Trizol, followed by RNA extraction and cDNA synthesis for qPCR analysis as described below.

\section{Enteroid culture}

Enteroids were grown as previously described (Sato et al., 2011). Briefly, the distal $11 \mathrm{~cm}$ of the SI was removed from GF or SPF C57BI/6 WT, $M y D 88^{+/-}$, or $M y D 88^{-/-}$mice and opened longitudinally. Tissues were rinsed in ice-cold PBS to remove contents. A glass slide was used to gently remove the villi, and the mucosa was minced into 1- to 2-mm pieces with a scalpel and collected into $10 \mathrm{ml}$ of ice-cold PBS. Pieces were agitated and rinsed several times using a serumcoated serological pipette. Intestinal pieces were resuspended in $25 \mathrm{ml}$ of ice-cold $2.5 \mathrm{mM}$ EDTAPBS and rotated at $4^{\circ} \mathrm{C}$ for $30 \mathrm{~min}$. Following incubation, EDTA-PBS was replaced with $10 \mathrm{ml}$ of Advanced DMEM/F12 (ADF) medium (Thermo Scientific). After gently disrupting with a pipette three times, supernatant was discarded and fresh ADF medium was added and repeated three times. Cells were centrifuged at $300 \mathrm{~g}$ at $4^{\circ} \mathrm{C}$ for $5 \mathrm{~min}$, resuspended in $10 \mathrm{ml}$ ADF medium, and passed through a $70-\mu \mathrm{m}$ cell strainer to remove debris. Cells were centrifuged at $300 \mathrm{~g}$ at $4^{\circ} \mathrm{C}$ for $3 \mathrm{~min}$ and resuspended in complete ADF medium containing GlutaMAX (Thermo Scientific), HEPES buffer (Thermo Scientific), penicillin-streptomycin (Thermo Scientific), N2 supplement (Thermo Scientific), B-27 Supplement Minus Vitamin A (Thermo Scientific), murine EGF (50 ng/ml; Thermo Scientific), noggin (100 ng/ml; Peprotech, Rocky Hill, NJ), jagged-1 (1 $\mu \mathrm{M}$; Anaspec), Y27632 (10 nM; Cayman Scientific, Ann Arbor, MI, USA), and R-spondin-1 (500 ng/ml; Peprotech). The cell pellet was resuspended in a ratio of 1:2 ADF to Matrigel (BD Biosciences, San Jose, CA, USA) and plated onto a pre-warmed, collagen-coated, 24-well-plate. Matrigel beads were allowed to solidify for $1 \mathrm{hr}$ at $5 \% \mathrm{CO}_{2}$ at $37^{\circ} \mathrm{C}$ before adding $500 \mu$ l ADF culture media. 


\section{Bacterial culture}

E. faecalis, E. coli K12, L. rhamnosus GG, L. reuteri, L. intestinalis, L. murinus, and L. johnsonii. $P$. stomatis Sizova, $P$. anaerobius, B. thetaiotamicron, and were streaked out from frozen glycerol stocks onto agar-containing plates of either brain heart infusion media (BHI, $E$. faecalis), Luria-Bertani media (LB, E.coli K12), BHI-Supplemented media (BHIS, P. stomatis Sizova), RCM media ( $P$. anaerobius), or de Man, Rogosa and Sharpe media (MRS, Lactobacillus strains). Single colonies were inoculated into their respective liquid media and cultivated under aerobic or anaerobic conditions (Coy Laboratory Products, Inc., Grass Lake, $\mathrm{MI})$ at $37^{\circ} \mathrm{C}$ for $24-48 \mathrm{hrs}$. Genomic DNA of indigenous strains $L$. reuteri, $L$. intestinalis, $L$. murinus, and L. johnsonii were isolated from individual colonies. Forward and reverse 16S rRNA gene sequences were obtained using universal PCR primers (8F and 1492R), joined, and BLAST results were used to identify most closely related species. See Key Resources Table for detailed information on each strain.

\section{Method Details}

\section{Quantitative PCR}

Total RNA was isolated by homogenizing tissue using TRIzol (1559018, Ambion, Hampton, NH) and chloroform extraction method, as previously described (Leone et al., 2015). RNA purity was validated through UV-Vis spectrophotometry via Nanodrop Lite (Thermo Scientific, Wilmington, DE, USA). $1 \mu \mathrm{g}$ of total RNA was reverse-transcribed to complementary DNA (cDNA) using the Transcriptor First Strand cDNA Synthesis Kit (Roche, Indianapolis, IN, USA) according to manufacturer's instructions. Relative quantification of gene expression was performed using a LightCycler 480 Real-Time PCR System (Roche). Forward and reverse primers were combined with SYBR Green PCR Supermix (Bio-rad) and nuclease-free water to amplify the following hostspecific gene expression: Reg3y, Lysozyme1, Cryptidin4, Ang4, TIr1, 2, 3, 4, 9, Clock, Bmal1, Per1-3, Cry1-2, Muc2, Sucrase Isomaltase, and GAPDH (see Key Resources Table for primer sequences). Gene expression data are presented as $2^{-\Delta C t}$ (housekeeping gene - target gene), where the house-keeping gene is GAPDH.

\section{Western Blot}

To prepare protein for Western blot, $5 \mathrm{mg}$ of tissue from distal ileal mucosal scrapings was lysed in $250 \mu \mathrm{L}$ of ice-cold protein lysis buffer (Cell Signaling Technology Cell Lysis Buffer, cOmplete

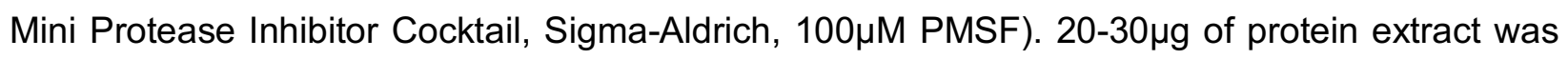
separated on a $4-20 \%$ precast polyacrylamide gel and transferred to a PVDF membrane 
(Millipore). Membranes were blocked with 5\% nonfat milk in Tris-buffered saline (TBS) (20 mM Tris pH7.6, $150 \mathrm{mM} \mathrm{NaCl}$ ) and incubated overnight at $4^{\circ} \mathrm{C}$ in $2 \%$ nonfat milk in Tris-buffered saline -Tween (TBS-T) (20 mM Tris pH7.6, $150 \mathrm{mM} \mathrm{NaCl,} \mathrm{0.1 \%} \mathrm{Tween-20)} \mathrm{containing} \mathrm{primary}$ antibodies: anti-REG3y (1:500; Abcam, Cambridge, MA), anti-GAPDH (1:1000; Invitrogen). Membranes were washed three times for $5 \mathrm{~min}$ in TBS-T and incubated for $1 \mathrm{hr}$ at room temperature in $2 \%$ nonfat milk in TBS-T containing goat anti rabbit Alexa Fluor 680, Donkey antimouse Alexa Fluor 790 secondary antibody (1:100,000 Abcam). Membranes were washed three times for 5 min each in TBS-T and imaged using the LI-COR Odyssey (LI-COR Biosceinces).

\section{Tissue Histology and Immunofluorescence}

For immunofluorescence, sections were fixed in $4 \%$ paraformalydehyde overnight. Fixed tissue sections were processed (Tissue-Tek VIP, Sakura Finetek, Torrance, CA) and embedded in paraffin. Five $\mu \mathrm{m}$ sections were cut and mounted on charged glass slides, and deparaffinized. To visually localize and semi-quantitatively measure REG3y protein within the ileal epithelium and Paneth cells, immunofluorescence was performed on paraformalydehyde fixed sections. Following deparaffinization and rehydration, antigen retrieval was performed by boiling slides in a $10 \mathrm{mM} / \mathrm{L}$ sodium citrate bath $(\mathrm{pH} 6.0)$. Slides were then blocked with $10 \%$ bovine serum albumin (BSA)-PBS for $1 \mathrm{hr}$. Samples were incubated with primary antibody for Lysozyme (1:400, ab108508, rat monoclonal IgG, Abcam) or REG3y (1:500, ab198216, rabbit polyclonal IgG, Abcam) overnight in $1 \% \mathrm{BSA}-\mathrm{PBS}$ at $4^{\circ} \mathrm{C}$ in a humidified chamber. Remaining solutions were washed and samples were incubated with respective secondary antibodies in $1 \%$ BSAPBS (1:1000, Alexa Fluor 594; Invitrogen, Grand Island, NY). Slides were imaged following DAPI staining and coverslip placement.

\section{S DNA Extraction, Sequencing, and Analysis}

Distal ileum luminal contents (DILC), and ileal mucosal scrapings (DIMS) were collected in screw cap tubes as previously described in DNA lysis buffer (Leone et al., 2015). After addition of 0.1mm-diameter zirconia/silica beads (BioSpec Products, Bartlesville, OK, USA), samples were disrupted using a Mini-Beadbeater-8k Cell Disrupter (BioSpec Products). Supernatants were extracted with an equal volume of Phenol:Chloroform:Isoamylalcohol (25:24:1; Ambion, Austin, TX, USA) and DNA precipitated using an equal volume of $100 \%$ ethanol. DNA concentration was then measured via Nanodrop Lite (Thermo Scientific, Wilmington, DE, USA) and subsequently diluted to $25 \mu \mathrm{g} / \mu \mathrm{l}$. The V4-V5 region of the $16 \mathrm{~S}$ rRNA encoding gene was amplified using standard Earth Microbiome Project protocols. Sequencing was performed at the High-Throughput 
Genome Analysis Core (HGAC; part of the Institute for Genomics \& Systems Biology [IGSB]) at Argonne National Laboratory. Forward and reverse reads were joined, trimmed and aligned using EA-utils, then classified using the Quantitative Insights Into Microbial Ecology (QIIME) toolkit (Caporaso et al., 2010). OTUs were picked at $97 \%$ sequence identity using open reference OTU picking protocol against the Greengenes database. These representative sequences were aligned using PyNAST and taxonomy was assigned using the RDP Classifier. The PyNASTaligned sequences were also used to build a phylogenetic tree with FastTree and Bray Curtis and Canberra distances were used to statistically compare beta-diversity, and visual comparisons were performed via Principal Coordinate Analysis (PCoA) ordination. To evaluate which microbial taxa exhibited rhythmic oscillations, empirical-JTK cycle with asymmetry (eJTK) software was implemented (Hutchison et al., 2015). Spearman and Pearson correlation was performed to determine which microbial taxa were correlated with host Reg3y gene expression. Analysis and Visualization Platform for 'Omics data (anvi'o) (Eren et al., 2015) was used to create at heatmap for visually assessing $16 \mathrm{~S}$ rRNA gene changes in taxonomic membership and abundance by diet and ZT.

\section{Bacterial Gene Quantification}

16S rRNA gene copy number was determined from DILC and DIMS as previously described (Leone et al., 2015). Genes were quantified by determining a standard curve for gene copy number by cloning $16 \mathrm{~S}$ sequence into pCR4-TOPO plasmid (see Key Resources Table for primer sequences).

\section{Enteroid stimulation with bacterial culture conditioned media}

Stimulation of enteroids with bacterial culture media was performed by adding $10 \%$ of filtersterilized conditioned media (CM) collected from log-phase Lactobacillus rhamnosus GG (ATCC 53103), P. stomatis (ATCC BAA-2664 CM2), or $P$. anaerobius to complete ADF enteroid culture media. CM treatment was compared to blank sterile-filtered media controls. Treated enteroid culture plates were kept at $5 \% \mathrm{CO}_{2}$ at $37^{\circ} \mathrm{C}$ until collection at 6,12 , and $24 \mathrm{hrs}$ post-treatment. RNA collection, cDNA synthesis, and qPCR analysis were performed as described above.

\section{Monoassociation Studies}

LGG was streaked from frozen glycerol stocks onto BHIS agar plates and incubated at Single LGG colonies were used to inoculate $5 \mathrm{~mL}$ of BHIS broth and grown overnight under static conditions at $37^{\circ} \mathrm{C}$ in an anaerobic chamber (Coy Laboratory Products, Inc., Grass Lake, MI). 
The next day, cells were passaged 1/50 into fresh BHIS and grown to an O.D. of 0.4-0.6 nm. Cells were pelleted at 10,000 RPM for $20 \mathrm{~min}$ at $4^{\circ} \mathrm{C}$ and resuspended in reduced PBS. 8-12 week old GF C57BI/6 male mice were fed and maintained on RC or HF in flexible film isolators within the UChicago GRAF for four weeks. After 1 week of diet switch, each mouse received $1.74 \times 10^{8}$ CFUs via gavage in $100 \mu \mathrm{L}$. Colonization was confirmed in fecal pellets. Serial dilutions of both gavage solution as well as fecal pellets from monoassociated mice after 4 weeks were plated onto BHIS agar and incubated at $37^{\circ} \mathrm{C}$ anaerobically. Mice were colonized with an average of $2.85 \times 10^{9} \pm 1.79 \times 10^{9} \mathrm{CFUs} /$ gram of feces.

\section{REG3y Bactericidal Assay}

Recombinant REG3y (rREG3y) was prepared as previously described (Cash et al., 2006b) and stored at $-80^{\circ} \mathrm{C}$. E. faecalis, E. coli K12, LGG, Peptostreptococcaceae, Bacteroides Thetaiotamicron, L. reuteri, L. intestinalis, L. murinus, and L. johnsonii were re-inoculated into fresh media and incubated at $37^{\circ} \mathrm{C}$ to mid-log phase. Cultures were spun, resuspended in standard assay buffer (10mM MES pH6, 25mM NaCl), re-pelleted, and diluted 1:25 in standard assay buffer. rREG3y $(0 \mu \mathrm{M}, 5 \mu \mathrm{M}, 10 \mu \mathrm{M}, 20 \mu \mathrm{M})$ was added followed by incubation at $37^{\circ} \mathrm{C}$ for $2 \mathrm{hrs}$. After $2 \mathrm{hr}$, dilution plating (1:10 and 1:100) was performed on agar media plates and incubated at $37^{\circ} \mathrm{C}$ for $24-48 \mathrm{hrs}$ under aerobic or anaerobic conditions. Colony forming units (CFUs) were determined and the average \% remaining bacteria was calculated relative to $0 \mu \mathrm{M}$ CFUs for each respective bacterial strain.

\section{Minimum Inhibitory Concentration (MIC) Assay}

For the selected Lactobacillus strains, E. faecalis, E. coli K12, P. stomatis, L. monocytogenes, $B$. thetaiotamicron, and $P$. anaerobius, the minimal inhibitory concentration (MIC) $(\mu \mathrm{M} / \mathrm{mL})$ for rREG3y was determined. Bacterial cultures in the exponential growth phase were diluted to a turbidity of $0.2+/-0.02$ and diluted 1:100 in each bacteria-specific media. 50ul of each diluted inoculum was added to each well of 96-well microdilution plate containing 50 $\mu$ l rREG3y (at concentrations of $15-0.01 \mu \mathrm{M})$ or vehicle control. Inoculated plates were incubated aerobically/anaerobically at $37^{\circ} \mathrm{C}$ for $24 \mathrm{hrs}$. After incubation, a 96 -well plate reader was used to determine O.D. at 600nm. MIC was determined as the lowest concentration of REG3y that reduced O.D. by $50 \%$ or $90 \%$ for MIC50 or MIC90.

$\underline{\text { Intraperitoneal Glucose Tolerance Test }}$ 
Male 8-10 week old SPF Reg3y $\gamma^{+/}$, or Reg $3 \gamma^{/-}$mice on a C57BI/6 background fed RC or HF were individually housed for 3 weeks. Mice were fasted overnight for $12 \mathrm{hrs}$. A $20 \%$ glucose in water solution ( $2 \mathrm{~g} / \mathrm{kg}$ body weight) was administered by intraperitoneal (IP) injection. Tail vein blood glucose was measured before and after IP injection at 0, 15, 30, 60, and 120 minutes using a OneTouch Glucose Meter (ADW Diabetes, Pompano Beach, FL). Area under the curve (AUC) was calculated and compared between genotypes using GraphPad Prism v8.

\section{Quantification and Statistical Analysis}

Data from in vivo and in vitro studies are presented as mean \pm SEM or box and whisker plots as mean $\pm \mathrm{min} / \mathrm{max}$. Statistical analysis was performed using two-way Analysis of Variance (ANOVA) tests followed by Tukey's test; Brown-Forsythe and Welch ANOVA followed by Dunnett's test; or Welch's t test; $p<0.05$ was considered significant. Significant changes in OTU abundances were assessed using ANOVA, as implemented in QIIME (Bonferroni correction for multiple tests; $\alpha=0.05)$. Multivariate statistical tests run on microbial community structure data include Analysis of Similarity (ANOSIM) and adonis tests, as implemented in QIIME. Relative abundances of individual OTUs over the course of $24 \mathrm{hrs}$ were compared against the relative expression of host expression of Reg3y in the ileum of both RC and HF SPF mice using Pearson Linear Regression correlation analysis and Spearman RHO non-parametric correlation analysis. False Discovery Rate (FDR) and Bonferroni were used as multi-test correction factors to correct the $p$-values to reduce Type I statistical error. Significant circadian oscillation of gene expression or copy number was determined using the software CircWave V1.4; a rhythm was determined as present by $p<0.05$. Significant microbial OTU abundance oscillations were determined via e_JTK_Cycle; an OTU was determined rhythmic at GammaP<0.05 (Hutchison et al., 2015).

\section{Data and Software Availability}

The 16S rRNA amplicon raw sequencing files have been deposited in the NCBI Sequence Read Archive under ID code SRP187770. 


\section{KEY RESOURCES TABLE}

\begin{tabular}{|c|c|c|}
\hline REAGENT or RESOURCE & SOURCE & IDENTIFIER \\
\hline \multicolumn{3}{|l|}{ Antibodies } \\
\hline Anti-Reg3Y rabbit polyclonal & Abcam & ab198216 \\
\hline Anti-GAPDH mouse monoclonal & Invitrogen & AM4300 \\
\hline Goat Anti-Rabbit Alexa Fluor 680 & Abcam & ab175773 \\
\hline Donkey Anti-mouse Alexa Fluor 790 & Abcam & ab186699 \\
\hline Lysozyme Rat Monoclonal IgG & Abcam & ab108508 \\
\hline Regllly rabbit polyclonal IgG & Abcam & ab198216 \\
\hline \multicolumn{3}{|l|}{ Bacterial and Virus Strains } \\
\hline Enterococcus faecalis & ATCC & BAA-2128 \\
\hline Escherichia coli K12 & ATCC & PTA-7555 \\
\hline Lactobacillus rhamnosus GG & ATCC & 53103 \\
\hline Peptostreptococcaceae & ATCC & BAA-2664 CM2 \\
\hline Bacteroides Thetaiotamicron & ATCC & 29148 \\
\hline Peptostrestococcus anaerobius & ATCC & 27337 \\
\hline $\begin{array}{l}\text { Lactobacillus reuteri DSM 20016; Query } \\
\text { Cover } 99 \% \text {; Identity } 99 \%\end{array}$ & $\begin{array}{l}\text { Cultured and isolated in } \\
\text { house }\end{array}$ & NR_075036.1 \\
\hline $\begin{array}{l}\text { Lactobacillus intestinalis DSM 6629; Query } \\
\text { Cover 100\%; Identity } 99 \%\end{array}$ & $\begin{array}{l}\text { Cultured and isolated in } \\
\text { house }\end{array}$ & NR_025449.1 \\
\hline $\begin{array}{l}\text { Lactobacillus murinus NBRC 14221; Query } \\
\text { Cover } 100 \% \text {; Identity } 99 \%\end{array}$ & $\begin{array}{l}\text { Cultured and isolated in } \\
\text { house }\end{array}$ & NR_112689.1 \\
\hline $\begin{array}{l}\text { Lactobacillus johnsonii CIP 103620; Query } \\
\text { Cover 100\%; Identity 99\% }\end{array}$ & $\begin{array}{l}\text { Cultured and isolated in } \\
\text { house }\end{array}$ & NR_117574.1 \\
\hline \multicolumn{3}{|c|}{ Chemicals, Peptides, and Recombinant Proteins } \\
\hline Brain Heart Infusion (BHI) Broth & $\mathrm{BD}$ & 237500 \\
\hline $\begin{array}{l}\text { BHI-Supplement Broth Hemin, Vitamin K, L- } \\
\text { cysteine }\end{array}$ & Sigma & $\begin{array}{l}51280, \\
\text { V3501,168149 }\end{array}$ \\
\hline De Man, Rogosa, and Sharpe (MRS) broth & $\mathrm{BD}$ & 288130 \\
\hline Trizol & Ambion & 1559018 \\
\hline Advanced DMEM/F12 (ADF) medium & Thermo Scientific & 12634028 \\
\hline GlutaMAX & Thermo Scientific & 35050061 \\
\hline HEPES buffer & Thermo Scientific & 15630080 \\
\hline Penicillin-streptomycin & Thermo Scientific & 15140122 \\
\hline N2 supplement & Thermo Scientific & 17502048 \\
\hline B-27 Supplement Minus Vitamin A & Thermo Scientific & 12587010 \\
\hline murine EGF & Thermo Scientific & PMG8044 \\
\hline noggin & Peprotech & $250-38$ \\
\hline jagged-1 & Anaspec & AS-61298 \\
\hline Y27632 & Cayman Scientific & CAS-129830-38-2 \\
\hline R-spondin-1 & Peprotech & $315-32$ \\
\hline Matrigel & Fisher Scientific & cb356239 \\
\hline Cell Lysis Buffer & Cell signaling & $9803 S$ \\
\hline cOmplete Mini Protease Inhibitor Cocktail & Sigma-Aldrich & 11836153001 \\
\hline Universal SYBR Green Supermix & Bio-rad & 1725274 \\
\hline DAPI & Thermo Scientific & $\mathrm{P} 36935$ \\
\hline LPS-EK & Invivogen & tlrl-eklps \\
\hline
\end{tabular}




\begin{tabular}{|c|c|c|}
\hline \multicolumn{3}{|l|}{ Critical Commercial Assays } \\
\hline Transcriptor First Strand cDNA Synthesis Kit & Roche & 04379012001 \\
\hline \multicolumn{3}{|l|}{ Deposited Data } \\
\hline 16S rRNA amplicon raw sequencing reads & NCBI BioProject & $\begin{array}{l}\text { https://www.ncbi.nl } \\
\text { m.nih.gov/bioproje } \\
\text { ct/; PRJNA522004 }\end{array}$ \\
\hline \multicolumn{3}{|l|}{ Experimental Models: Organisms/Strains } \\
\hline Mouse: C57BL6 (B6) & The Jackson Laboratory & Stock No. 000664 \\
\hline Mouse: MyD88 ${ }^{-1-}$ (B6 background) & The Jackson Laboratory & Stock No. 009088 \\
\hline Mouse: Regllly ${ }^{-1-}$ (B6 background) & The Jackson Laboratory & Stock No. 017480 \\
\hline \multicolumn{3}{|l|}{ Oligonucleotides } \\
\hline $\begin{array}{l}\text { Reg3y_F: } \\
\text { CCACTCACСTGCTGCTACTCAT-3. }\end{array}$ & this paper & $\mathrm{N} / \mathrm{A}$ \\
\hline $\begin{array}{l}\text { Reg3Y_R: } \\
\text { TGGTGATCCTCTTGTAGCTCTCC }\end{array}$ & this paper & $\mathrm{N} / \mathrm{A}$ \\
\hline $\begin{array}{l}\text { Lysozyme1_F: } \\
\text { GAGACCGAAGCACCGACTATG }\end{array}$ & this paper & $\mathrm{N} / \mathrm{A}$ \\
\hline $\begin{array}{l}\text { Lysozyme1_R: } \\
\text { CGGTTTTGACATTGTGTTCGC }\end{array}$ & this paper & $\mathrm{N} / \mathrm{A}$ \\
\hline $\begin{array}{l}\text { Cryptidin4_F: } \\
\text { TCGTGGGACATTCGTGAAGA }\end{array}$ & this paper & $\mathrm{N} / \mathrm{A}$ \\
\hline Cryptidin4_R: GCGGGCTGCTGTCCAG & this paper & $\mathrm{N} / \mathrm{A}$ \\
\hline Clock_F: GGGAGTTTGGCTCCAGAGTTT & this paper & $\mathrm{N} / \mathrm{A}$ \\
\hline Clock_R: TGTGTCTTCAGGGGTCCTTAG & this paper & $\mathrm{N} / \mathrm{A}$ \\
\hline Bmal1_F: GGGAGTTTGGCTCCAGAGTTT & this paper & $\mathrm{N} / \mathrm{A}$ \\
\hline Bmal1_R: TGTGTCTTCAGGGGTCCTTAG & this paper & $\mathrm{N} / \mathrm{A}$ \\
\hline Per1_F: TGAAGCAAGACCGGGAGA & this paper & $\mathrm{N} / \mathrm{A}$ \\
\hline Per1_R: CACACACGCCGTCACATC & this paper & $\mathrm{N} / \mathrm{A}$ \\
\hline Per2_F: TGTGCGATGATGATTCGTGA & this paper & $\mathrm{N} / \mathrm{A}$ \\
\hline Per2_R: GGTGAAGGTACGTTTGGTTTGC & this paper & $\mathrm{N} / \mathrm{A}$ \\
\hline Per3_F: AAAAGCACCACGGATACTGGC & this paper & $\mathrm{N} / \mathrm{A}$ \\
\hline Per3_R: GGGAGGCTGTAGCTTGTCA & this paper & $\mathrm{N} / \mathrm{A}$ \\
\hline Cry1_F: CACTGGTTCCGAAAGGGACTC & this paper & $\mathrm{N} / \mathrm{A}$ \\
\hline Cry1_R: CTGAAGCAAAAATCGCCACCT & this paper & $\mathrm{N} / \mathrm{A}$ \\
\hline Cry2_F: CACTGGTTCCGCAAAGGACTA & this paper & $\mathrm{N} / \mathrm{A}$ \\
\hline Cry2_R: CCACGGGTCGAGGATGTAGA & this paper & $\mathrm{N} / \mathrm{A}$ \\
\hline $\begin{array}{l}\text { Sucrase_Isomaltase_F: } \\
\text { ATGAGCAAATGTTTGGGTG }\end{array}$ & this paper & $\mathrm{N} / \mathrm{A}$ \\
\hline $\begin{array}{l}\text { Sucrase_Isomaltase_R: } \\
\text { GGCCATACCTCTCCAATAAG }\end{array}$ & this paper & $\mathrm{N} / \mathrm{A}$ \\
\hline Gapdh_F: GGCAAATTCAACGGCACAGT & this paper & $\mathrm{N} / \mathrm{A}$ \\
\hline Gapdh_R: AGATGGTGATGGGCTTCCC & this paper & $\mathrm{N} / \mathrm{A}$ \\
\hline Ang4_F: GGTTGTGATTCCTCCAACTCTG & this paper & $\mathrm{N} / \mathrm{A}$ \\
\hline $\begin{array}{l}\text { Ang4_R: } \\
\text { CTGAAGTTTTCTCCATAAGGGCT }\end{array}$ & this paper & $\mathrm{N} / \mathrm{A}$ \\
\hline Muc2_F: GCTGACGAGTGGTTGGTGAATG & this paper & $\mathrm{N} / \mathrm{A}$ \\
\hline
\end{tabular}




\begin{tabular}{|c|c|c|}
\hline Muc2_R: GATGAGGTGGCAGACAGGAGA & this paper & $\mathrm{N} / \mathrm{A}$ \\
\hline $\begin{array}{l}\text { 16S_universal_F: } \\
\text { ATGGYTGTCGTCAGCTCGTG }\end{array}$ & this paper & $\mathrm{N} / \mathrm{A}$ \\
\hline 16S_universal_R: GGGTTGCGCTCGTTGC & this paper & $\mathrm{N} / \mathrm{A}$ \\
\hline TIr1_F: TGAGGGTCCTGATAATGTCCTAC & this paper & $\mathrm{N} / \mathrm{A}$ \\
\hline TIr1_R: AGAGGTCCAAATGCTTGAGGC & this paper & $\mathrm{N} / \mathrm{A}$ \\
\hline TIr2_F: GCAAACGCTGTTCTGCTCAG & this paper & $\mathrm{N} / \mathrm{A}$ \\
\hline TIr2_R: AGGCGTCTCCCTCTATTGTATT & this paper & $\mathrm{N} / \mathrm{A}$ \\
\hline TIr3_F: GTGAGATACAACGTAGCTGACTG & this paper & $\mathrm{N} / \mathrm{A}$ \\
\hline TIr3_R: TCCTGCATCCAAGATAGCAAGT & this paper & $\mathrm{N} / \mathrm{A}$ \\
\hline TIr4_F: ATGGCATGGCTTACACCACC & this paper & $\mathrm{N} / \mathrm{A}$ \\
\hline TIr4_R: GAGGCCAATTTTGTCTCCACA & this paper & $\mathrm{N} / \mathrm{A}$ \\
\hline TIr9_F: ATGGTTCTCCGTCGAAGGACT & this paper & $\mathrm{N} / \mathrm{A}$ \\
\hline TIr9_R: GAGGCTTCAGCTCACAGGG & this paper & $\mathrm{N} / \mathrm{A}$ \\
\hline \multicolumn{3}{|l|}{ Recombinant DNA } \\
\hline pET3a Reglllg plasmid & Cash et al. 2006 & $\begin{array}{l}\text { Addgene plasmid } \\
64936 \\
\text { RRID: } \\
\text { Addgene_64936 }\end{array}$ \\
\hline \multicolumn{3}{|l|}{ Software and Algorithms } \\
\hline Graphpad Prism 8 & Graphpad software & $\begin{array}{l}\text { graphpad.com/scie } \\
\text { ntific- } \\
\text { software/prism }\end{array}$ \\
\hline eJTK & Hutchison et al. 2015 & $\mathrm{n} / \mathrm{a}$ \\
\hline QIIME & Caporaso et al. 2010 & qiime.org \\
\hline Anvi'o & Eren et al. 2015 & $\begin{array}{l}\text { merenlab.org/softw } \\
\text { are/anvio }\end{array}$ \\
\hline ImageJ & Schindelin et al. 2015 & imagej.net \\
\hline Adobe illustrator CC2020 & Adobe & $\begin{array}{l}\text { https://www.adobe. } \\
\text { com/product/photo } \\
\text { shop.html }\end{array}$ \\
\hline \multicolumn{3}{|l|}{ Other } \\
\hline $10 \%$ dietary fat mouse diet & Envigo & TD.2018S \\
\hline $37.4 \%$ dietary fat mouse diet & Envigo & TD.97222 \\
\hline OneTouch Glucose Meter & ADW Diabetes & 5388500027 \\
\hline
\end{tabular}




\section{References}

Bluemel, S., Wang, L., Martino, C., Lee, S., Wang, Y., Williams, B., Horvath, A., Stadlbauer, V., Zengler, K., and Schnabl, B. (2018). The Role of Intestinal C-type Regenerating Islet Derived-3 Lectins for Nonalcoholic Steatohepatitis. Hepatol. Commun. 2, 393-406.

Caporaso, J.G., Kuczynski, J., Stombaugh, J., Bittinger, K., Bushman, F.D., Costello, E.K., Fierer, N., Peña, A.G., Goodrich, J.K., Gordon, J.I., et al. (2010). QIIME allows analysis of highthroughput community sequencing data. Nat. Methods 7, 335-336.

Carmody, R.N., Gerber, G.K., Luevano, J.M., Gatti, D.M., Somes, L., Svenson, K.L., and Turnbaugh, P.J. (2015). Diet dominates host genotype in shaping the murine gut microbiota. Cell Host Microbe 17, 72-84.

Cash, H.L., Whitham, C.V., Behrendt, C.L., and Hooper, L.V. (2006a). Symbiotic bacteria direct expression of an intestinal bactericidal lectin. Science 313, 1126-1130.

Cash, H.L., Whitham, C.V., and Hooper, L.V. (2006b). Refolding, purification, and characterization of human and murine Reglll proteins expressed in Escherichia coli. Protein Expr. Purif. 48, 151159.

Devkota, S., Wang, Y., Musch, M.W., Leone, V., Fehlner-Peach, H., Nadimpalli, A., Antonopoulos, D.A., Jabri, B., and Chang, E.B. (2012). Dietary-fat-induced taurocholic acid promotes pathobiont expansion and colitis in II10-/- mice. Nature 487, 104-108.

Dibner, C., Schibler, U., and Albrecht, U. (2010). The Mammalian Circadian Timing System: Organization and Coordination of Central and Peripheral Clocks. Annu. Rev. Physiol. 72, 517549.

Eren, A.M., Esen, Ö.C., Quince, C., Vineis, J.H., Morrison, H.G., Sogin, M.L., and Delmont, T.O. (2015). Anvi'o: an advanced analysis and visualization platform for 'omics data. PeerJ 3, e1319.

Everard, A., Belzer, C., Geurts, L., Ouwerkerk, J.P., Druart, C., Bindels, L.B., Guiot, Y., Derrien, M., Muccioli, G.G., Delzenne, N.M., et al. (2013). Cross-talk between Akkermansia muciniphila and intestinal epithelium controls diet-induced obesity. Proc. Natl. Acad. Sci. 110, 9066-9071.

Everard, A., Lazarevic, V., Gaïa, N., Johansson, M., Ståhlman, M., Backhed, F., Delzenne, N.M., Schrenzel, J., François, P., and Cani, P.D. (2014). Microbiome of prebiotic-treated mice reveals novel targets involved in host response during obesity. ISME J. 8, 2116-2130.

Ferraris, R.P., Villenas, S.A., and Diamond, J. (1992). Regulation of brush-border enzyme activities and enterocyte migration rates in mouse small intestine. Am. J. Physiol. 262, G10471059.

Huang, Y., Qi, H., Zhang, Z., Wang, E., Yun, H., Yan, H., Su, X., Liu, Y., Tang, Z., Gao, Y., et al. (2017). Gut REG3y-Associated Lactobacillus Induces Anti-inflammatory Macrophages to Maintain Adipose Tissue Homeostasis. Front. Immunol. 8.

Hutchison, A.L., Maienschein-Cline, M., Chiang, A.H., Tabei, S.M.A., Gudjonson, H., Bahroos, N., Allada, R., and Dinner, A.R. (2015). Improved Statistical Methods Enable Greater Sensitivity in Rhythm Detection for Genome-Wide Data. PLOS Comput. Biol. 11, e1004094. 
Jacobi, D., Liu, S., Burkewitz, K., Kory, N., Knudsen, N.H., Alexander, R.K., Unluturk, U., Li, X., Kong, X., Hyde, A.L., et al. (2015). Hepatic Bmal1 Regulates Rhythmic Mitochondrial Dynamics and Promotes Metabolic Fitness. Cell Metab. 22, 709-720.

Joyce, S.A., MacSharry, J., Casey, P.G., Kinsella, M., Murphy, E.F., Shanahan, F., Hill, C., and Gahan, C.G.M. (2014). Regulation of host weight gain and lipid metabolism by bacterial bile acid modification in the gut. Proc. Natl. Acad. Sci. 111, 7421-7426.

Karlsson, B.H., Knutsson, A.K., Lindahl, B.O., and Alfredsson, L.S. (2003). Metabolic disturbances in male workers with rotating three-shift work. Results of the WOLF study. Int. Arch. Occup. Environ. Health 76, 424-430.

Leone, V., Gibbons, S.M., Martinez, K., Hutchison, A.L., Huang, E.Y., Cham, C.M., Pierre, J.F., Heneghan, A.F., Nadimpalli, A., Hubert, N., et al. (2015). Effects of diurnal variation of gut microbes and high fat feeding on host circadian clock function and metabolism. Cell Host Microbe 17, 681-689.

Liang, X., Bushman, F.D., and FitzGerald, G.A. (2015). Rhythmicity of the intestinal microbiota is regulated by gender and the host circadian clock. Proc. Natl. Acad. Sci. 112, 10479-10484.

Loonen, L.M., Stolte, E.H., Jaklofsky, M.T., Meijerink, M., Dekker, J., van Baarlen, P., and Wells, J.M. (2014). REG3y-deficient mice have altered mucus distribution and increased mucosal inflammatory responses to the microbiota and enteric pathogens in the ileum. Mucosal Immunol. 7, 939-947.

Mukherjee, S., and Hooper, L.V. (2015). Antimicrobial defense of the intestine. Immunity 42, 2839.

Mukherjee, S., Zheng, H., Derebe, M.G., Callenberg, K.M., Partch, C.L., Rollins, D., Propheter, D.C., Rizo, J., Grabe, M., Jiang, Q.-X., et al. (2014). Antibacterial membrane attack by a poreforming intestinal C-type lectin. Nature 505, 103-107.

Mukherji, A., Kobiita, A., Ye, T., and Chambon, P. (2013). Homeostasis in intestinal epithelium is orchestrated by the circadian clock and microbiota cues transduced by TLRs. Cell 153, 812-827.

Narushima, Y., Unno, M., Nakagawara, K., Mori, M., Miyashita, H., Suzuki, Y., Noguchi, N., Takasawa, S., Kumagai, T., Yonekura, H., et al. (1997). Structure, chromosomal localization and expression of mouse genes encoding type III Reg, Reglll alpha, Reglll beta, Reglll gamma. Gene 185, 159-168.

Nata, K., Liu, Y., Xu, L., Ikeda, T., Akiyama, T., Noguchi, N., Kawaguchi, S., Yamauchi, A., Takahashi, I., Shervani, N.J., et al. (2004). Molecular cloning, expression and chromosomal localization of a novel human REG family gene, REG III. Gene 340, 161-170.

Natividad, J.M.M., Hayes, C.L., Motta, J.-P., Jury, J., Galipeau, H.J., Philip, V., Garcia-Rodenas, C.L., Kiyama, H., Bercik, P., and Verdu, E.F. (2013). Differential Induction of Antimicrobial REGIII by the Intestinal Microbiota and Bifidobacterium breve NCC2950. Appl. Environ. Microbiol. 79, 7745-7754.

O'Flaherty, S., Briner Crawley, A., Theriot, C.M., and Barrangou, R. (2018). The Lactobacillus Bile Salt Hydrolase Repertoire Reveals Niche-Specific Adaptation. MSphere 3. 
Sato, T., Stange, D.E., Ferrante, M., Vries, R.G.J., Van Es, J.H., Van den Brink, S., Van Houdt, W.J., Pronk, A., Van Gorp, J., Siersema, P.D., et al. (2011). Long-term expansion of epithelial organoids from human colon, adenoma, adenocarcinoma, and Barrett's epithelium. Gastroenterology 141, 1762-1772.

Thaiss, C.A., Zeevi, D., Levy, M., Zilberman-Schapira, G., Suez, J., Tengeler, A.C., Abramson, L., Katz, M.N., Korem, T., Zmora, N., et al. (2014). Transkingdom Control of Microbiota Diurnal Oscillations Promotes Metabolic Homeostasis. Cell 159, 514-529.

Thaiss, C.A., Levy, M., Korem, T., Dohnalová, L., Shapiro, H., Jaitin, D.A., David, E., Winter, D.R., Gury-BenAri, M., Tatirovsky, E., et al. (2016). Microbiota Diurnal Rhythmicity Programs Host Transcriptome Oscillations. Cell 167, 1495-1510.e12.

Turek, F.W., Joshu, C., Kohsaka, A., Lin, E., Ivanova, G., McDearmon, E., Laposky, A., LoseeOlson, S., Easton, A., Jensen, D.R., et al. (2005). Obesity and metabolic syndrome in circadian Clock mutant mice. Science 308, 1043-1045.

Vaishnava, S., Behrendt, C.L., Ismail, A.S., Eckmann, L., and Hooper, L.V. (2008). Paneth cells directly sense gut commensals and maintain homeostasis at the intestinal host-microbial interface. Proc. Natl. Acad. Sci. 105, 20858-20863.

Vaishnava, S., Yamamoto, M., Severson, K.M., Ruhn, K.A., Yu, X., Koren, O., Ley, R., Wakeland, E.K., and Hooper, L.V. (2011). The antibacterial lectin Regllly promotes the spatial segregation of microbiota and host in the intestine. Science 334, 255-258.

Wang, L., Fouts, D.E., Stärkel, P., Hartmann, P., Chen, P., Llorente, C., DePew, J., Moncera, K., Ho, S.B., Brenner, D.A., et al. (2016). Intestinal REG3 Lectins Protect against Alcoholic Steatohepatitis by Reducing Mucosa-Associated Microbiota and Preventing Bacterial Translocation. Cell Host Microbe 19, 227-239.

Wang, Y., Kuang, Z., Yu, X., Ruhn, K.A., Kubo, M., and Hooper, L.V. (2017). The intestinal microbiota regulates body composition through NFIL3 and the circadian clock. Science 357, 912916.

Weiser, M.M. (1973). Intestinal epithelial cell surface membrane glycoprotein synthesis. I. An indicator of cellular differentiation. J. Biol. Chem. 248, 2536-2541.

Zarrinpar, A., Chaix, A., Yooseph, S., and Panda, S. (2014). Diet and Feeding Pattern Affect the Diurnal Dynamics of the Gut Microbiome. Cell Metab. 20, 1006-1017.

Zhang, R., Lahens, N.F., Ballance, H.I., Hughes, M.E., and Hogenesch, J.B. (2014). A circadian gene expression atlas in mammals: Implications for biology and medicine. Proc. Natl. Acad. Sci. U. S. A. $111,16219-16224$. 
bioRxiv preprint doi: https://doi.org/10.1101/2020.06.17.130393; this version posted June 18, 2020. The copyright holder for this preprint

A.

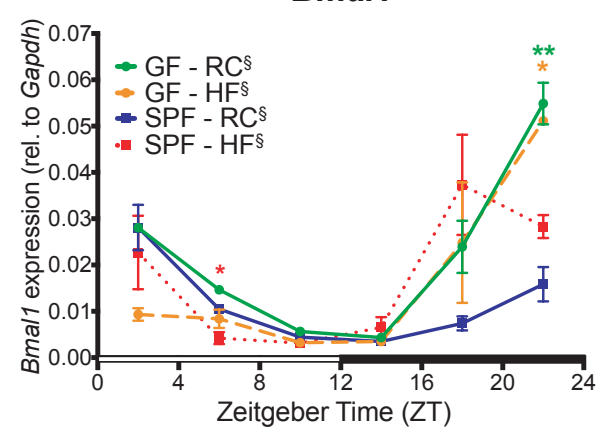

Clock

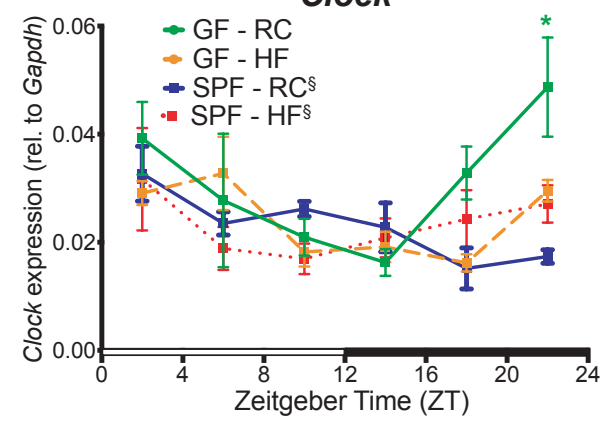

Per2

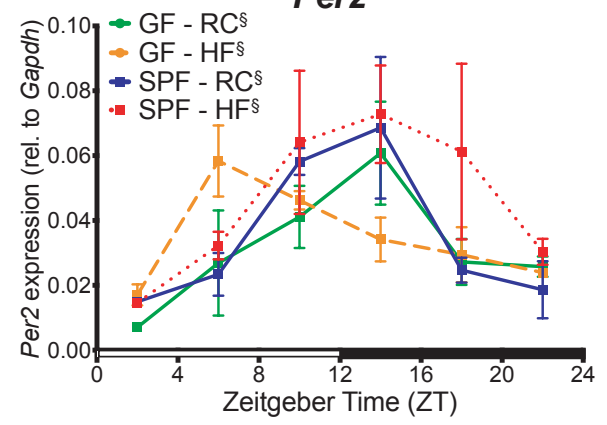

Cry1

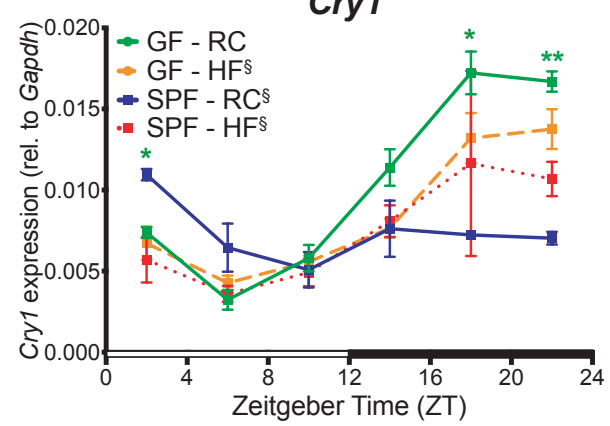

B.

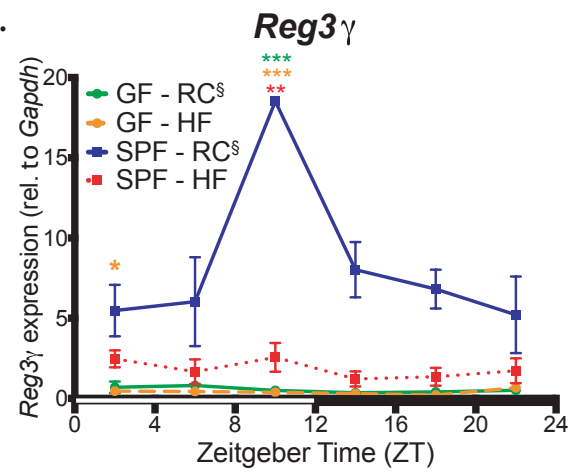

Lyz1

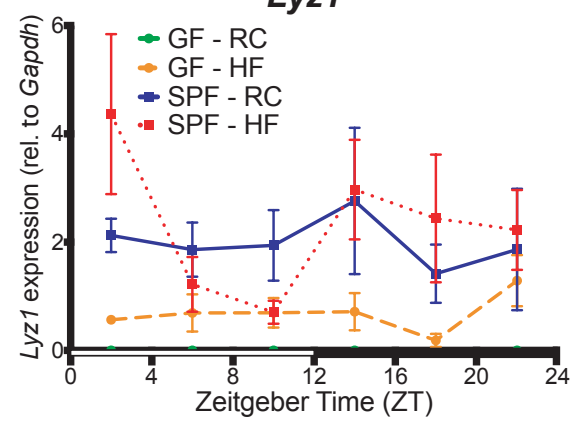

Ang4

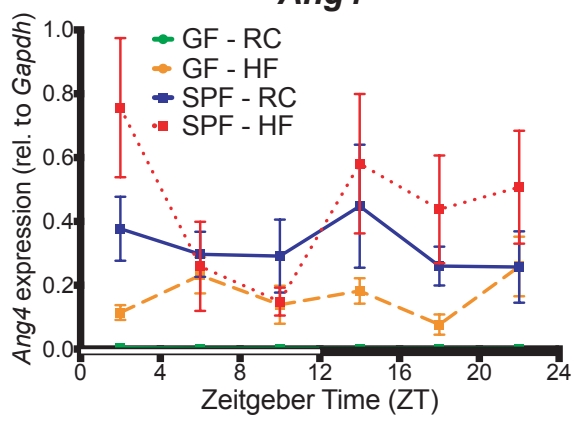

Crypt4

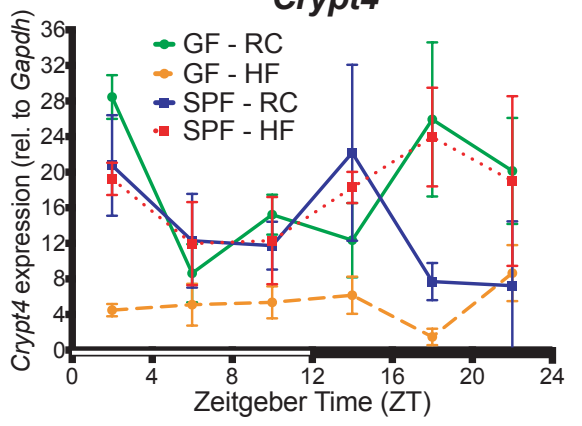

C.

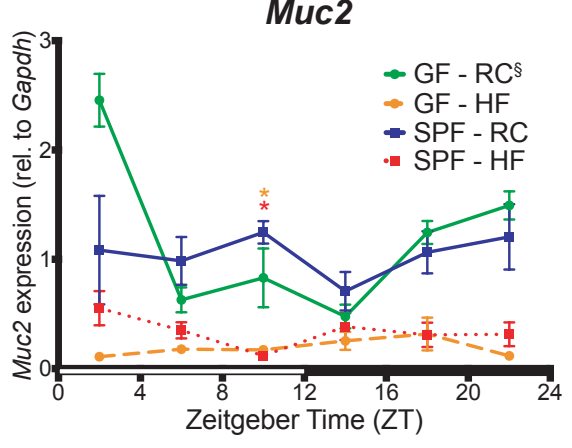

D.
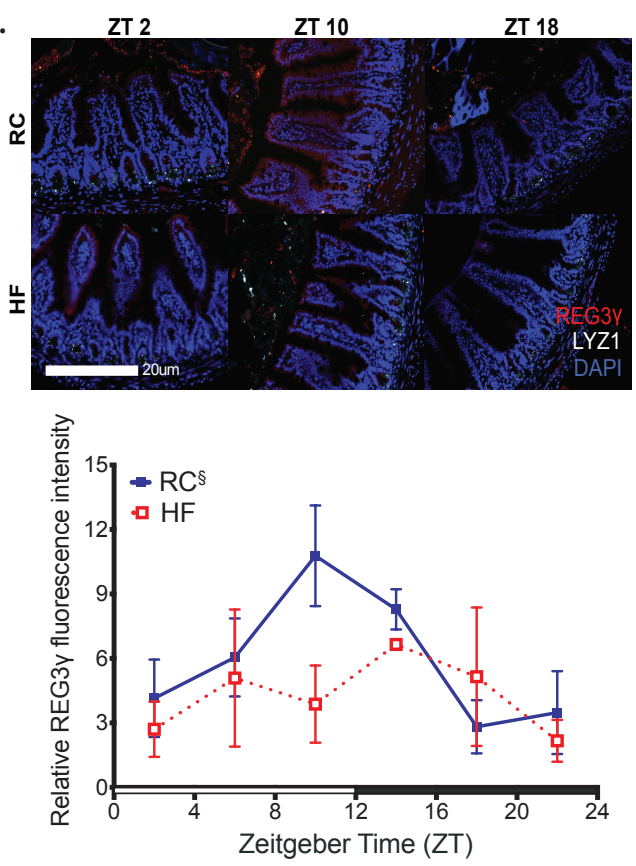

E.

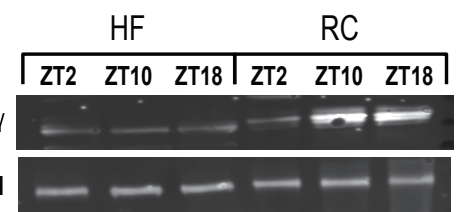

F. 홍

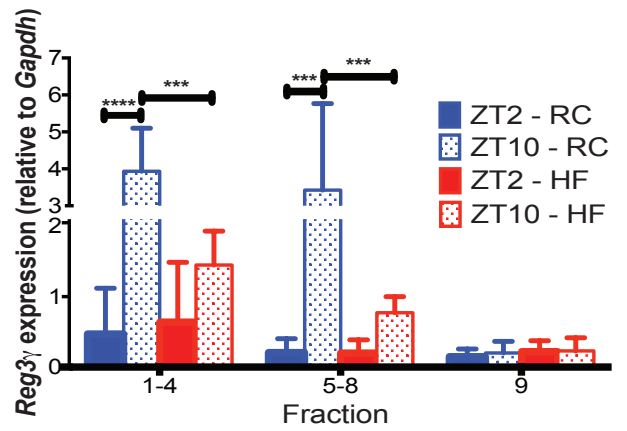


bioRxiv preprint doi: https://doi.org/10.1101/2020.06.17.130393; this version posted June 18, 2020. The copyright holder for this preprint (which was not certified by peer review) is the author/funder. All rights reserved. No reuse allowed without permission.

Figure 2

A.

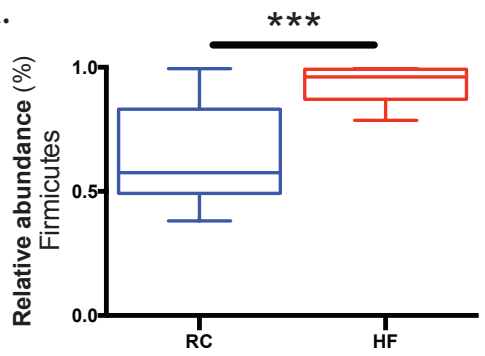

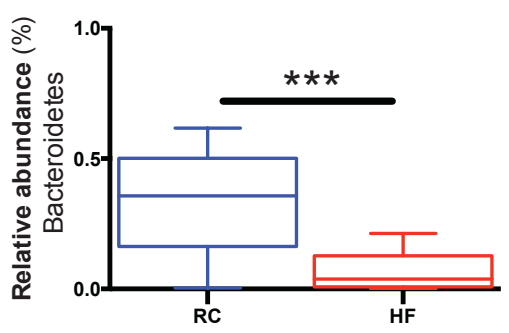

B.

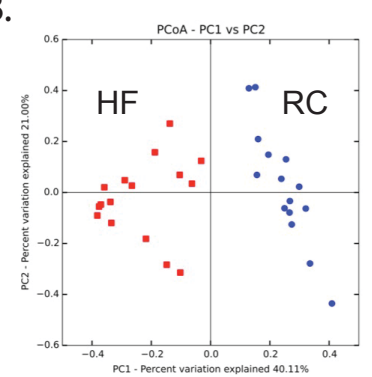

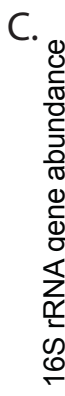

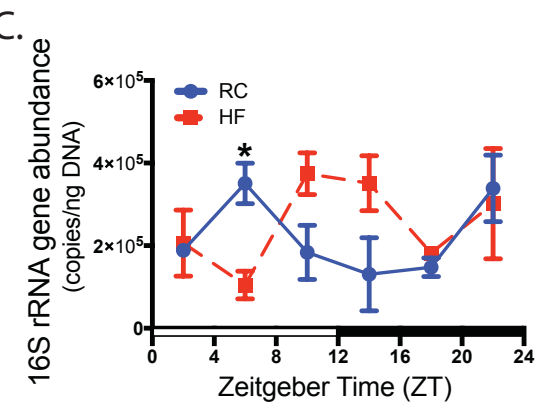

D.
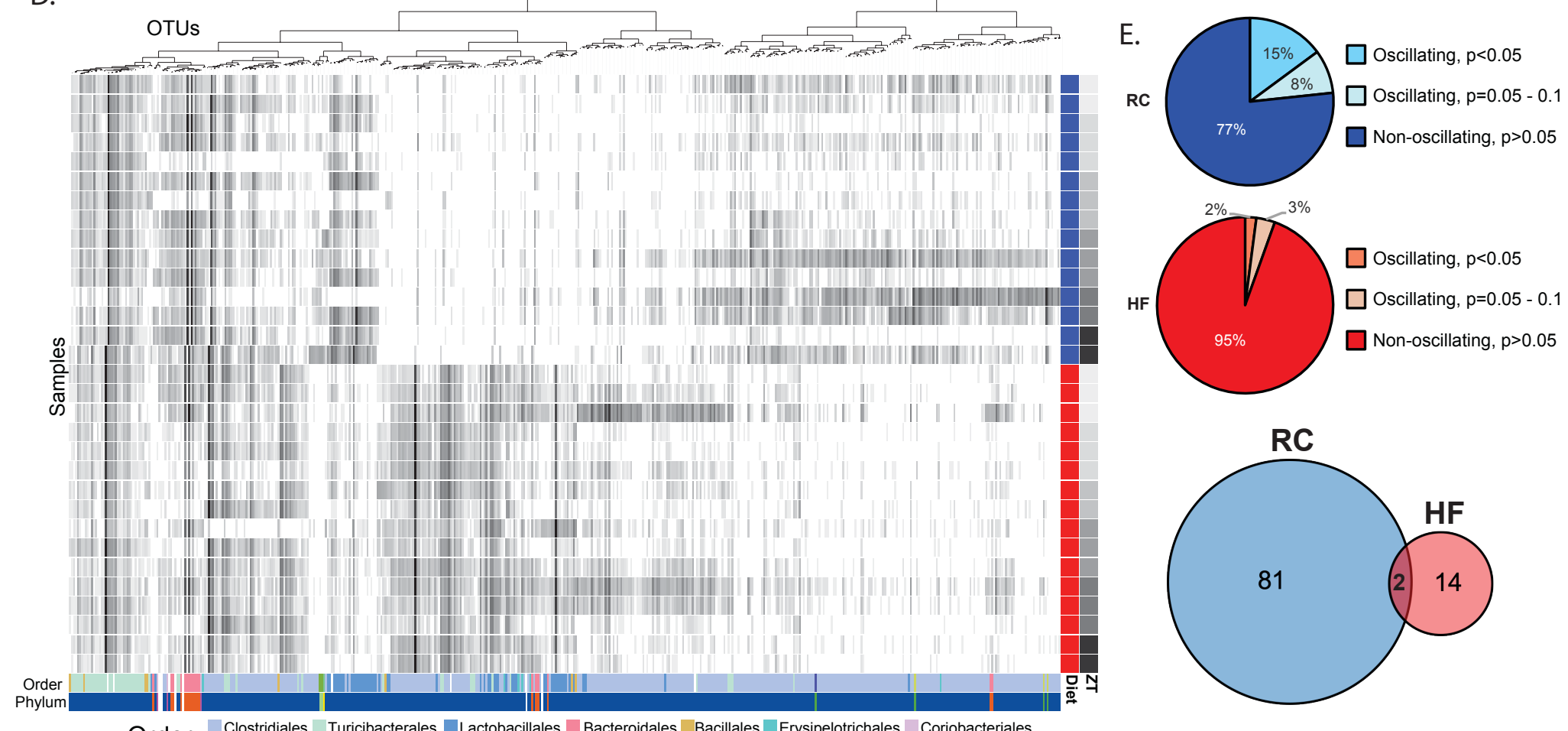

Order: Clostridiales Turicibacterales Lactobacillales Bacteroidales Bacillales Erysipelotrichales Coriobacteriales

Phylum: $\square$ Firmicutes $\square$ Bacteroidetes $\square$ Tenericutes $\square$ Actinobacteria $\square$ Cyanobacteria $\square$ Proteobacteria $\square$ None

Diet: $\square \mathrm{RC} \square \mathrm{HF}$

Zeitgeber: $\square 2 \square 6 \square 10 \square 14 \square 18 \square 22$

F. OTU\#182764 - Lactobacillus

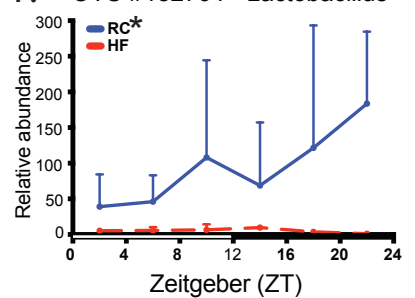

OTU \#328905 - Oscillospira

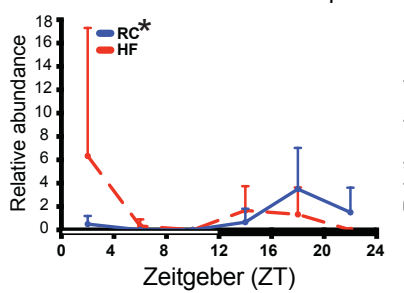

OTU \#590168 - Lactobacillus

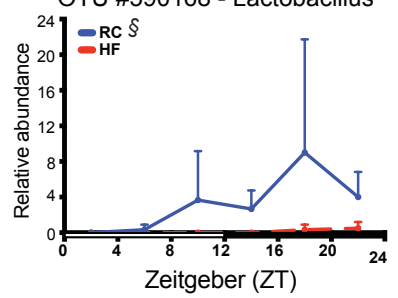

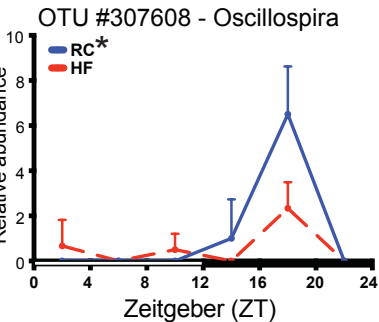

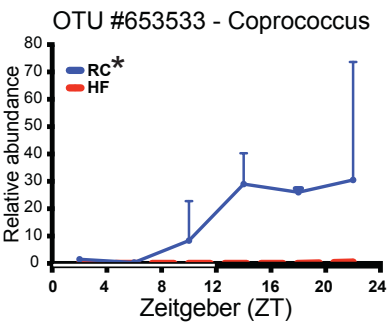

OTU \#327900 - Ruminococcus

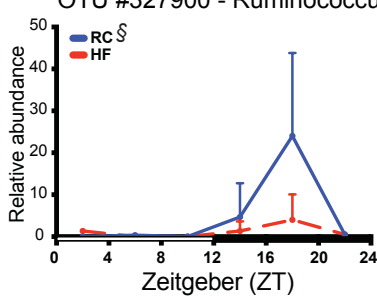

G.

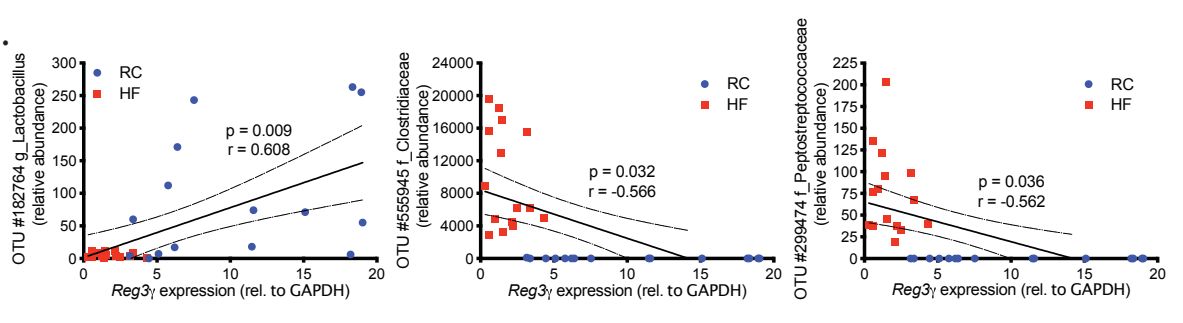

$\mathrm{H}$.
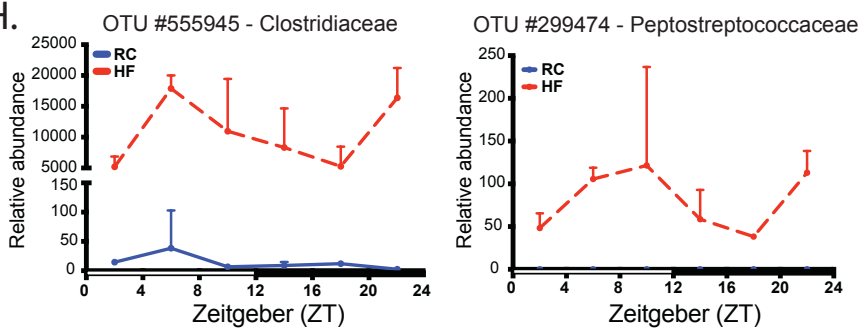

I.
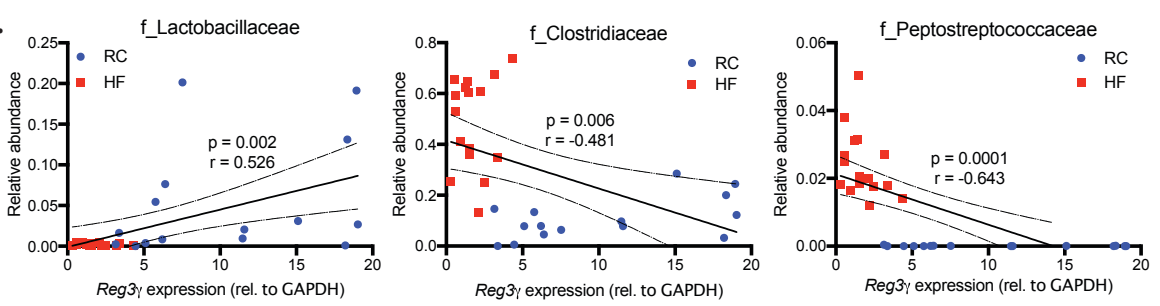
bioRxiv preprint doi: https://doi.org/10.1101/2020.06.17.130393; this version posted June 18, 2020. The copyright holder for this preprint Figure 3 (which was not certified by peer review) is the author/funder. All rights reserved. No reuse allowed without permission.
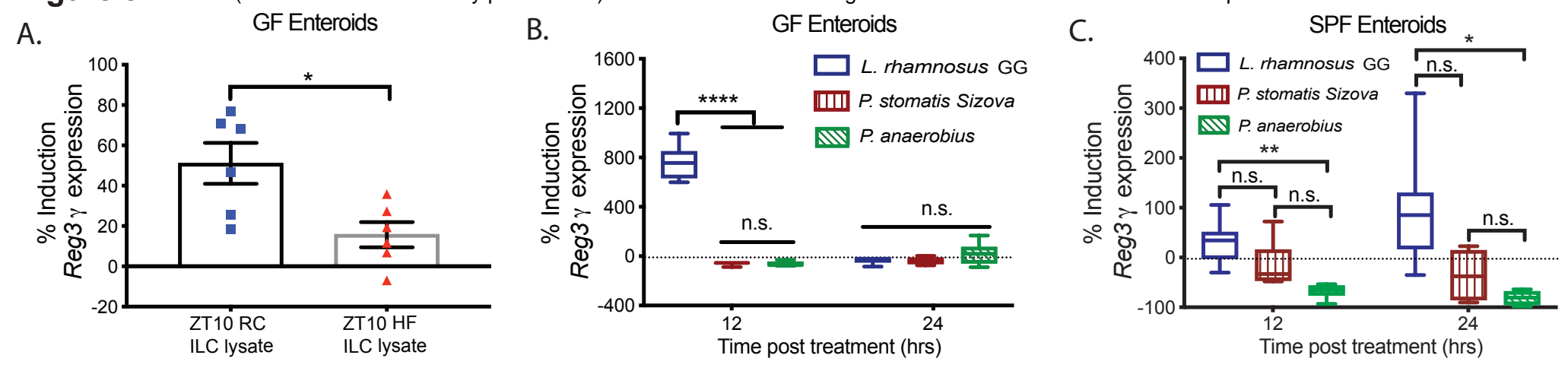

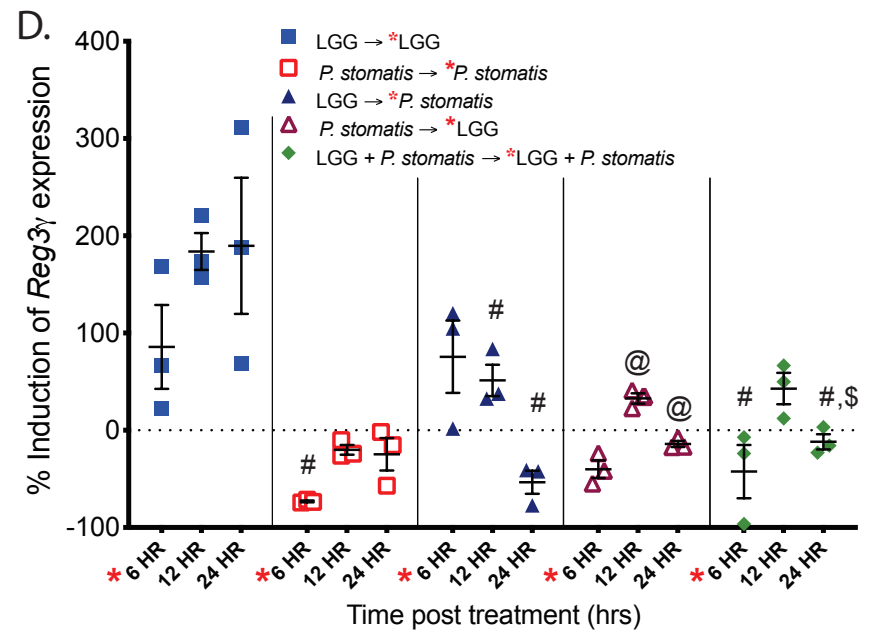

G.

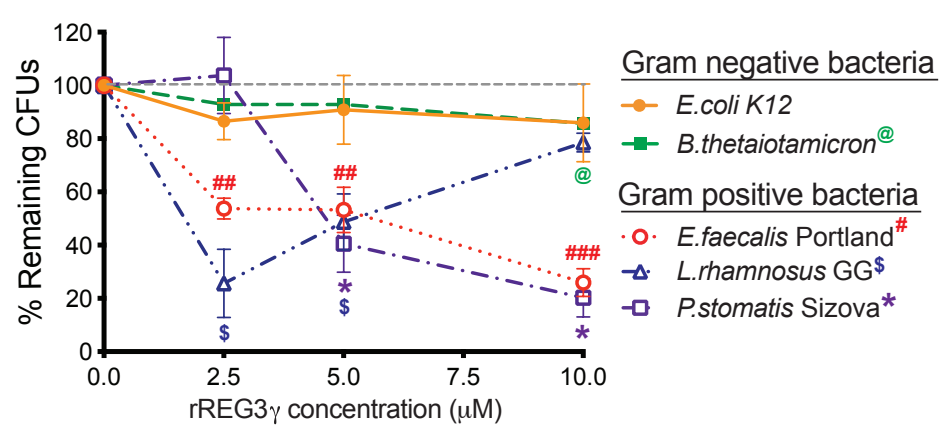

I.

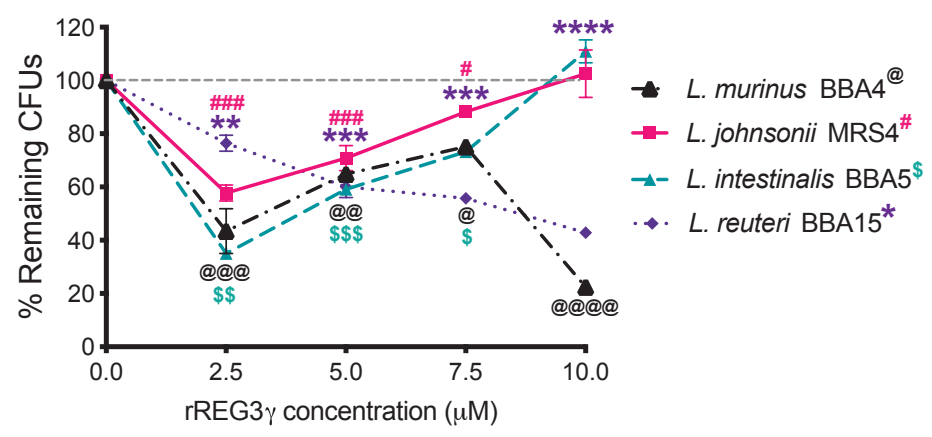

K.

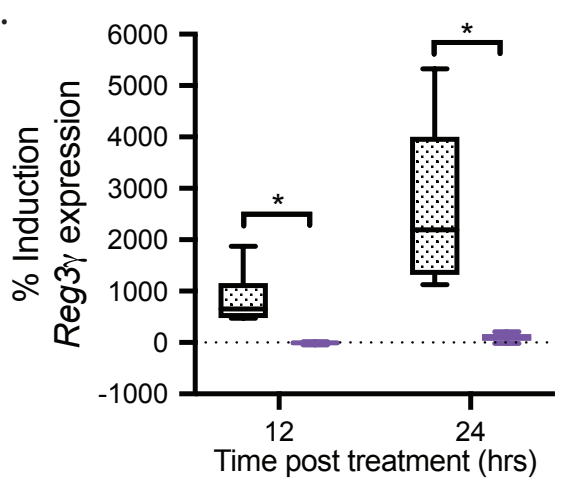

L. murinus BBA4

L. reuteri BBA15
E.

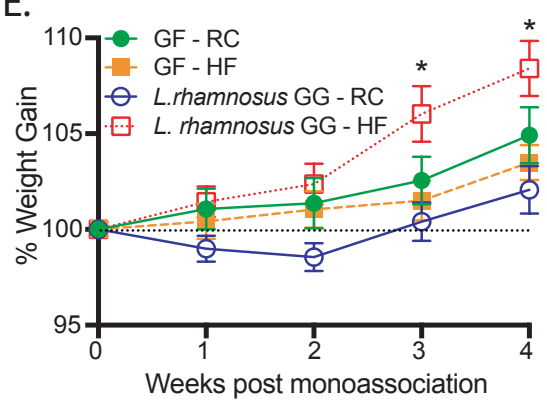

F.

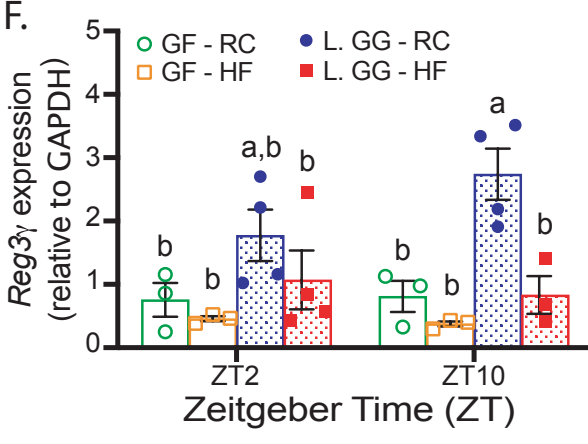

H.

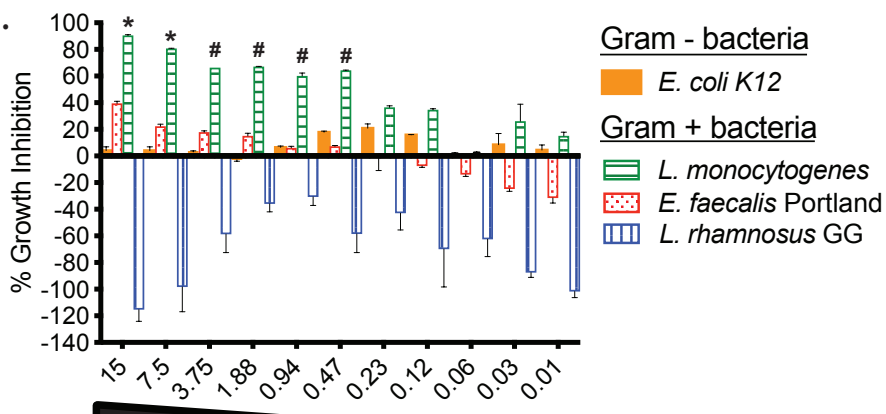

rREG3y Concentration ( $\mu \mathrm{M})$

J.

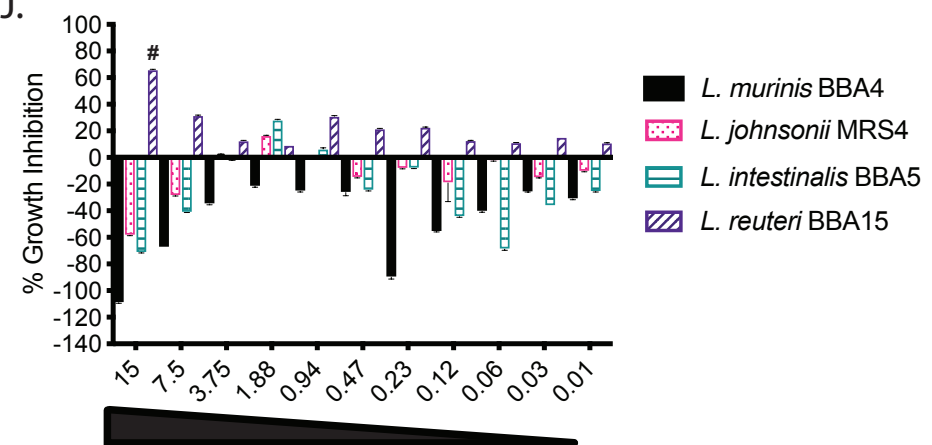

rREG3 $\gamma$ Concentration $(\mu \mathrm{M})$ 
bioRxiv preprint doi: https://doi.org/10.1101/2020.06.17.130393; this version posted June 18, 2020. The copyright holder for this preprint (which was not certified by peer review) is the author/funder. All rights reserved. No reuse allowed without permission.

Figure 4

A.

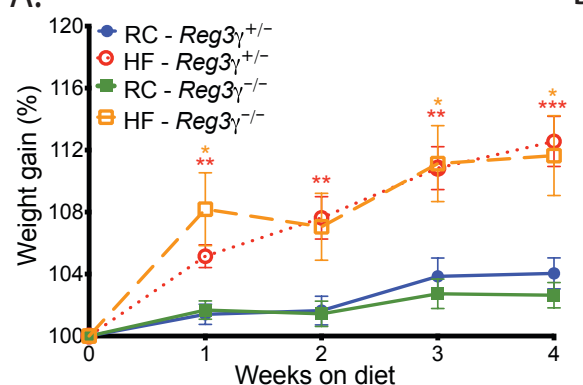

D.

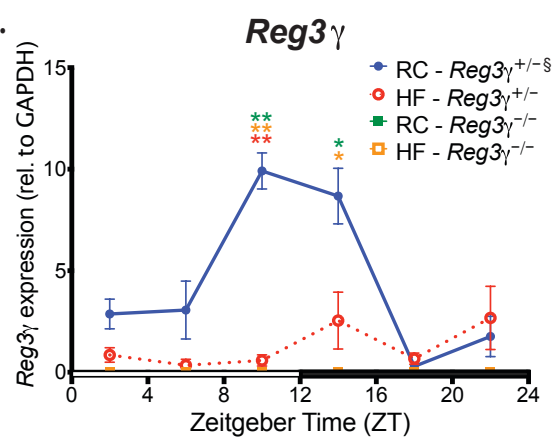

Lyz1

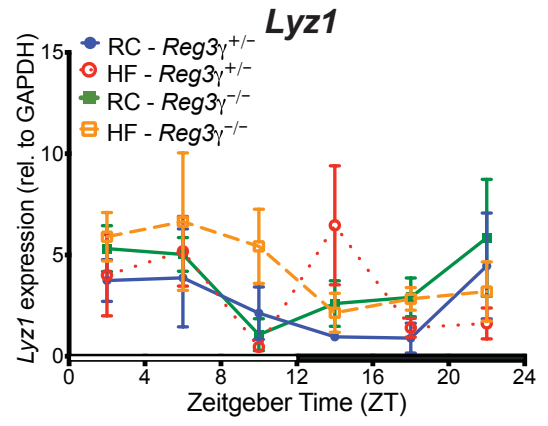

B.
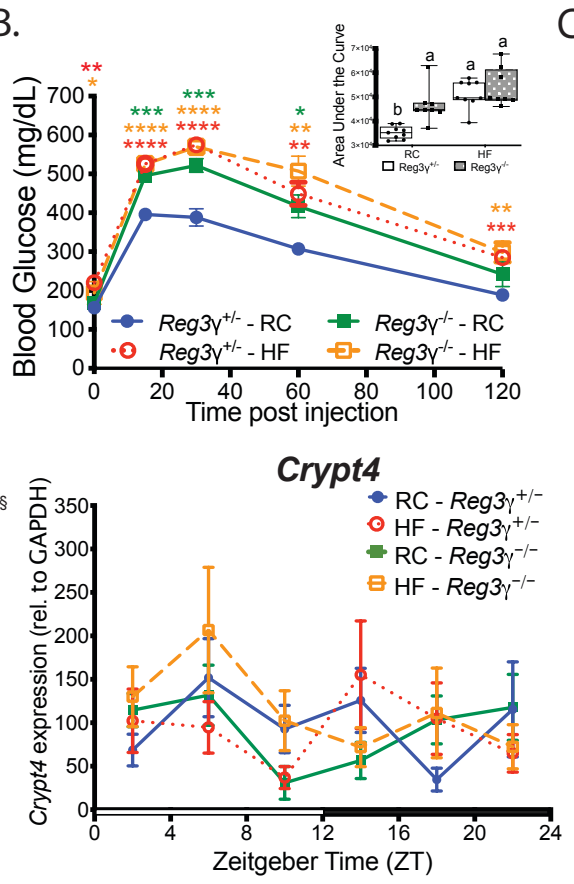

Ang4

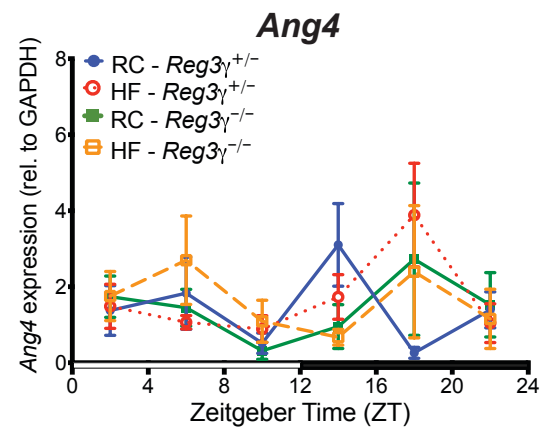

C.

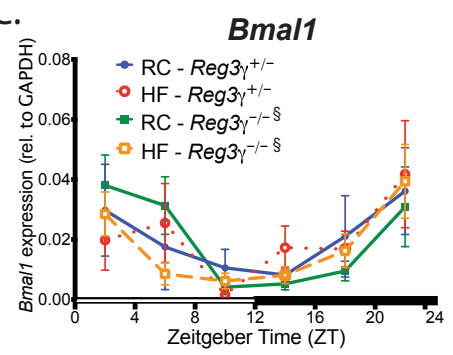

Per2
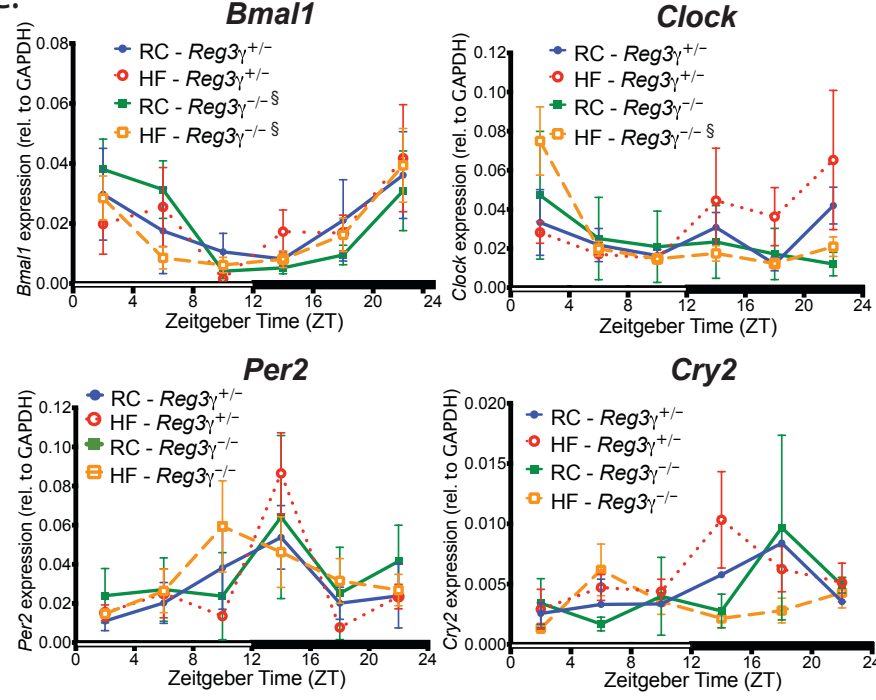

Cry2

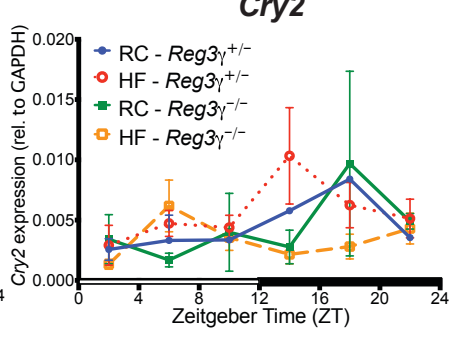

E.

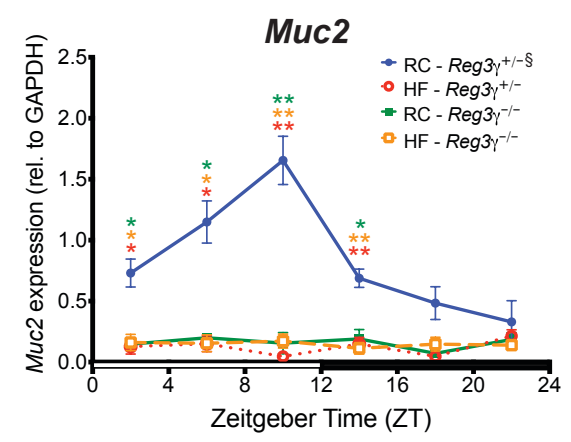


bioRxiv preprint doi: https://doi.org/10.1101/2020.06.17.130393; this version posted June 18, 2020. The copyright holder for this preprint Figure 5 (which was not certified by peer review) is the author/funder. All rights reserved. No reuse allowed without permission.

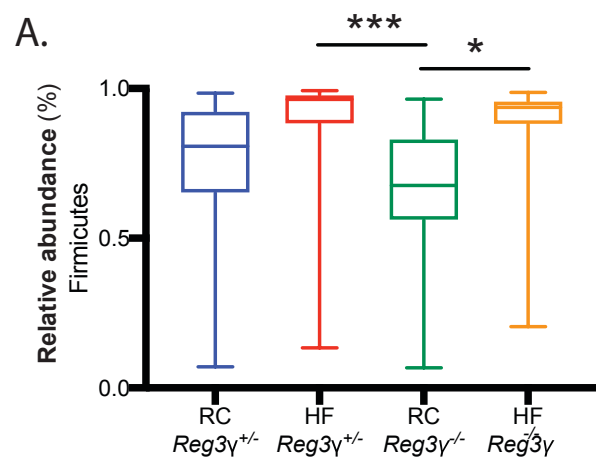

C.

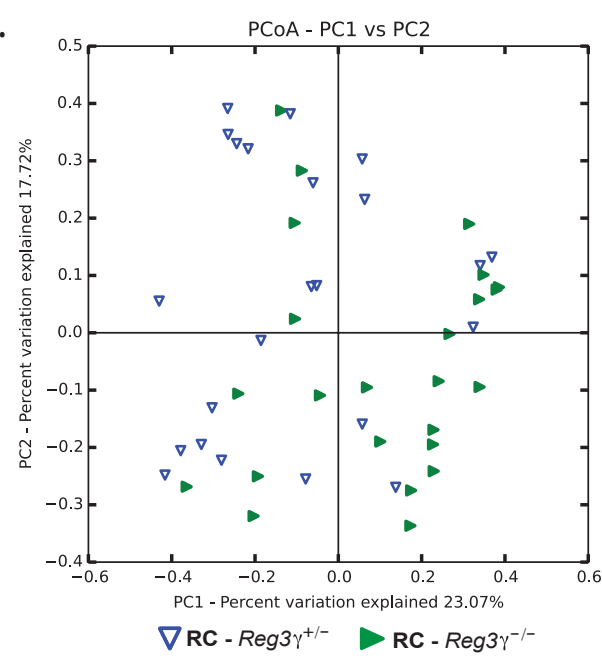

E.
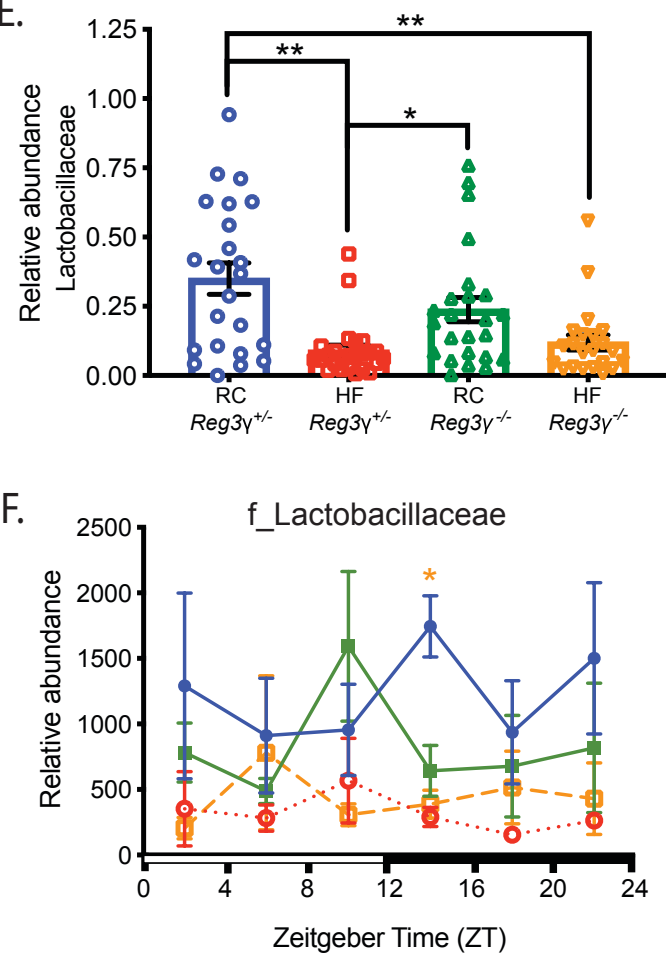
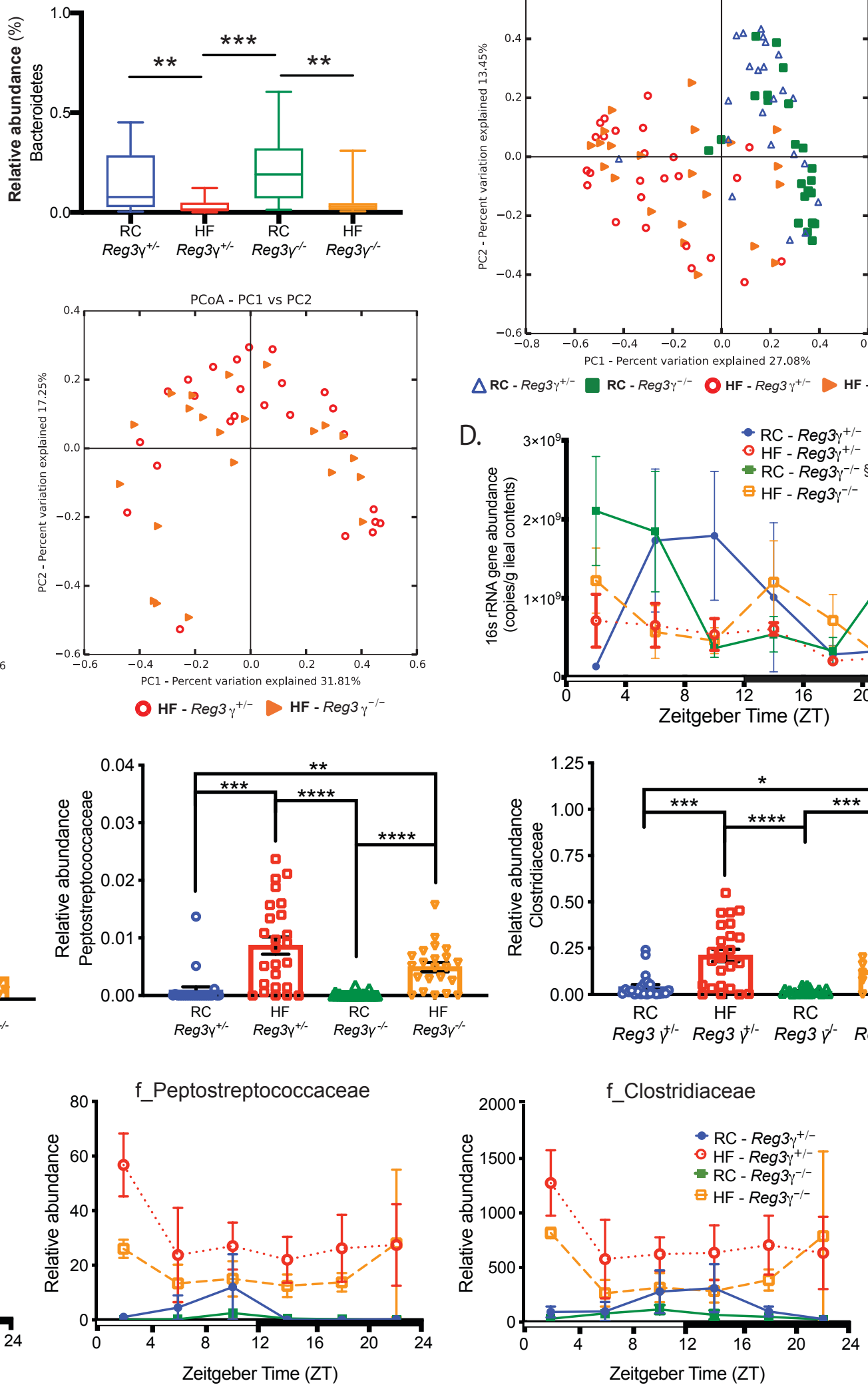

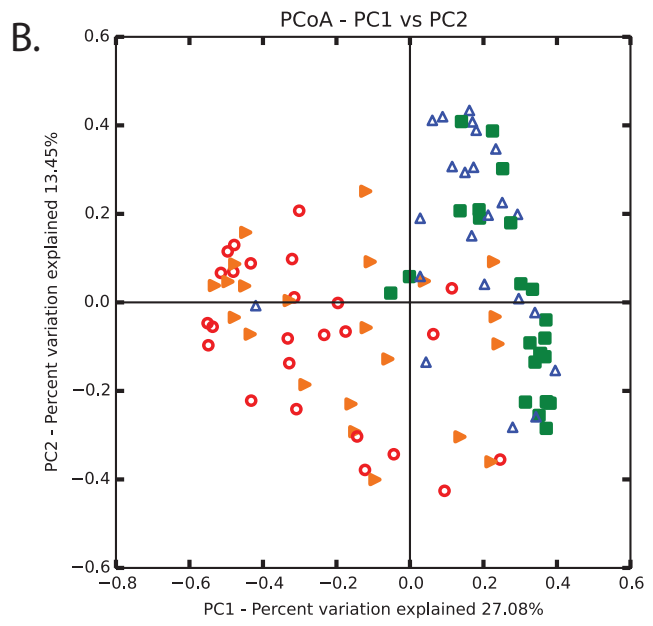

$\Delta \mathrm{RC}-\mathrm{Reg} 3 \gamma^{+/-} \square \mathrm{RC}-\operatorname{Reg} 3 \gamma^{-/-} \mathrm{HF}-\operatorname{Reg} 3 \gamma^{+/-} D \mathrm{HF}-\operatorname{Reg} 3 \gamma^{-/-}$
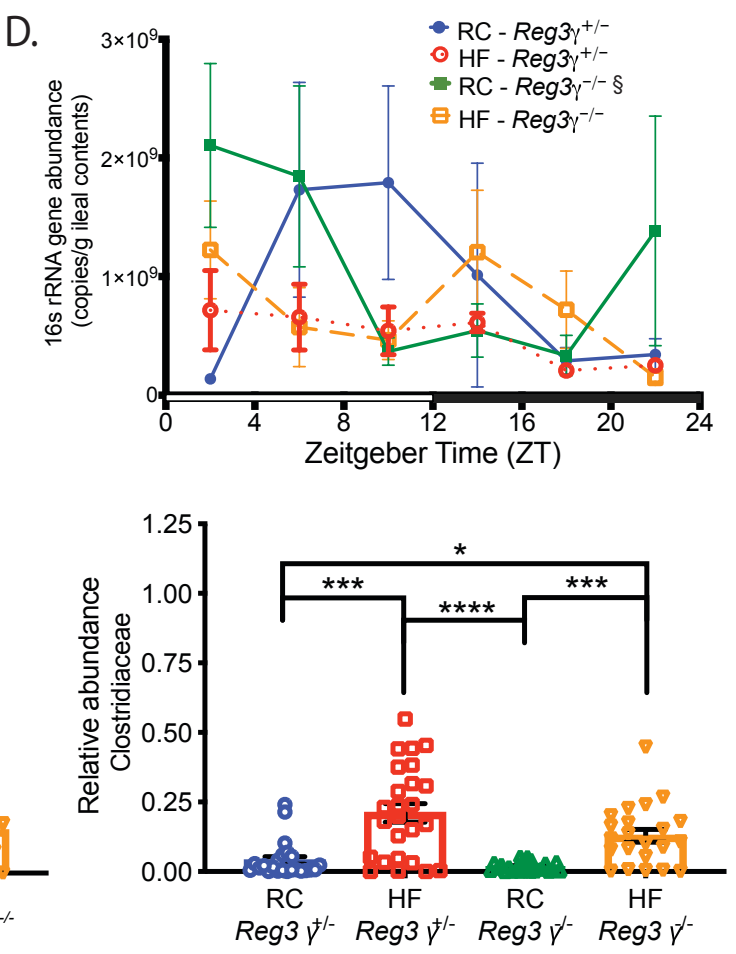

Zeitgeber Time (ZT) 
bioRxiv preprint doi: https://doi.org/10.1101/2020.06.17.130393; this version posted June 18, 2020. The copyright holder for this preprint

Figure 6 (which was not certified by peer review) is the author/funder. All rights reserved. No reuse allowed without permission.

A.

\begin{tabular}{|c|c|c|c|}
\hline Condition & $\begin{array}{c}\text { Oscillating } \\
\text { OTUs } \\
(p<0.05)\end{array}$ & $\begin{array}{c}\begin{array}{c}\text { Oscillating } \\
\text { OTUs }\end{array} \\
(p=0.05-0.1)\end{array}$ & Total OTUs \\
\hline$R e g 3 \gamma^{+/-}-\mathrm{RC}$ & 23 & 14 & 358 \\
\hline$R e g 3 \gamma^{+/-}-\mathrm{HF}$ & 14 & 8 & 291 \\
\hline$R e g 3 \gamma^{\prime-}-\mathrm{RC}$ & 18 & 26 & 312 \\
\hline$R e g 3 \gamma^{\prime-}-\mathrm{HF}$ & 21 & 21 & 349 \\
\hline
\end{tabular}

B.

Distal ileum mucosal scrapings (DIMS)

\begin{tabular}{|c|c|c|c|}
\hline Condition & $\begin{array}{l}\text { Oscillating } \\
\text { OTUs } \\
\text { ( } p<0.05 \text { ) }\end{array}$ & 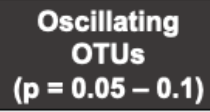 & Total OTUs \\
\hline $\operatorname{Reg} 3 \gamma^{+1-}-\mathrm{RC}$ & 12 & 11 & 384 \\
\hline $\operatorname{Reg} 3 \gamma^{+1-}-\mathrm{HF}$ & 19 & 18 & 393 \\
\hline$R e g 3 Y^{\prime-}-\mathrm{RC}$ & 50 & 24 & 380 \\
\hline Reg3$y^{\prime-}-\mathrm{HF}$ & 34 & 39 & 393 \\
\hline
\end{tabular}

C.

\section{Oscillating OTUs - DILC}

$\operatorname{Reg}_{\gamma}+1-$
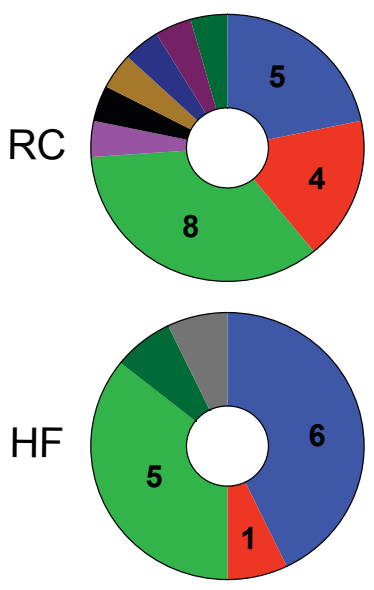

$\operatorname{Reg}_{\gamma}{ }^{-1-}$
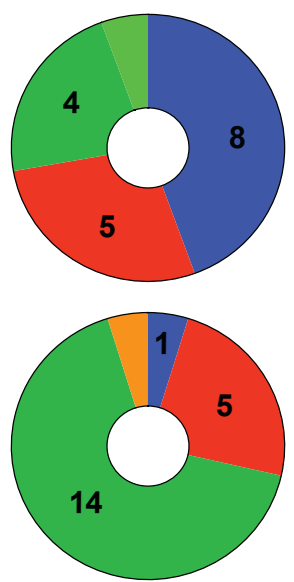

$\square$ Bacteroidales

$\square$ Lactobacillales

$\square$ Clostridiales

$\square$ Actinomycetales

$\square$ Coriobacteriales

- Bifidobacteriales

$\square$ Streptophyta

$\square$ Deferribacterales

$\square$ Bacillales

$\square$ Turicibacterales

$\square$ Rhizobiales

$\square$ Burkholderiales

$\square$ Erysipelotrichales

$\square$ Enterobacteriales

$\square$ Pseudomonadales

$\square$ CW040

\section{Oscillating OTUs - DIMS}

$\operatorname{Reg}_{\gamma}+/-$

$\operatorname{Reg}_{\gamma}{ }^{-1-}$
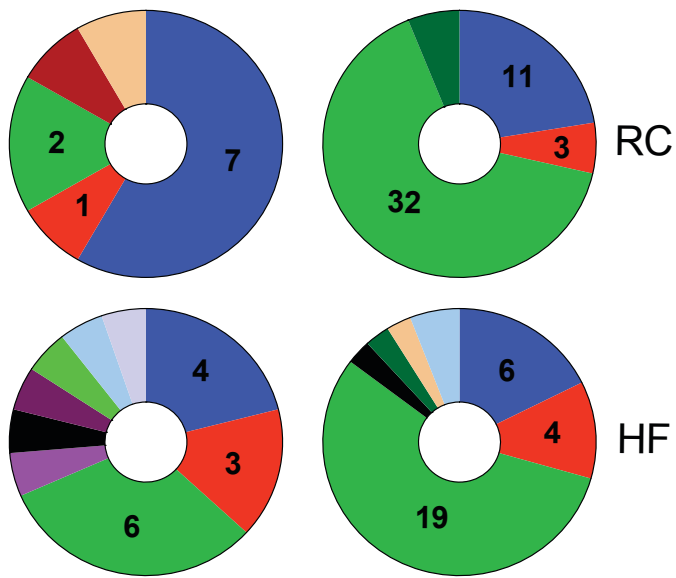

D.

DILC

DIMS

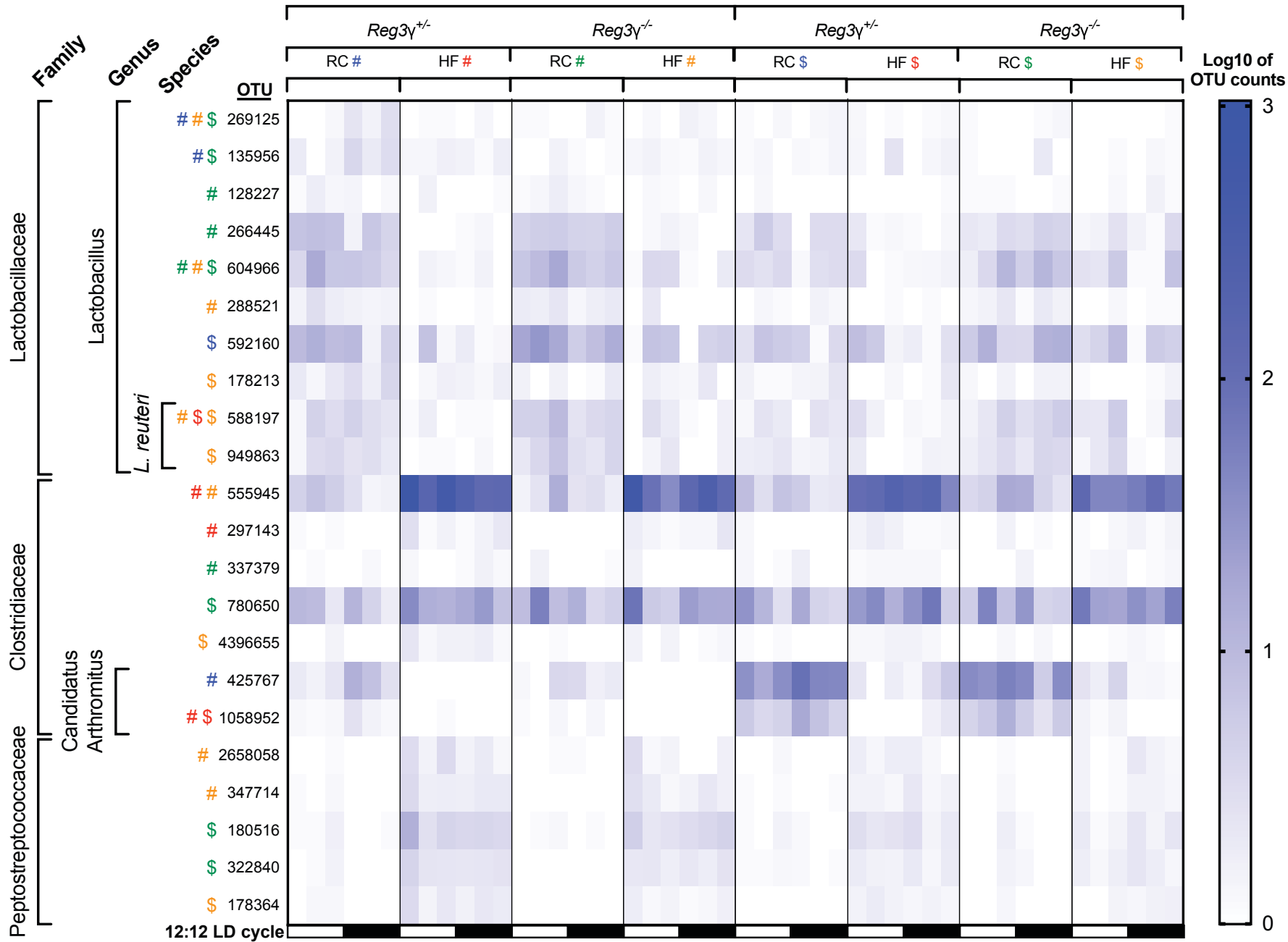


bioRxiv preprint doi: https://doi.org/10.1101/2020.06.17.130393; this version posted June 18, 2020. The copyright holder for this preprint

Figure S1

A.
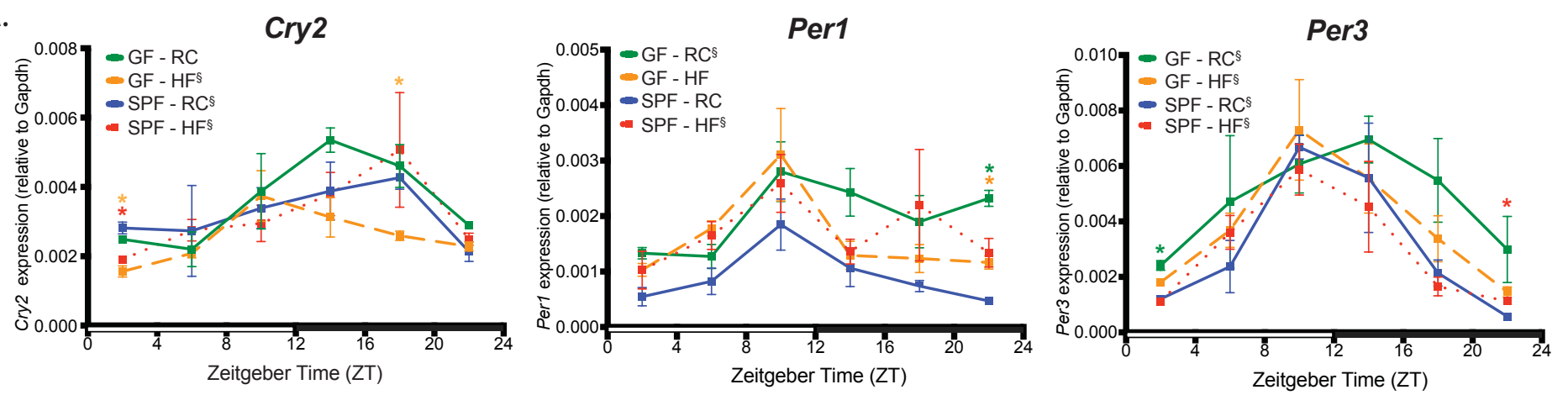

B.
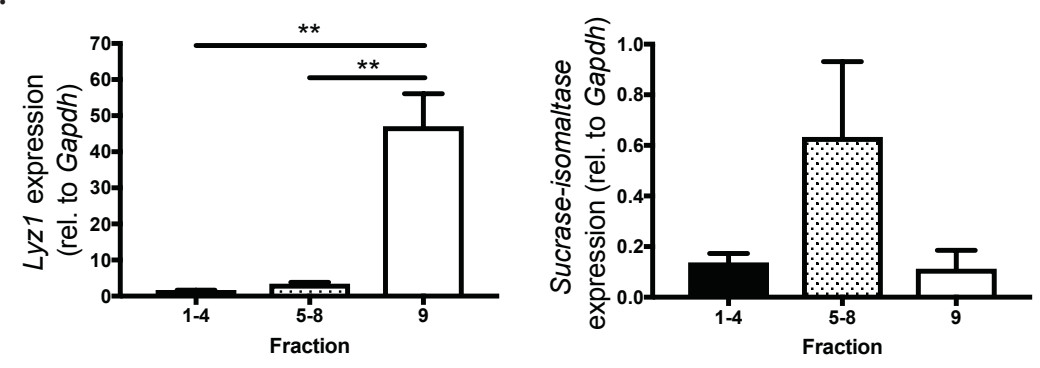
Figure S2 (which was not certified by peer review) is the author/funder. All rights reserved. No reuse allowed without permission.

A.
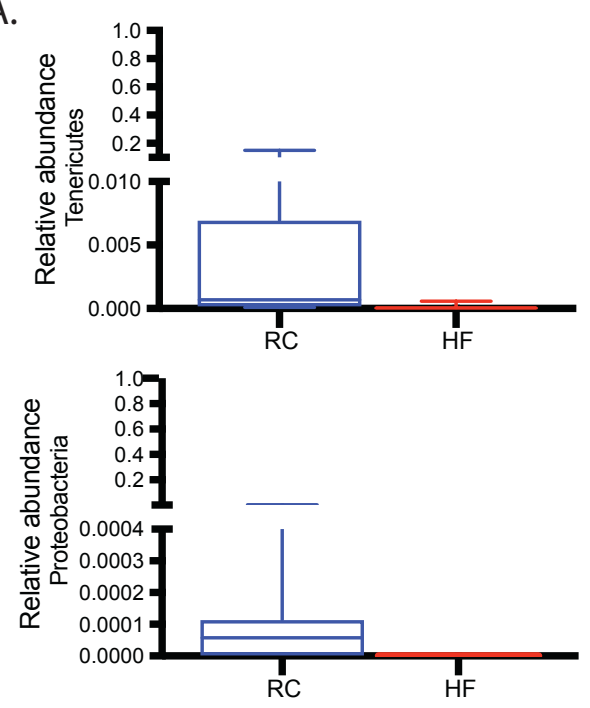

C.

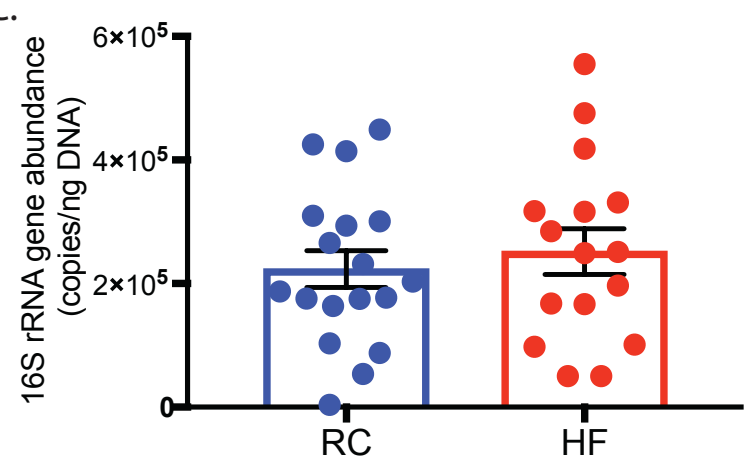

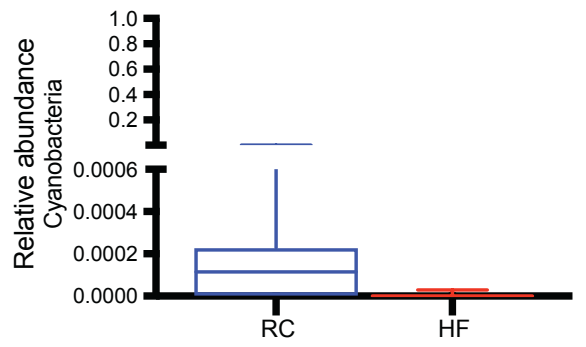

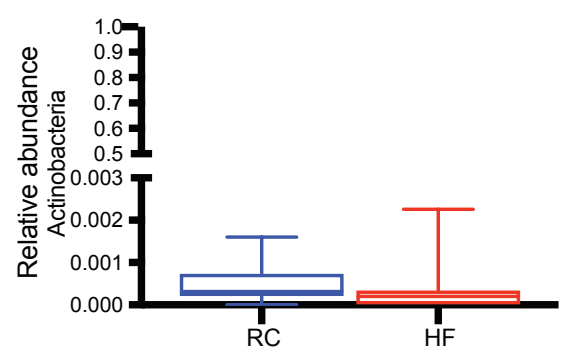

D.

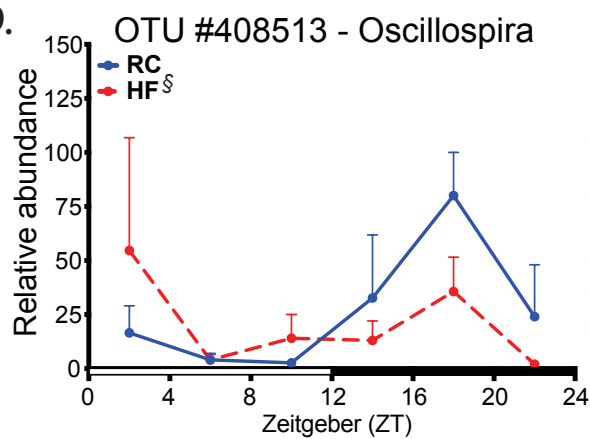

E.

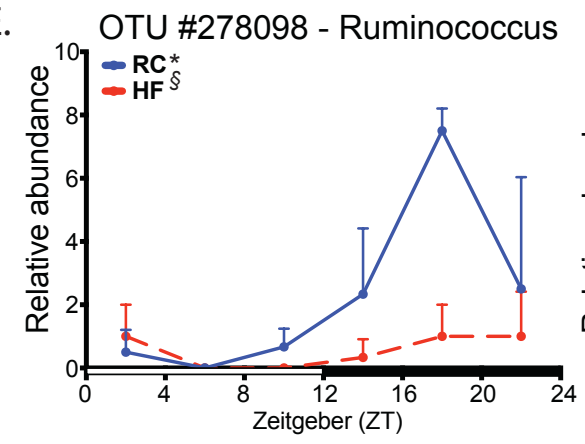

B.
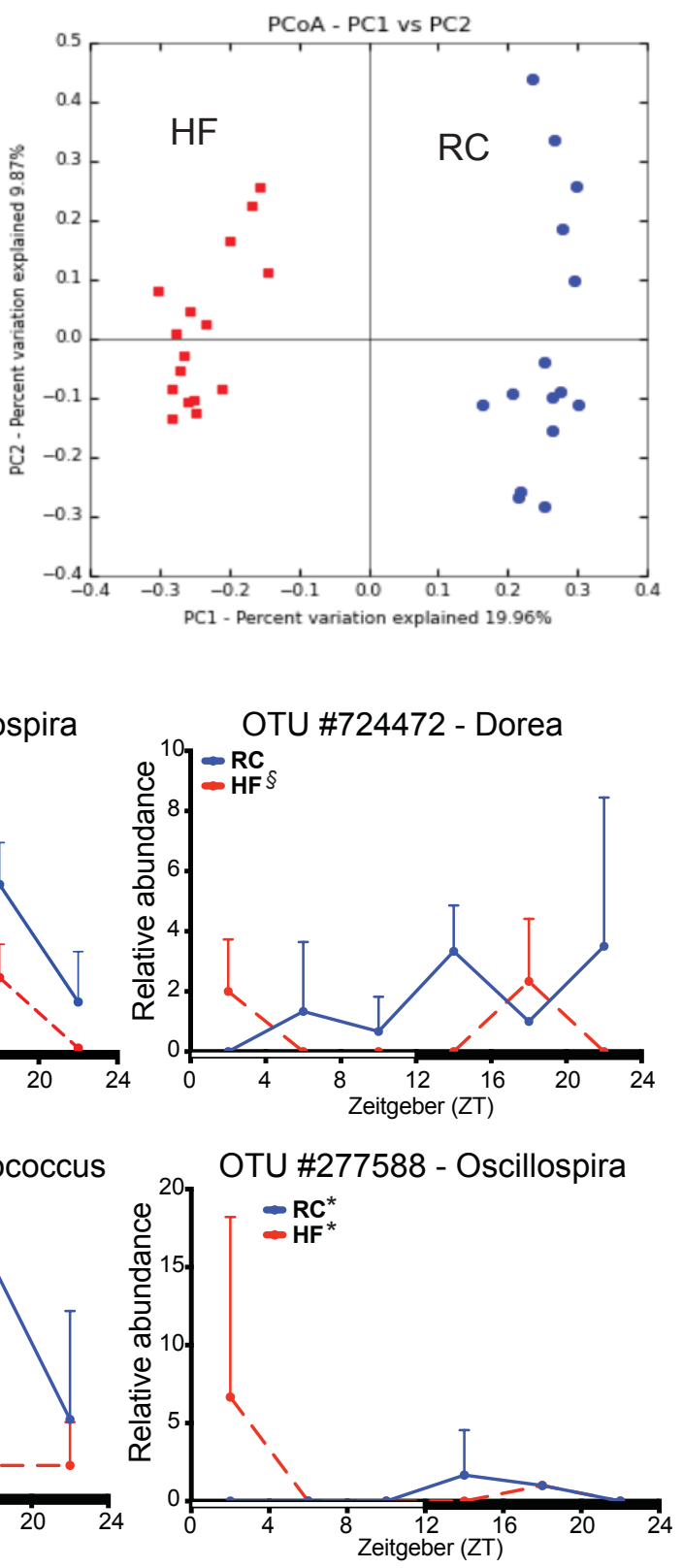

F.

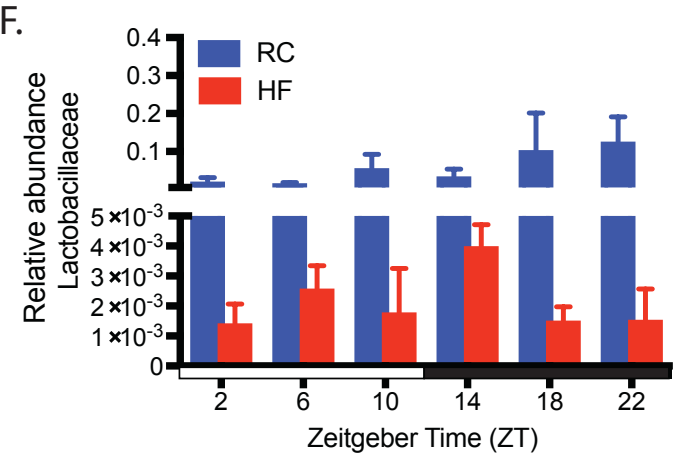

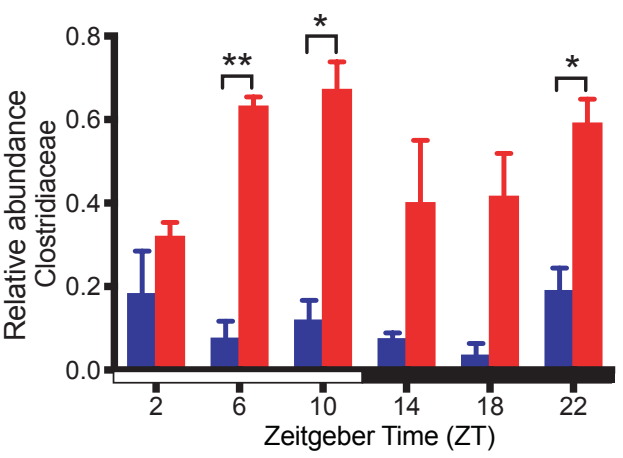


Figure S3

(which was not certified by peer review) is the author/funder. All rights reserved. No reuse allowed without permission.

A.

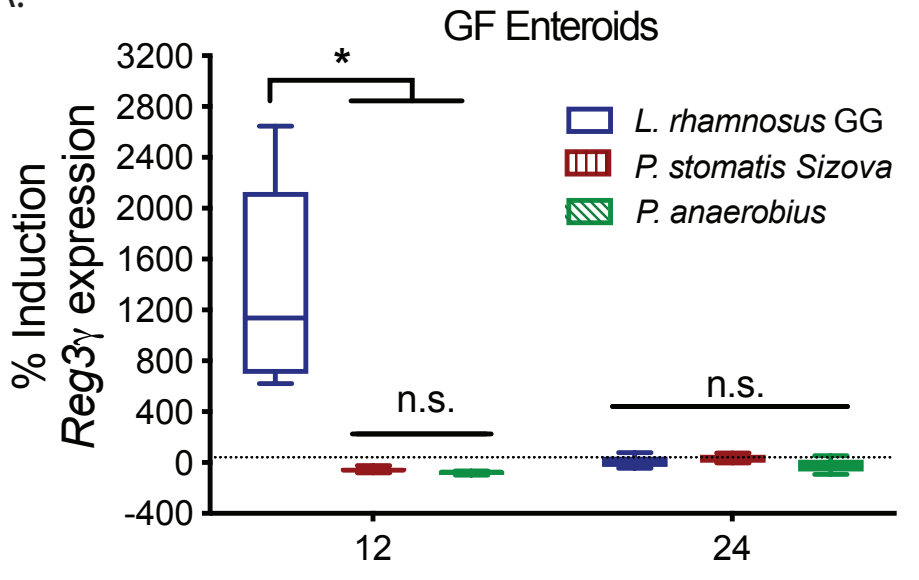

Time Post Treatment (hrs)

B.

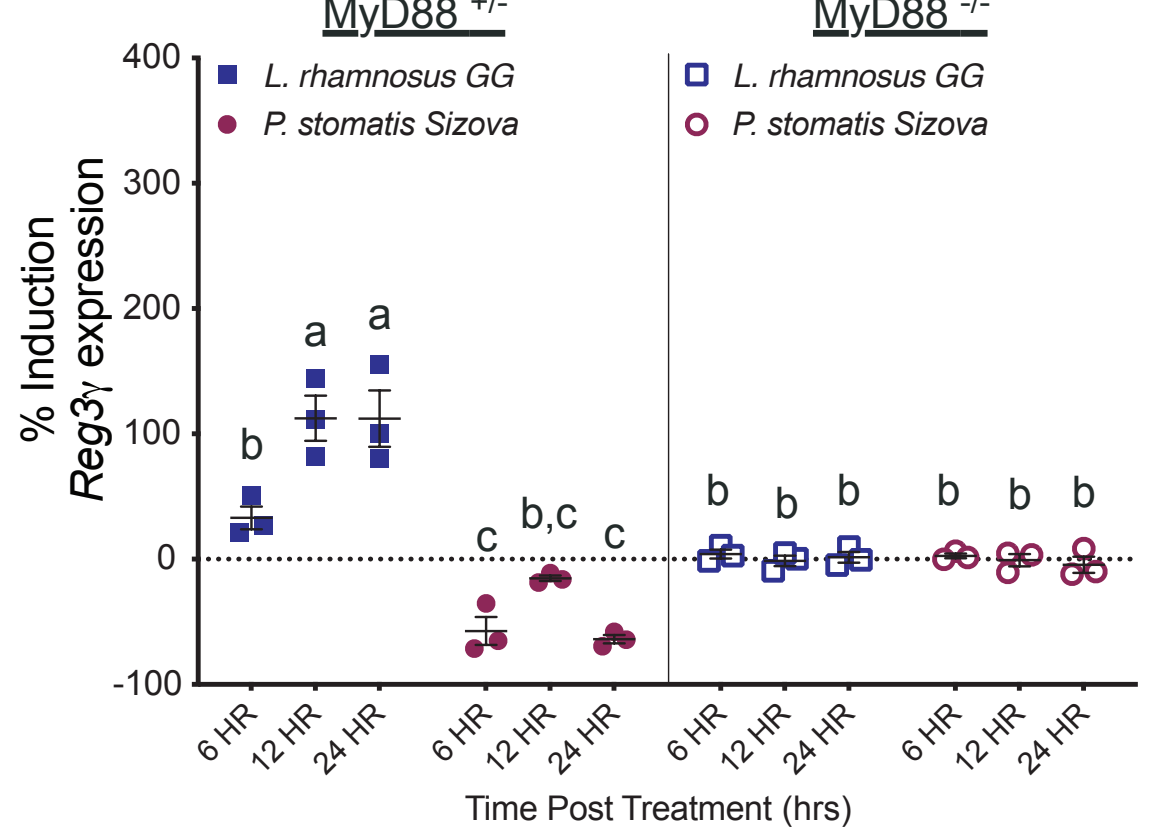

C.

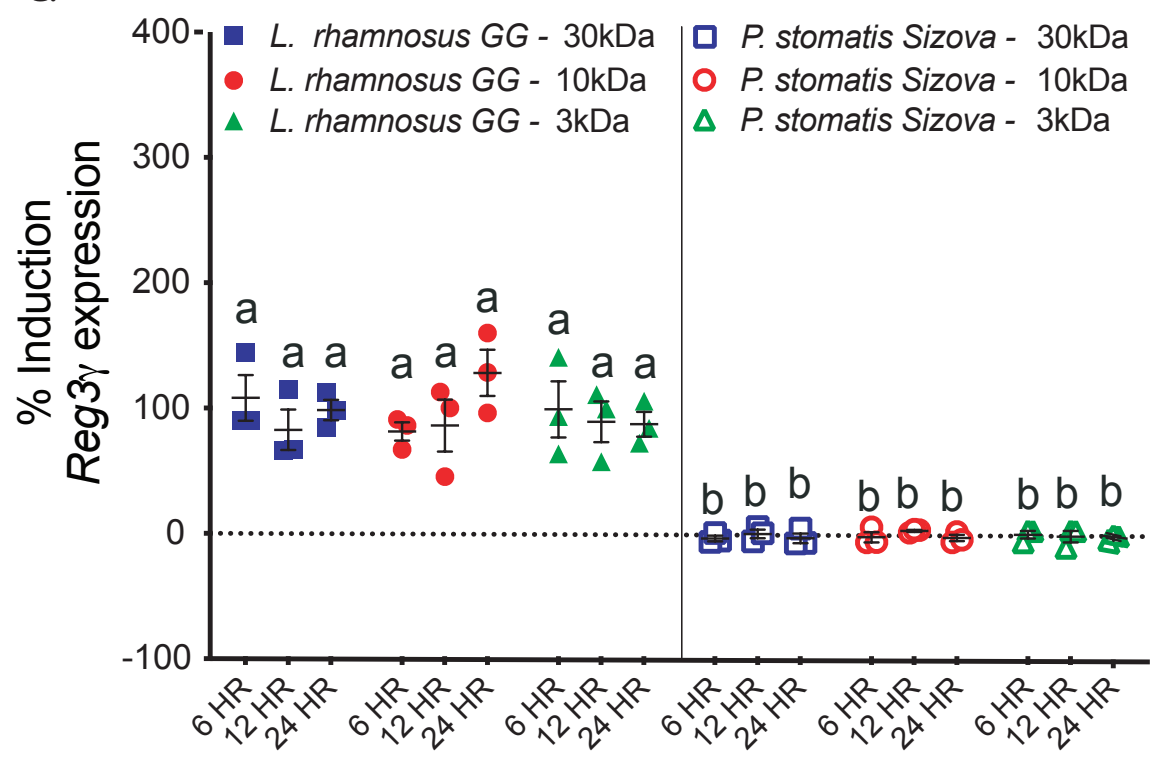

Time Post Treatment (hrs)
D.
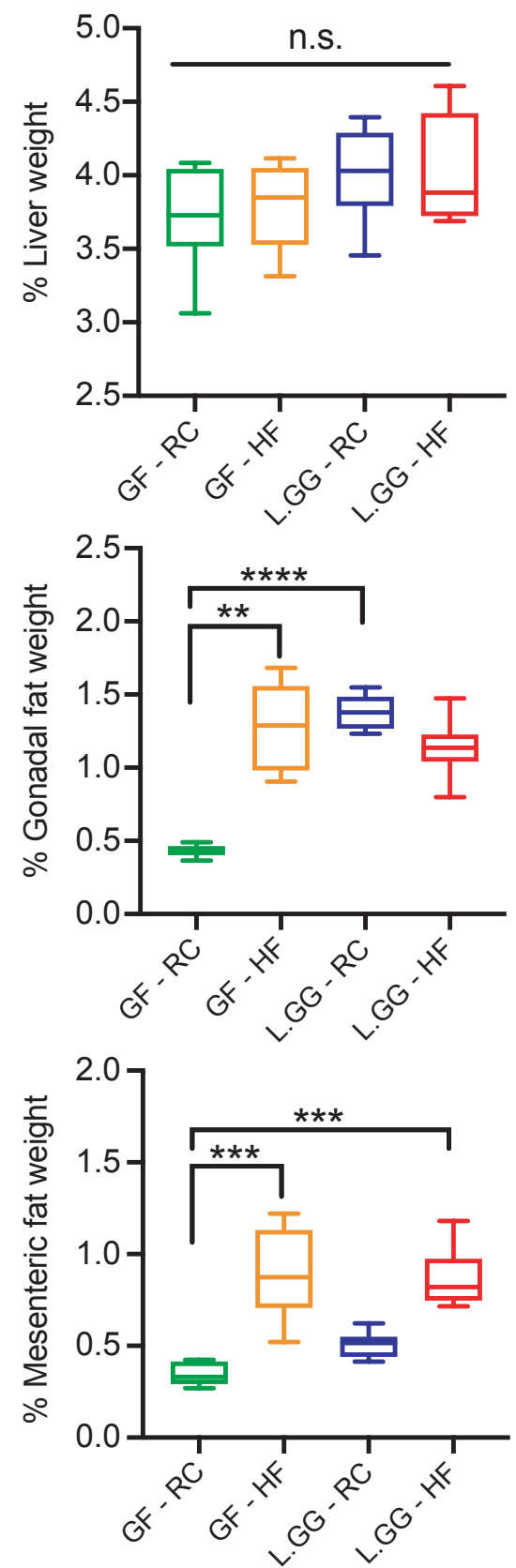

E.

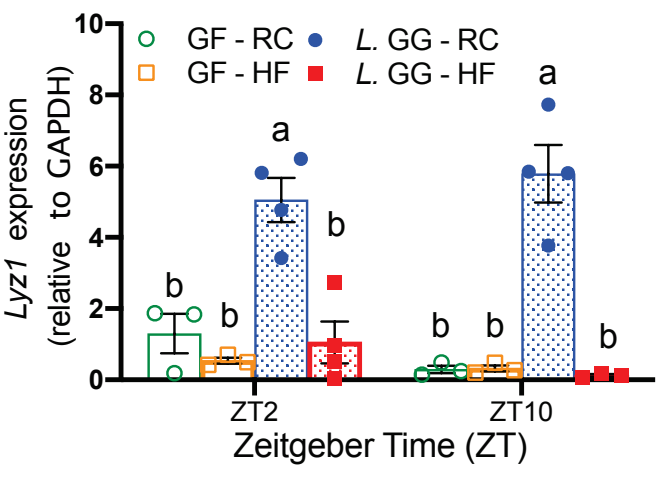


bioRxiv preprint doi: https://doi.org/10.1101/2020.06.17.130393; this version posted June 18, 2020. The copyright holder for this preprint Figure S4 (which was not certified by peer review) is the author/funder. All rights reserved. No reuse allowed without permission.

A.

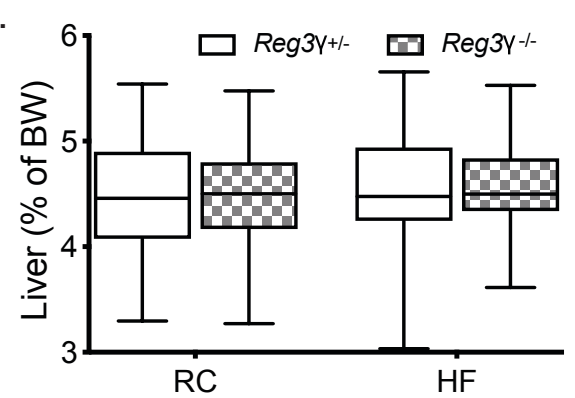

B.

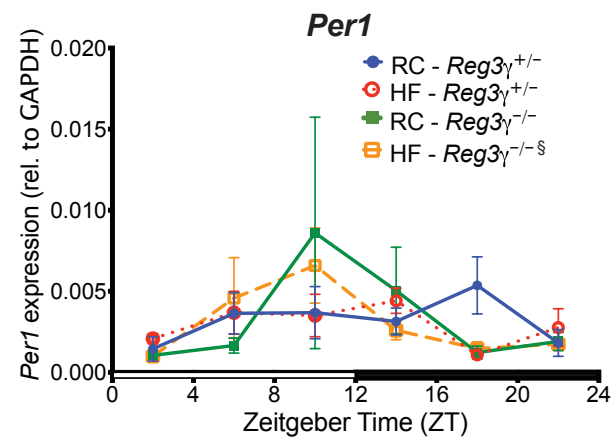

C.

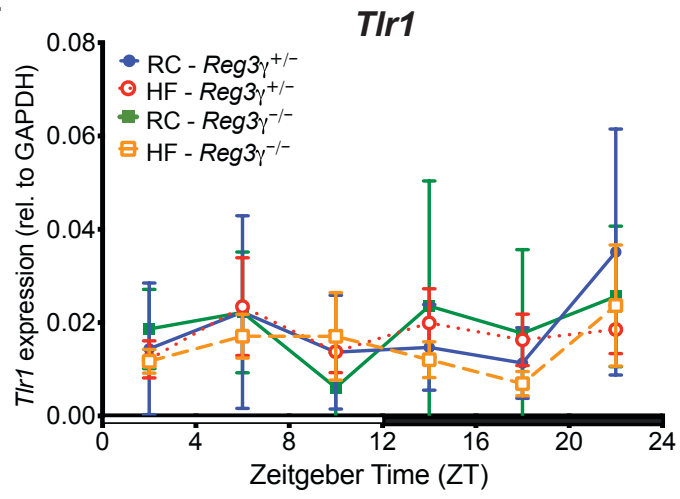

TIr3

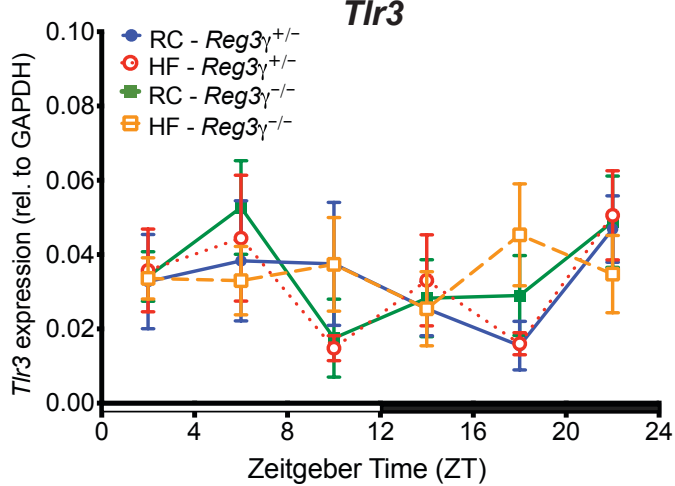

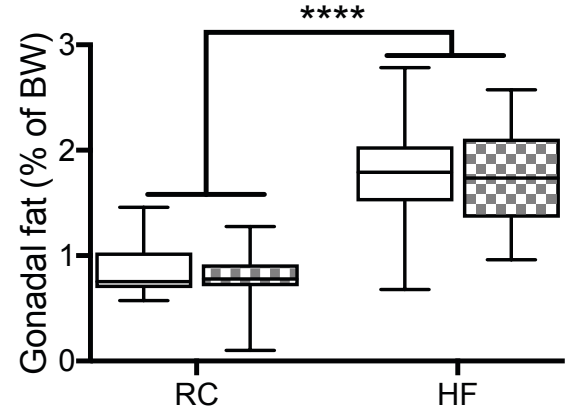

Per3

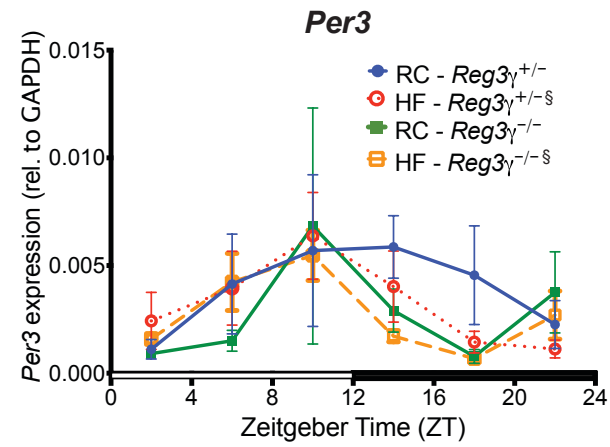

TIr2

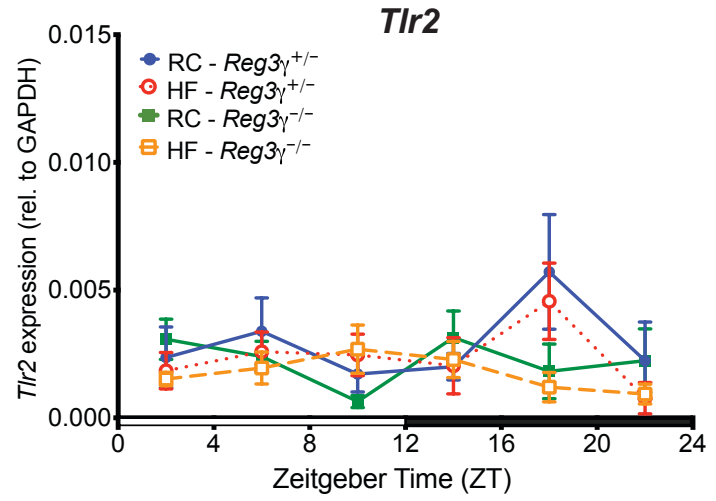

TIr4

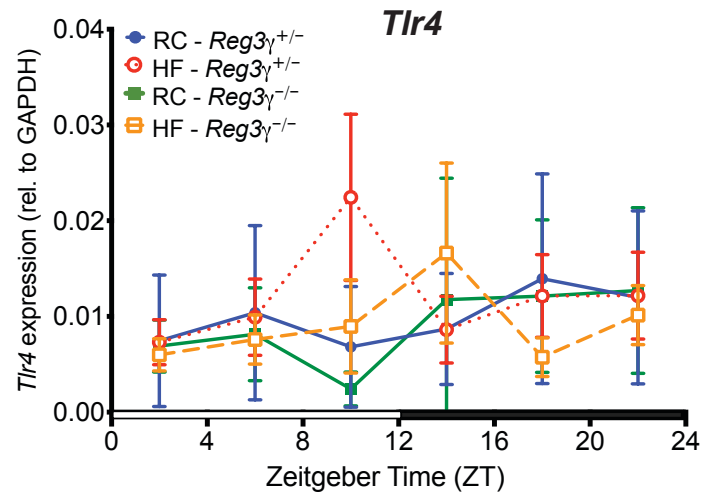

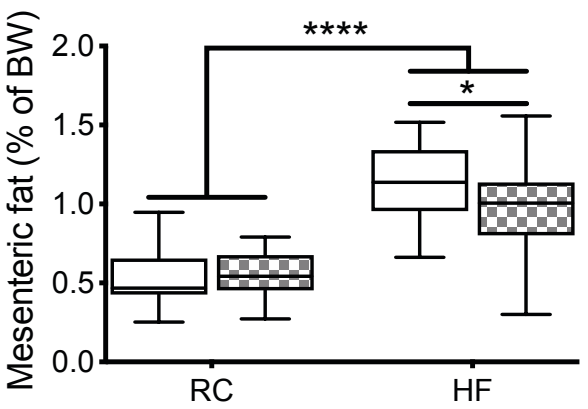

Cry1

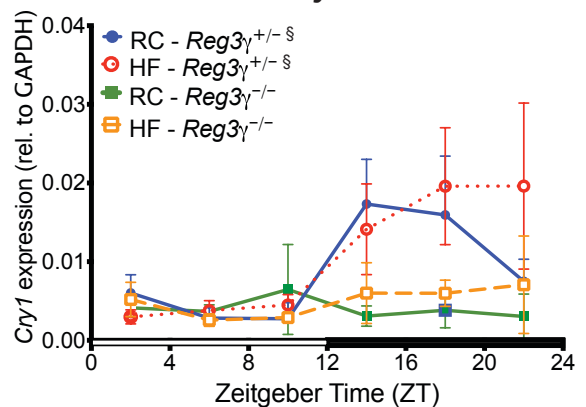

Zeitgeber Time (ZT) 
Figure S5

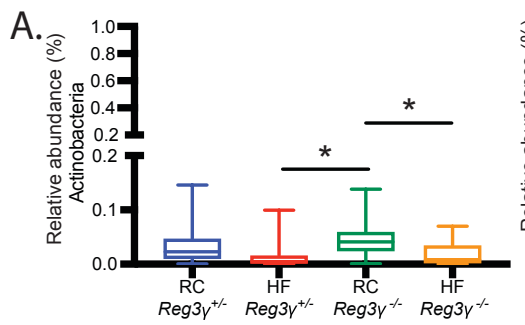

B. Distal ileum mucosal scrapings (DIMS)

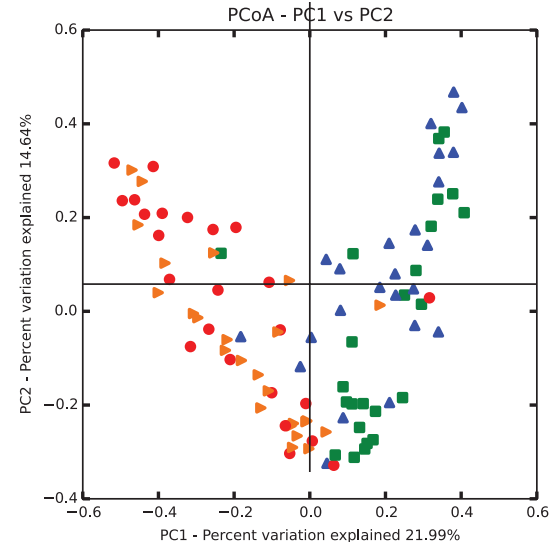

$\Delta \mathrm{RC}-\mathrm{Reg} 3 \gamma^{+/-} \square \mathrm{RC}-\operatorname{Reg} 3 \gamma^{-/-} \bigcirc \mathrm{HF}-\operatorname{Reg} 3 \gamma^{+/-} \quad \mathrm{HF}-\operatorname{Reg} 3 \gamma^{-/-}$

D.

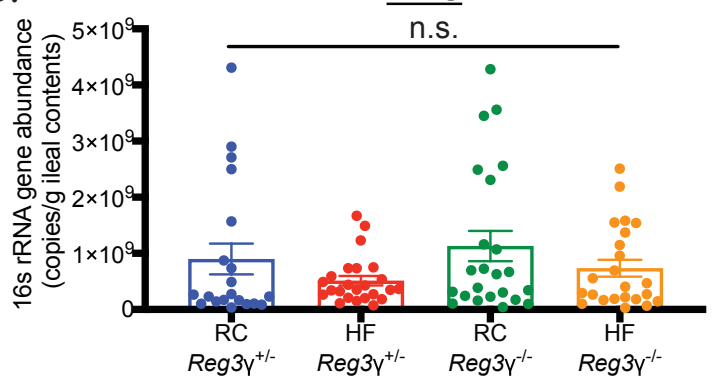

F.
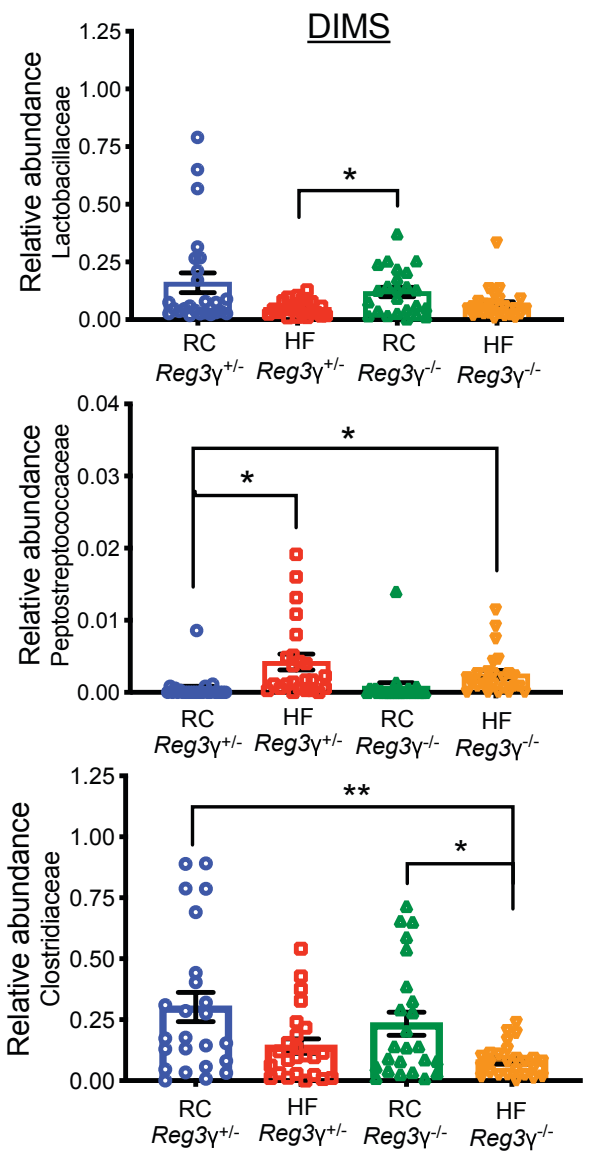

G.
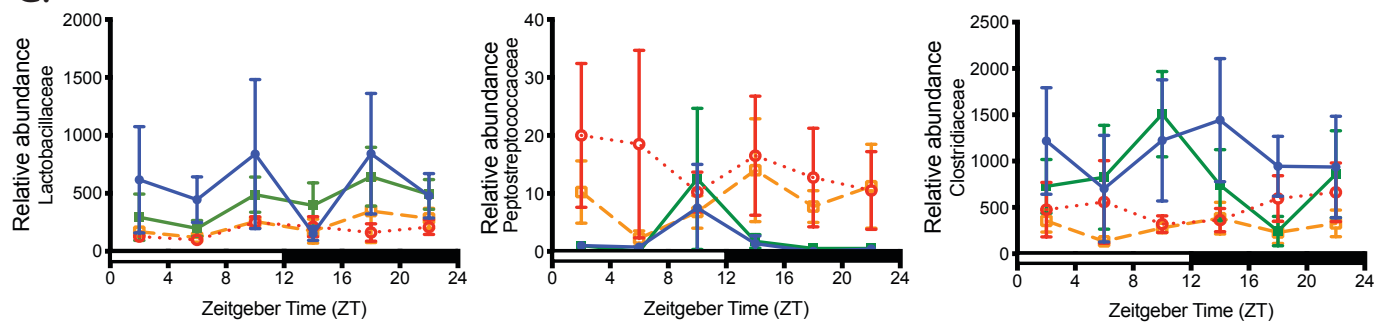
Table S1. CircWave Co-sinor p-values. Related to Figures 1, 2, 4, 5, S1, S2, S4.

\begin{tabular}{|c|c|c|c|c|}
\hline & \multicolumn{4}{|c|}{ Microbial status } \\
\hline & SPF & GF & SPF & GF \\
\hline & \multicolumn{4}{|c|}{ Diet } \\
\hline & \multicolumn{2}{|c|}{$\mathrm{RC}$} & \multicolumn{2}{|c|}{$\mathrm{HF}$} \\
\hline Gene target & \multicolumn{4}{|c|}{ CircWave $p$-value* } \\
\hline Bmal1 & $6.00 \mathrm{E}-07$ & 0.0001 & 0.0001 & 0.0006 \\
\hline Clock & 0.008 & n.s. & 0.007 & n.s. \\
\hline Per1 & n.s. & 0.009 & 0.025 & n.s. \\
\hline Per2 & 0.01 & 0.0002 & 0.01 & 0.008 \\
\hline Per3 & 0.02 & 0.0002 & 0.0005 & 0.0002 \\
\hline Cry1 & 0 & n.s. & 4.30E-06 & 0.02 \\
\hline Cry 2 & 0.0006 & n.s. & 0.0085 & 0.048 \\
\hline $\operatorname{Reg} 3 y$ & 0.04 & n.s. & 0.0009 & n.s. \\
\hline Lyz1 & n.s. & n.s. & n.s. & n.s. \\
\hline Ang4 & n.s. & n.s. & n.s. & n.s. \\
\hline Crypt4 & n.s. & n.s. & n.s. & n.s. \\
\hline Muc2 & n.s. & 0.003 & n.s. & n.s. \\
\hline \multirow[t]{5}{*}{$\begin{array}{c}\text { 16S rRNA } \\
\text { gene copy \# }\end{array}$} & n.s. & ---- & n.s. & ----- \\
\hline & \multicolumn{4}{|c|}{ Diet } \\
\hline & $\mathrm{RC}$ & $\mathrm{HF}$ & $\mathrm{RC}$ & $\mathrm{HF}$ \\
\hline & \multicolumn{4}{|c|}{ Genotype } \\
\hline & \multicolumn{2}{|c|}{$\operatorname{Reg} 3 y^{+/-}$} & \multicolumn{2}{|c|}{$\operatorname{Reg} 3 \gamma^{\prime-}$} \\
\hline Gene target & \multicolumn{4}{|c|}{ CircWave $p$-value* } \\
\hline Bmal1 & n.s. & n.s. & 0.0013 & 0.0014 \\
\hline Clock & n.s. & n.s. & n.s. & 0.0009 \\
\hline Per1 & n.s. & n.s. & n.s. & 0.032 \\
\hline Per2 & n.s. & n.s. & n.s. & n.s. \\
\hline Per3 & n.s. & 0.0159 & n.s. & 0.0037 \\
\hline Cry1 & 0.0228 & 0.0219 & n.s. & n.s. \\
\hline Cry 2 & n.s. & n.s. & n.s. & n.s. \\
\hline $\operatorname{Reg} 3 y$ & $1.70 \mathrm{E}-06$ & n.s. & n.s. & n.s. \\
\hline Lyz1 & n.s. & n.s. & 0.0469 & n.s. \\
\hline Ang4 & n.s. & n.s. & n.s. & n.s. \\
\hline Crypt4 & n.s. & n.s. & n.s. & n.s. \\
\hline Muc2 & $2.28 \mathrm{E}-05$ & n.s. & n.s. & n.s. \\
\hline $\begin{array}{c}\text { 16S rRNA } \\
\text { gene copy \# }\end{array}$ & n.s. & n.s. & 0.0367 & n.s. \\
\hline
\end{tabular}

*Significant co-sinor expression pattern indicated by $p<0.05$ n.s. $=$ Not significant 
Table S2. Statistical analysis of OTU relative abundances in DILC from RC and HF-fed WT mice determined via ANOVA. OTUs exhibiting Bonferroni P-value less than 0.05 are shown. Related to Figures 2, $\mathbf{S 2 .}$

\begin{tabular}{|c|c|c|c|c|c|c|}
\hline Taxonomy & OTU ID & Test-stat & $\begin{array}{c}\text { FDR } \\
\text { P-value }\end{array}$ & $\begin{array}{c}\text { Bonferroni } \\
\text { P-value }\end{array}$ & $\begin{array}{l}\text { RC mean } \\
\text { relative } \\
\text { abundance }\end{array}$ & $\begin{array}{l}\text { HF mean } \\
\text { relative } \\
\text { abundance }\end{array}$ \\
\hline $\begin{array}{l}\text { p_Firmicutes; c_CClostridia; o__Clostridiales; } \\
\text { f_Clostridiaceae }\end{array}$ & 270200 & 91.2795535 & 1.15E-07 & 1.15E-07 & 0.06666667 & 8.5 \\
\hline p__Firmicutes; c__Clostridia; o__Clostridiales & 270382 & $2.14 \mathrm{E}-08$ & 4.44E-06 & 1.33E-05 & 0.13333333 & 17.125 \\
\hline $\begin{array}{l}\text { p__Firmicutes; c__Clostridia; o__Clostridiales; } \\
\text { f__Clostridiaceae }\end{array}$ & 272964 & 42.5045951 & 4.03E-05 & 0.00024152 & 0 & 11.125 \\
\hline $\begin{array}{l}\mathrm{p} \text { __Firmicutes; c__Clostridia; o__Clostridiales; } \\
\mathrm{f} \text { _Clostridiaceae }\end{array}$ & 308802 & 40.5376344 & 5.22E-05 & 0.0003651 & 0 & 19.5 \\
\hline $\begin{array}{l}\text { p_Firmicutes; c_CClostridia; o__Clostridiales; } \\
\text { f_Clostridiaceae }\end{array}$ & 297143 & 39.8811545 & 5.25E-05 & 0.00042022 & 0 & 13.5 \\
\hline $\begin{array}{l}\text { p__Firmicutes; c_CClostridia; o__Clostridiales; } \\
\text { f__Clostridiaceae }\end{array}$ & 555945 & 38.0056438 & 6.33E-05 & 0.0006329 & 14.6666667 & 10293.0625 \\
\hline $\begin{array}{l}\text { p_Firmicutes; c_Clostridia; o__Clostridiales; } \\
\text { f_Peptostreptococcaceae }\end{array}$ & 299474 & 37.4706922 & $6.48 \mathrm{E}-05$ & 0.00071287 & 0 & 78.6875 \\
\hline $\begin{array}{l}\text { p_Firmicutes; c_Clostridia; o_Clostridiales; } \\
\text { f__Peptostreptococcaceae }\end{array}$ & 198209 & 36.5559682 & 6.97E-05 & 0.00087576 & 0 & 18.5 \\
\hline $\begin{array}{l}\text { p_Firmicutes; c_Clostridia; o__Clostridiales; } \\
\text { f_Peptostreptococcaceae }\end{array}$ & 180516 & 36.403972 & 6.97E-05 & 0.00090649 & 0 & 6.75 \\
\hline $\begin{array}{l}\text { p__Firmicutes; c__Clostridia; o__Clostridiales; } \\
\text { f__Clostridiaceae }\end{array}$ & 189407 & 35.3035256 & 8.33E-05 & 0.0011665 & 0 & 16.1875 \\
\hline $\begin{array}{l}\text { p_Firmicutes; c_Clostridia; o__Clostridiales; } \\
\text { f__Peptostreptococcaceae }\end{array}$ & 2658058 & 34.261319 & 9.92E-05 & 0.00148741 & 0 & 22.5625 \\
\hline $\begin{array}{l}\text { p_Firmicutes; c_Clostridia; o__Clostridiales; } \\
\text { f__Peptostreptococcaceae }\end{array}$ & 262060 & 33.8324487 & 0.00010182 & 0.00164586 & 0.13333333 & 27.8125 \\
\hline $\begin{array}{l}\text { p__Firmicutes; c_Clostridia; o__Clostridiales; } \\
\text { f__Clostridiaceae }\end{array}$ & 4396655 & 33.6200207 & 0.00010182 & 0.00173095 & 0 & 8.3125 \\
\hline $\begin{array}{l}\text { p_Firmicutes; c_CClostridia; o__Clostridiales; } \\
\mathrm{f} \text { _Clostridiaceae }\end{array}$ & 199268 & 32.5943636 & 0.0001165 & 0.00221353 & 0 & 12.9375 \\
\hline $\begin{array}{l}\text { p_Firmicutes; c_Clostridia; o__Clostridiales; } \\
\text { f__Peptostreptococcaceae }\end{array}$ & 4380137 & 31.8914956 & 0.00013132 & 0.00262637 & 0 & 7.5 \\
\hline $\begin{array}{l}\text { p__Firmicutes; c_CClostridia; o__Clostridiales; } \\
\mathrm{f} \text { _Clostridiaceae }\end{array}$ & 191803 & 30.2844404 & 0.00017017 & 0.0039139 & 0 & 18 \\
\hline $\begin{array}{l}\text { p_Firmicutes; c_CClostridia; o__Clostridiales; } \\
\text { f_Clostridiaceae }\end{array}$ & 4238179 & 29.2910551 & 0.00018657 & 0.00503728 & 6.2 & 77.8125 \\
\hline $\begin{array}{l}\text { p_Firmicutes; c_Clostridia; o__Clostridiales; } \\
\text { f__Peptostreptococcaceae }\end{array}$ & 531374 & 28.4401959 & 0.00020918 & 0.00627536 & 0 & 5.1875 \\
\hline $\begin{array}{l}\text { p_Firmicutes; c_Clostridia; o__Clostridiales; } \\
\text { f_Peptostreptococcaceae }\end{array}$ & 514988 & 27.5382615 & 0.0002565 & 0.00795165 & 0.13333333 & 19.625 \\
\hline p_Firmicutes; c_Clostridia; o__Clostridiales & 316496 & 26.8123327 & 0.00030153 & 0.00964901 & 0.13333333 & 22.4375 \\
\hline $\begin{array}{l}\text { p__Firmicutes; c__Clostridia; o__Clostridiales; } \\
\text { f__Clostridiaceae }\end{array}$ & 331881 & 26.6387914 & 0.00030636 & 0.01010979 & 0.06666667 & 8.6875 \\
\hline $\begin{array}{l}\text { p_Firmicutes; c_Clostridia; o__Clostridiales; } \\
\text { f__Peptostreptococcaceae }\end{array}$ & 322840 & 25.7399593 & 0.00036872 & 0.01290507 & 0 & 28.5625 \\
\hline $\begin{array}{l}\text { p_Bacteroidetes; c___Bacteroidia; } \\
\text { o__Bacteroidales; f _ S } 24-7\end{array}$ & 211761 & 25.1705115 & 0.00041936 & 0.01509705 & 14.8 & 3.1875 \\
\hline $\begin{array}{l}\text { p_Firmicutes; c_Clostridia; o__Clostridiales; } \\
\text { f__Peptostreptococcaceae }\end{array}$ & 1896700 & 24.1234347 & 0.00051895 & 0.02023918 & 0 & 3.875 \\
\hline p_Firmicutes; c__Clostridia; o__Clostridiales & 248126 & 23.2327365 & 0.00060792 & 0.0260987 & 0 & 11.8125 \\
\hline $\begin{array}{l}\text { P_Bacteroidetes; c__Bacteroidia; } \\
\text { o__Bacteroidales; f_S } 24-7\end{array}$ & 445144 & 23.0523244 & 0.00060975 & 0.02749365 & 6785.86667 & 1321.375 \\
\hline $\begin{array}{l}\text { p_Bacteroidetes; c__Bacteroidia; } \\
\text { o__Bacteroidales; f_ S24-7 }\end{array}$ & 331720 & 22.9832477 & 0.00060975 & 0.02804873 & 242.066667 & 64 \\
\hline $\begin{array}{l}\text { p_Firmicutes; c_Clostridia; o__Clostridiales; } \\
\text { f_Peptostreptococcaceae }\end{array}$ & 347714 & 22.7885602 & 0.0006251 & 0.02967879 & 0 & 9.9375 \\
\hline $\begin{array}{l}\text { p_Firmicutes; c_Clostridia; o_Clostridiales; } \\
\text { f_Clostridiaceae; g_Clostridium }\end{array}$ & 235424 & 21.4259046 & 0.000837 & 0.04436084 & 0.4 & 191.75 \\
\hline $\begin{array}{l}\text { p__Firmicutes; c_Clostridia; o__Clostridiales; } \\
\text { f_Clostridiaceae }\end{array}$ & 575768 & 21.3329183 & 0.0008447 & 0.04561388 & 5.06666667 & 18.625 \\
\hline
\end{tabular}


Table S3. Adonis and ANOSIM R statistics and P-values from Beta-diversity analyses between DILC from RC and HF-fed WT mice, and from DILC and DIMS from RC and HF-fed Reg $3 \gamma^{+/}$and $R e g 3 \gamma^{-/-}$mice.

Related to Figures 2, 5, S2, S5.

\begin{tabular}{|c|c|c|c|c|c|c|c|c|}
\hline \multirow{4}{*}{ DILC } & \multicolumn{4}{|c|}{ Canberra: RC vs HF } & \multicolumn{4}{|c|}{ Bray Curtis: RC vs HF } \\
\hline & \multicolumn{2}{|c|}{ adonis } & \multicolumn{2}{|c|}{ ANOSIM } & \multicolumn{2}{|c|}{ adonis } & \multicolumn{2}{|c|}{ ANOSIM } \\
\hline & $\mathrm{R}^{2}$ & $P$ value & $\mathrm{R}$ & $\mathrm{P}$ value & $\mathrm{R}^{2}$ & $\mathrm{P}$ value & $\mathrm{R}$ & $P$ value \\
\hline & 0.372 & 0.001 & 0.862 & 0.001 & 0.371 & 0.001 & 0.657 & 0.001 \\
\hline \multirow{12}{*}{ DILC } & \multicolumn{8}{|c|}{ Bray Curtis } \\
\hline & \multicolumn{4}{|c|}{ adonis } & \multicolumn{4}{|c|}{ ANOSIM } \\
\hline & \multicolumn{2}{|c|}{$\mathrm{R}^{2}$} & \multicolumn{2}{|c|}{$P$ value } & \multicolumn{2}{|c|}{$\mathrm{R}$} & \multicolumn{2}{|c|}{$P$ value } \\
\hline & \multicolumn{2}{|c|}{0.2253} & \multicolumn{2}{|c|}{0.001} & \multicolumn{2}{|c|}{0.3426} & \multicolumn{2}{|c|}{0.001} \\
\hline & \multicolumn{4}{|c|}{ Bray Curtis: RC, $\operatorname{Reg} 3 y^{+/-}$vs $\operatorname{Reg} 3 y^{-/-}$} & \multicolumn{4}{|c|}{ Bray Curtis: HF, $\operatorname{Reg} 3 y^{+/-}$vs $\operatorname{Reg} 3 y^{-/-}$} \\
\hline & \multicolumn{2}{|c|}{ adonis } & \multicolumn{2}{|c|}{ ANOSIM } & \multicolumn{2}{|c|}{ adonis } & \multicolumn{2}{|c|}{ ANOSIM } \\
\hline & $\mathrm{R}^{2}$ & $P$ value & $\mathrm{R}$ & $P$ value & $\mathrm{R}^{2}$ & $\mathrm{P}$ value & $\mathrm{R}$ & $P$ value \\
\hline & 0.0653 & 0.003 & 0.1064 & 0.0089 & 0.0234 & 0.328 & 0.0086 & 0.28 \\
\hline & \multicolumn{4}{|c|}{ Bray Curtis: $\operatorname{Reg} 3 y^{+-}$, RC vs HF } & \multicolumn{4}{|c|}{ Bray Curtis: $\operatorname{Reg} 3 \gamma^{\prime-}, \mathrm{RC}$ vs HF } \\
\hline & adonis & ANOSIM & adonis & ANOSIM & & & & \\
\hline & $\mathrm{R}^{2}$ & $P$ value & $\mathrm{R}$ & $P$ value & $\mathrm{R}^{2}$ & $\mathrm{P}$ value & $\mathrm{R}$ & $P$ value \\
\hline & 0.2127 & 0.001 & 0.532 & 0.001 & 0.194 & 0.001 & 0.4215 & 0.001 \\
\hline \multirow{12}{*}{ DIMS } & \multicolumn{8}{|c|}{ Bray Curtis: RC $\operatorname{Reg} 3 \gamma^{+/-}, \operatorname{Reg} 3 \gamma^{-/-}$vs HF $\operatorname{Reg} 3 \gamma^{+/}, \operatorname{Reg} 3 \gamma^{-/-}$} \\
\hline & \multicolumn{4}{|c|}{ adonis } & \multicolumn{4}{|c|}{ ANOSIM } \\
\hline & & 2 & & alue & & $R$ & & alue \\
\hline & & 691 & & 01 & & 786 & & 001 \\
\hline & Bray & rtis: RC, & $g 3 y^{+/-} v$ & $\operatorname{Reg} 3 \gamma^{-/-}$ & Bray & urtis: HF, & $\operatorname{egg} 3 y^{+/-}$ & $\operatorname{Reg} 3 y^{-/-}$ \\
\hline & & nis & AN & SIM & & onis & & DSIM \\
\hline & $\mathrm{R}^{2}$ & $P$ value & $\mathrm{R}$ & $\mathrm{P}$ value & $\mathrm{R}^{2}$ & $\mathrm{P}$ value & $R$ & $P$ value \\
\hline & 0.032 & 0.136 & 0.0297 & 0.148 & 0.0211 & 0.4 & 0.0015 & 0.38 \\
\hline & Bra & Surtis: $R$ & $3 y^{+/-}, \mathrm{RC}$ & vs HF & Bra & Curtis: $R$ & $93 \gamma^{-1-}, \mathbf{R}$ & vs HF \\
\hline & & nis & AN & SIM & & onis & & DSIM \\
\hline & $\mathrm{R}^{2}$ & $P$ value & $\mathrm{R}$ & $P$ value & $\mathrm{R}^{2}$ & $\mathrm{P}$ value & $\mathrm{R}$ & $P$ value \\
\hline & 0.166 & 0.001 & 0.4465 & 0.001 & 0.1408 & 0.001 & 0.3364 & 0.001 \\
\hline
\end{tabular}


bioRxiv preprint doi: https://doi.org/10.1101/2020.06.17.130393; this version posted June 18, 2020. The copyright holder for this preprint (which was not certified by peer review) is the author/funder. All rights reserved. No reuse allowed without permission.

Table S4. eJTK OTU rhythmicity in DILC of RC and HF-fed SPF WT mice. Related to Figures 2, S2

\begin{tabular}{|c|c|c|c|c|c|c|c|c|c|c|c|c|}
\hline Diet & Taxonomy & OTU_ID & Phase & Mean & Std_Dev & Max & Min & $\begin{array}{l}\text { Max- } \\
\text { Amp }\end{array}$ & Tau & $\mathbf{P}$ & $\begin{array}{c}\text { Gamma } \\
\mathbf{P}\end{array}$ & $\begin{array}{c}\text { Gamma } \\
\text { BH }\end{array}$ \\
\hline & \multicolumn{12}{|c|}{$p<0.05$} \\
\hline \multirow{50}{*}{$\mathrm{RC}$} & $\begin{array}{l}\text { p_Firmicutes; c_Clostridia; o_Clostridiales; } \\
\text { f_Clostridiaceae }\end{array}$ & 225316 & 0 & 0.867 & 1.087 & 3 & 0 & 3 & 0.758 & $\begin{array}{c}4.13 \mathrm{E}- \\
05\end{array}$ & 0.0006 & 0.081 \\
\hline & $\begin{array}{l}\text { p__Firmicutes; c_Clostridia; o_CClostridiales; } \\
\text { f__Lachnospiraceae }\end{array}$ & 345709 & 16 & 54.067 & 94.339 & 339 & 0 & 339 & 0.736 & $\begin{array}{c}6.52 \mathrm{E}- \\
05\end{array}$ & 0.0009 & 0.081 \\
\hline & $\begin{array}{l}\text { p_Firmicutes; c_Bacilli; o_Lactobacillales; } \\
\text { f L Lactobacillaceae; g Lactobacillus }\end{array}$ & 182764 & 0 & 90.4 & 93.203 & 263 & 0 & 263 & 0.718 & $\begin{array}{l}9.45 \mathrm{E}- \\
05\end{array}$ & 0.0009 & 0.081 \\
\hline & p__ Firmicutes; c C Clostridia; o C Clostridiales & 459276 & 16 & 6.467 & 16.796 & 68 & 0 & 68 & 0.674 & 0.0002 & 0.0035 & 0.081 \\
\hline & $\begin{array}{llll}\text { p } & \text { Firmicutes; c } & \text { Clostridia; o } & \text { Clostridiales } \\
\end{array}$ & 406247 & 20 & 2.067 & 2.977 & 10 & 0 & 10 & 0.672 & 0.0002 & 0.0036 & 0.081 \\
\hline & \begin{tabular}{|cccl} 
p & Firmicutes; $c$ Clostridia; o _ Clostridiales \\
\end{tabular} & 1108078 & 16 & 3.4 & 5.401 & 18 & 0 & 18 & 0.637 & 0.0005 & 0.0039 & 0.081 \\
\hline & $\begin{array}{l}\text { p_Firmicutes; c_Clostridia; o_Clostridiales; } \\
\text { f_Clostridiaceae }\end{array}$ & 256232 & 0 & 0.933 & 1.526 & 5 & 0 & 5 & 0.661 & 0.0003 & 0.0039 & 0.081 \\
\hline & $\begin{array}{l}\text { p_Firmicutes; c_Clostridia; o_Clostridiales; } \\
\text { f_Lachnospiraceae; g_Coprococcus }\end{array}$ & 1105328 & 12 & 0.667 & 1.135 & 3 & 0 & 3 & 0.629 & 0.0005 & 0.0039 & 0.081 \\
\hline & 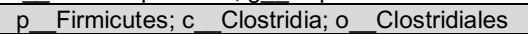 & 340650 & 16 & 0.8 & 1.833 & 7 & 0 & 7 & 0.637 & 0.0005 & 0.0039 & 0.081 \\
\hline & p_Firmicutes; c_Clostridia; o_Clostridiales & 346719 & 16 & 10 & 19.610 & 70 & 0 & 70 & 0.637 & 0.0005 & 0.0039 & 0.081 \\
\hline & $\begin{array}{l}\text { p_Firmicutes; c_Clostridia; o_Clostridiales; } \\
\text { f Ruminococcaceae }\end{array}$ & 375106 & 16 & 0.933 & 1.769 & 7 & 0 & 7 & 0.630 & 0.0005 & 0.0039 & 0.081 \\
\hline & $\mathrm{p}$ _Firmicutes; c_Clostridia; o_Clostridiales & 400599 & 16 & 1.333 & 3.360 & 13 & 0 & 13 & 0.637 & 0.0005 & 0.0039 & 0.081 \\
\hline & $\begin{array}{l}\text { p_Firmicutes; c_Clostridia; o_Clostridiales; } \\
\text { f_Lachnospiraceae }\end{array}$ & 355175 & 16 & 2.933 & 4.509 & 16 & 0 & 16 & 0.654 & 0.0003 & 0.0039 & 0.081 \\
\hline & $\begin{array}{l}\text { p_Firmicutes; c_Clostridia; o_Clostridiales; } \\
\text { f_Ruminococcaceae }\end{array}$ & 346804 & 16 & 0.667 & 1.491 & 6 & 0 & 6 & 0.621 & 0.0006 & 0.0039 & 0.081 \\
\hline & $\begin{array}{l}\text { p_Firmicutes; c_Clostridia; o_Clostridiales; } \\
\text { f_Ruminococcaceae; g_Ruminococcus }\end{array}$ & 278098 & 20 & 2 & 2.658 & 8 & 0 & 8 & 0.634 & 0.0005 & 0.0039 & 0.081 \\
\hline & $\begin{array}{l}\text { p__Firmicutes; c_Clostridia; o__Clostridiales; } \\
\text { f__Lachnospiraceae }\end{array}$ & 355771 & 16 & 9.4 & 22.633 & 81 & 0 & 81 & 0.629 & 0.0005 & 0.0039 & 0.081 \\
\hline & p_Firmicutes; c C Clostridia; o Clostridiales & 307170 & 16 & 3.533 & 7.890 & 31 & 0 & 31 & 0.654 & 0.0003 & 0.0039 & 0.081 \\
\hline & P_Firmicutes; c C Clostridia; o C Clostridiales & 335267 & 16 & 0.933 & 1.948 & 7 & 0 & 7 & 0.631 & 0.0005 & 0.0039 & 0.081 \\
\hline & $\begin{array}{llll}\mathrm{p} & \text { Firmicutes; } \mathrm{c} & \text { Clostridia; o } & \text { Clostridiales } \\
\end{array}$ & 1571092 & 16 & 7.867 & 16.095 & 63 & 0 & 63 & 0.611 & 0.0008 & 0.0079 & 0.114 \\
\hline & p_ Firmicutes; c C Clostridia; o Clostridiales & 826541 & 16 & 2.933 & 3.415 & 10 & 0 & 10 & 0.615 & 0.0007 & 0.0079 & 0.114 \\
\hline & $\begin{array}{l}\text { p_Firmicutes; c_Bacilli; o Turicibacterales; } \\
\text { f_Turicibacteraceae; } g \text { Turicibacter }\end{array}$ & 347529 & 4 & 2.133 & 1.310 & 4 & 0 & 4 & 0.605 & 0.0008 & 0.0079 & 0.114 \\
\hline & $\begin{array}{l}\text { p_Firmicutes; c_Clostridia; o_Clostridiales; } \\
\text { f_Ruminococcaceae; g_Oscillospira }\end{array}$ & 307608 & 20 & 1.067 & 2.323 & 8 & 0 & 8 & 0.598 & 0.0009 & 0.0079 & 0.114 \\
\hline & $\begin{array}{l}\text { p_Tenericutes; c_ Mollicutes; } \\
\text { o_Anaeroplasmatales; } \\
\text { f_Anaeroplasmataceae; g_Anaeroplasma }\end{array}$ & 252684 & 16 & 1.467 & 4.485 & 18 & 0 & 18 & 0.598 & 0.0009 & 0.0079 & 0.114 \\
\hline & $\begin{array}{l}\text { p_Firmicutes; c_Clostridia; o_Clostridiales; } \\
\text { f_Lachnospiraceae }\end{array}$ & 344726 & 0 & 6.267 & 9.692 & 33 & 0 & 33 & 0.579 & 0.0013 & 0.0129 & 0.129 \\
\hline & P_Firmicutes; c_Clostridia; o__Clostridiales & 697874 & 16 & 1.8 & 3.468 & 11 & 0 & 11 & 0.594 & 0.0010 & 0.0129 & 0.129 \\
\hline & $\begin{array}{l}\text { p__Firmicutes; c_Clostridia; o_Clostridiales; } \\
\text { f_Lachnospiraceae; g_Anaerostipes }\end{array}$ & 534926 & 16 & 7.4 & 13.908 & 56 & 0 & 56 & 0.588 & 0.0011 & 0.0129 & 0.129 \\
\hline & 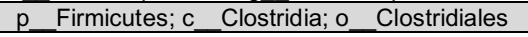 & 229452 & 16 & 18.667 & 49.076 & 198 & 0 & 198 & 0.579 & 0.0013 & 0.0129 & 0.129 \\
\hline & p__Firmicutes; c_Clostridia; o__Clostridiales & 1106614 & 16 & 16.667 & 29.236 & 98 & 0 & 98 & 0.585 & 0.0012 & 0.0129 & 0.129 \\
\hline & $\begin{array}{l}\text { p_Firmicutes; c_Clostridia; o_Clostridiales; } \\
\text { f_Lachnospiraceae }\end{array}$ & 305012 & 16 & 3.867 & 7.745 & 30 & 0 & 30 & 0.595 & 0.0010 & 0.0129 & 0.129 \\
\hline & P_Firmicutes; C_Clostridia; o_Clostridiales & 408877 & 16 & 5.133 & 11.871 & 45 & 0 & 45 & 0.579 & 0.0013 & 0.0129 & 0.129 \\
\hline & P_Firmicutes; c_Clostridia; o_Clostridiales & 345862 & 16 & 8.333 & 12.451 & 37 & 0 & 37 & 0.578 & 0.0013 & 0.0129 & 0.129 \\
\hline & p_Firmicutes; c_Clostridia; o_Clostridiales & 356590 & 16 & 15.933 & 21.947 & 75 & 0 & 75 & 0.581 & 0.0013 & 0.0129 & 0.129 \\
\hline & $\begin{array}{l}\text { k_Bacteria; } p \text { _Cyanobacteria; } \\
\text { c_Chloroplast; o } \quad \text { Streptophyta }\end{array}$ & 3541 & 0 & 7.133 & 12.516 & 41 & 0 & 41 & 0.561 & 0.0018 & 0.0219 & 0.200 \\
\hline & $\begin{array}{l}\text { p__Firmicutes; c_Clostridia; o_Clostridiales; } \\
\text { f_Ruminococcaceae; g_Oscillospira }\end{array}$ & 328905 & 16 & 0.867 & 1.628 & 6 & 0 & 6 & 0.567 & 0.0016 & 0.0219 & 0.200 \\
\hline & $\begin{array}{l}\text { p_Firmicutes; c_Clostridia; o_Clostridiales; } \\
\text { f_Ruminococcaceae }\end{array}$ & 331737 & 16 & 5.8 & 11.594 & 45 & 0 & 45 & 0.555 & 0.0020 & 0.0292 & 0.259 \\
\hline & p_Firmicutes; c C Clostridia; o _ Clostridiales & 1112121 & 20 & 16.333 & 57.426 & 231 & 0 & 231 & 0.553 & 0.0020 & 0.0302 & 0.260 \\
\hline & $\begin{array}{l}\text { p__Firmicutes; c_Clostridia; o_Clostridiales; } \\
\text { f__Lachnospiraceae }\end{array}$ & 316946 & 16 & 1.4 & 3.460 & 13 & 0 & 13 & 0.548 & 0.0022 & 0.0331 & 0.260 \\
\hline & $\begin{array}{l}\text { p_Firmicutes; c_Clostridia; o__Clostridiales; } \\
\text { f_Ruminococcaceae }\end{array}$ & 170926 & 20 & 1.067 & 2.620 & 10 & 0 & 10 & 0.548 & 0.0022 & 0.0331 & 0.260 \\
\hline & $\begin{array}{l}\text { p_Firmicutes; c_Clostridia; o__Clostridiales; } \\
\text { f_Ruminococcaceae }\end{array}$ & 434089 & 0 & 4.4 & 8.732 & 33 & 0 & 33 & 0.541 & 0.0025 & 0.0359 & 0.260 \\
\hline & $\begin{array}{l}\text { p_Firmicutes; c_Clostridia; o_Clostridiales; } \\
\text { f_Ruminococcaceae; g_Oscillospira }\end{array}$ & 277588 & 16 & 0.467 & 1.258 & 5 & 0 & 5 & 0.538 & 0.0026 & 0.0359 & 0.260 \\
\hline & $\begin{array}{l}\text { p_Firmicutes; c_Clostridia; o__Clostridiales; } \\
\text { f_Ruminococcaceae }\end{array}$ & 1110008 & 16 & 3.533 & 7.374 & 28 & 0 & 28 & 0.541 & 0.0025 & 0.0360 & 0.260 \\
\hline & $\begin{array}{l}\text { p_Firmicutes; c_Clostridia; o_Clostridiales; } \\
\text { f_Ruminococcaceae }\end{array}$ & 318370 & 16 & 2.000 & 4.131 & 16 & 0 & 16 & 0.540 & 0.0025 & 0.0360 & 0.260 \\
\hline & p_ Firmicutes; c C Clostridia; o Clostridiales & 343581 & 16 & 12.467 & 27.131 & 99 & 0 & 99 & 0.535 & 0.0027 & 0.0408 & 0.269 \\
\hline & $\begin{array}{l}\text { p_Firmicutes; c_Clostridia; o__Clostridiales; } \\
\text { f_LLachnospiraceae; }\end{array}$ & 354163 & 20 & 12.800 & 20.582 & 69 & 0 & 69 & 0.534 & 0.0028 & 0.0413 & 0.269 \\
\hline & $\begin{array}{l}\text { p_Firmicutes; c_Clostridia; o Clostridiales; } \\
\text { f_Ruminococcaceae; g_Oscillospira }\end{array}$ & 345582 & 16 & 1.533 & 3.775 & 14 & 0 & 14 & 0.531 & 0.0029 & 0.0432 & 0.269 \\
\hline & $\begin{array}{l}\text { p_Firmicutes; c_Clostridia; o_Clostridiales; } \\
\text { f_Clostridiaceae }\end{array}$ & 555945 & 12 & 14.667 & 26.810 & 113 & 1 & 113 & 0.531 & 0.0029 & 0.0433 & 0.269 \\
\hline & P_Firmicutes; c_Clostridia; o_Clostridiales & 382220 & 16 & 7.333 & 20.758 & 83 & 0 & 83 & 0.529 & 0.0030 & 0.0447 & 0.269 \\
\hline & P_Firmicutes; c_Clostridia; o_Clostridiales & 377946 & 16 & 1.667 & 3.360 & 11 & 0 & 11 & 0.528 & 0.0030 & 0.0456 & 0.269 \\
\hline & $\begin{array}{l}\text { p_Firmicutes; c_Clostridia; o_Clostridiales; } \\
\text { f_Lachnospiraceae; g_Coprococcus }\end{array}$ & 653533 & 16 & 15.267 & 18.234 & 61 & 0 & 61 & 0.527 & 0.0031 & 0.0464 & 0.269 \\
\hline & $\begin{array}{l}\text { p_Firmicutes; c_Clostridia; o_Clostridiales; } \\
\text { f_Ruminococcaceae; g_Oscillospira }\end{array}$ & 167509 & 16 & 2.667 & 9.714 & 39 & 0 & 39 & 0.519 & 0.0035 & 0.0499 & 0.269 \\
\hline
\end{tabular}


bioRxiv preprint doi: https://doi.org/10.1101/2020.06.17.130393; this version posted June 18, 2020. The copyright holder for this preprint (which was not certified by peer review) is the author/funder. All rights reserved. No reuse allowed without permission.

\begin{tabular}{|c|c|c|c|c|c|c|c|c|c|c|c|c|}
\hline & p_ Firmicutes; c Clostridia; o Clostridiales & 747987 & 16 & 1.133 & 2.276 & 8 & 0 & 8 & 0.518 & 0.0035 & 0.0499 & 0.269 \\
\hline & p_ Firmicutes; c C Clostridia; o C Clostridiales & 197290 & 16 & 1.200 & 2.663 & 10 & 0 & 10 & 0.522 & 0.0033 & 0.0499 & 0.269 \\
\hline & $\begin{array}{l}\text { p__Firmicutes; c_Clostridia; o_Clostridiales; } \\
\text { f_Ruminococcaceae; g_Oscillospira }\end{array}$ & 327808 & 16 & 0.733 & 1.123 & 3 & 0 & 3 & 0.517 & 0.0036 & 0.0499 & 0.269 \\
\hline \multirow{7}{*}{ HF } & $\begin{array}{l}\text { P_Firmicutes; c_Erysipelotrichi; } \\
\text { o_Erysipelotrichales; f Erysipelotrichaceae }\end{array}$ & 167420 & 0 & 3.875 & 7.432 & 28 & 0 & 28 & 0.684 & 0.0001 & 0.0016 & 0.444 \\
\hline & $\begin{array}{l}\text { p_Firmicutes; c_Bacilli; o_Lactobacillales; } \\
\text { f_Lactobacillaceae; g_Lactobacillus }\end{array}$ & 306306 & 12 & 2.938 & 3.030 & 11 & 0 & 11 & 0.582 & 0.0008 & 0.0124 & 0.693 \\
\hline & $\begin{array}{l}\text { p_Bacteroidetes; c__Bacteroidia; } \\
\text { o__Bacteroidales; f_S } 24-7\end{array}$ & 271131 & 0 & 1.875 & 2.058 & 6 & 0 & 6 & 0.552 & 0.0014 & 0.0214 & 0.693 \\
\hline & $\begin{array}{l}\text { p__Firmicutes; c_Clostridia; o__Clostridiales; } \\
\text { f_Ruminococcaceae; g_Oscillospira }\end{array}$ & 277588 & 16 & 1.438 & 4.808 & 20 & 0 & 20 & 0.530 & 0.0021 & 0.0312 & 0.693 \\
\hline & $\begin{array}{l}\text { p_Firmicutes; c_Clostridia; o__Clostridiales; } \\
\text { f_Lachnospiraceae }\end{array}$ & 352559 & 0 & 5.125 & 12.639 & 53 & 0 & 53 & 0.508 & 0.0030 & 0.0453 & 0.693 \\
\hline & $\begin{array}{l}\text { p__Firmicutes; c_Clostridia; o__Clostridiales; } \\
\text { f_Lachnospiraceae }\end{array}$ & 345536 & 4 & 1.000 & 2.208 & 9 & 0 & 9 & 0.503 & 0.0033 & 0.0495 & 0.693 \\
\hline & \multicolumn{12}{|c|}{$p=0.05-0.1$} \\
\hline \multirow{31}{*}{$\mathrm{RC}$} & $\begin{array}{l}\text { P_Bacteroidetes; c__Bacteroidia; } \\
\text { o__Bacteroidales; f _ S24-7 }\end{array}$ & 445144 & 16 & $\begin{array}{c}6785.8 \\
67\end{array}$ & 4072.125 & 12745 & 103 & 12642 & 0.516 & 0.0037 & 0.0549 & 0.285 \\
\hline & $\begin{array}{l}\text { p_Firmicutes; c_Erysipelotrichi; } \\
\text { o_Erysipelotrichales; f_Erysipelotrichaceae }\end{array}$ & 167420 & 16 & 6.733 & 6.486 & 21 & 0 & 21 & 0.516 & 0.0037 & 0.0551 & 0.285 \\
\hline & p Firmicutes; c C Clostridia; o Clostridiales & 348404 & 20 & 4.933 & 7.602 & 28 & 0 & 28 & 0.516 & 0.0037 & 0.0554 & 0.285 \\
\hline & P_Firmicutes; $c \_$Clostridia; o_ Clostridiales & 628218 & 16 & 2.200 & 7.204 & 29 & 0 & 29 & 0.515 & 0.0037 & 0.0561 & 0.285 \\
\hline & $\begin{array}{l}\text { p_Firmicutes; c_Clostridia; o_Clostridiales; } \\
\text { f_Ruminococcaceae; g Oscillospira }\end{array}$ & 276985 & 16 & 4.667 & 10.593 & 42 & 0 & 42 & 0.510 & 0.0040 & 0.0594 & 0.290 \\
\hline & $\begin{array}{l}\text { p__Firmicutes; c_Clostridia; o_Clostridiales; } \\
\text { f_Ruminococcaceae; g_Oscillospira }\end{array}$ & 1110378 & 0 & 7.667 & 15.023 & 59 & 0 & 59 & 0.503 & 0.0045 & 0.0645 & 0.290 \\
\hline & $\begin{array}{l}\text { p_Firmicutes; c_Clostridia; o_Clostridiales; } \\
\text { f_Clostridiaceae }\end{array}$ & 3358082 & 0 & 1.000 & 1.317 & 4 & 0 & 4 & 0.498 & 0.0049 & 0.0659 & 0.290 \\
\hline & $\begin{array}{l}\text { p_Firmicutes; c_Bacilli; o_Lactobacillales; } \\
\text { f__Lactobacillaceae; } g \text { L_Lactobacillus }\end{array}$ & 549756 & 20 & 1.200 & 1.869 & 6 & 0 & 6 & 0.498 & 0.0048 & 0.0659 & 0.290 \\
\hline & $\begin{array}{l}\text { p_Firmicutes; c_Bacilli; o _Bacillales; } \\
\text { f__Staphylococcaceae; g__taphylococcus; } \\
\text { s__sciuri }\end{array}$ & 1084865 & 12 & 6.467 & 9.763 & 33 & 0 & 33 & 0.500 & 0.0047 & 0.0659 & 0.290 \\
\hline & $\begin{array}{l}\text { p_Firmicutes; c_Clostridia; o__Clostridiales; } \\
\text { f_Lachnospiraceae }\end{array}$ & 262104 & 16 & 1.533 & 3.442 & 12 & 0 & 12 & 0.499 & 0.0048 & 0.0659 & 0.290 \\
\hline & p_ Firmicutes; c Clostridia; o _ Clostridiales & 194662 & 16 & 3.733 & 10.408 & 42 & 0 & 42 & 0.499 & 0.0048 & 0.0659 & 0.290 \\
\hline & $\begin{array}{l}\text { p_Firmicutes; c_Clostridia; o__Clostridiales; } \\
\text { f_Lachnospiraceae }\end{array}$ & 258202 & 12 & 2.467 & 3.538 & 11 & 0 & 11 & 0.495 & 0.0050 & 0.0702 & 0.302 \\
\hline & P_Firmicutes; C_Clostridia; o__Clostridiales & 309054 & 16 & 2.067 & 3.820 & 14 & 0 & 14 & 0.495 & 0.0050 & 0.0703 & 0.302 \\
\hline & $\begin{array}{l}\text { p_Firmicutes; c_Bacilli; o Lactobacillales; } \\
\text { f Lactobacillaceae; g Lactobacillus }\end{array}$ & 590168 & 12 & 3.067 & 4.864 & 18 & 0 & 18 & 0.492 & 0.0053 & 0.0730 & 0.308 \\
\hline & p__Firmicutes; c__Clostridia; o__Clostridiales & 327284 & 16 & 4.933 & 12.678 & 51 & 0 & 51 & 0.490 & 0.0054 & 0.0743 & 0.309 \\
\hline & p_ Firmicutes; c C Clostridia; o Clostridiales & 564961 & 16 & 0.867 & 2.729 & 11 & 0 & 11 & 0.488 & 0.0056 & 0.0764 & 0.309 \\
\hline & $\begin{array}{l}\text { p__Firmicutes; c_Clostridia; o__Clostridiales; } \\
\text { f_Ruminococcaceae }\end{array}$ & 343140 & 16 & 8.933 & 16.723 & 66 & 0 & 66 & 0.488 & 0.0056 & 0.0766 & 0.309 \\
\hline & $\begin{array}{l}\text { p_Firmicutes; c_Clostridia; o__Clostridiales; } \\
\text { f_Lachnospiraceae }\end{array}$ & 759751 & 16 & 11.067 & 23.245 & 92 & 0 & 92 & 0.484 & 0.0060 & 0.0801 & 0.309 \\
\hline & $\begin{array}{l}\text { p__Firmicutes; c_Clostridia; o__Clostridiales; } \\
\text { f_Lachnospiraceae }\end{array}$ & 1076587 & 20 & 4.933 & 7.818 & 31 & 0 & 31 & 0.484 & 0.0060 & 0.0801 & 0.309 \\
\hline & $\begin{array}{l}\text { p_Firmicutes; c_Clostridia; o__Clostridiales; } \\
\text { f_Ruminococcaceae }\end{array}$ & 275218 & 16 & 1.933 & 5.285 & 21 & 0 & 21 & 0.482 & 0.0062 & 0.0820 & 0.309 \\
\hline & $\begin{array}{l}\text { P_Proteobacteria; c_Alphaproteobacteria; } \\
\text { o__Rickettsiales; f_Emitochondria }\end{array}$ & 1892252 & 16 & 9.533 & 24.857 & 100 & 0 & 100 & 0.481 & 0.0062 & 0.0825 & 0.309 \\
\hline & p_Firmicutes; c_Clostridia; o__Clostridiales & 434339 & 16 & 2.533 & 4.064 & 16 & 0 & 16 & 0.481 & 0.0062 & 0.0826 & 0.309 \\
\hline & $\begin{array}{l}\text { p_Firmicutes; c_Clostridia; o _Clostridiales; } \\
\text { f_Ruminococcaceae; g_Oscillospira }\end{array}$ & 180235 & 16 & 1.200 & 1.869 & 6 & 0 & 6 & 0.480 & 0.0063 & 0.0834 & 0.310 \\
\hline & $\mathrm{p}$ _ Firmicutes; c C Clostridia; o _ Clostridiales & 339718 & 20 & 2.400 & 6.888 & 28 & 0 & 28 & 0.476 & 0.0067 & 0.0869 & 0.313 \\
\hline & p F Firmicutes; c C Clostridia; o Clostridiales & 351062 & 20 & 7.000 & 11.736 & 44 & 0 & 44 & 0.476 & 0.0067 & 0.0869 & 0.313 \\
\hline & $\mathrm{p}$ Firmicutes; c Clostridia; o $\quad$ Clostridiales & 336276 & 16 & 7.200 & 12.357 & 43 & 0 & 43 & 0.475 & 0.0068 & 0.0879 & 0.313 \\
\hline & p_ Firmicutes; c Clostridia; o Clostridiales & 351859 & 20 & 6.000 & 8.989 & 26 & 0 & 26 & 0.475 & 0.0068 & 0.0879 & 0.313 \\
\hline & $\begin{array}{l}\text { p_Firmicutes; c_Clostridia; o_Clostridiales; } \\
\text { f_Clostridiaceae }\end{array}$ & 342504 & 16 & 0.467 & 0.618 & 2 & 0 & 2 & 0.472 & 0.0070 & 0.0905 & 0.315 \\
\hline & $\begin{array}{l}\text { P_Firmicutes; c_Clostridia; o_Clostridiales; } \\
\text { f_Ruminococcaceae; g Ruminococcus }\end{array}$ & 327900 & 20 & 4.267 & 9.896 & 38 & 0 & 38 & 0.472 & 0.0070 & 0.0905 & 0.315 \\
\hline & p Firmicutes; c Clostridia; o Clostridiales & 272949 & 16 & 9.867 & 28.234 & 113 & 0 & 113 & 0.469 & 0.0074 & 0.0937 & 0.321 \\
\hline & p Firmicutes; $c$ Clostridia; 0 Clostridiales & 458550 & 0 & 11.133 & 10.831 & 36 & 0 & 36 & 0.467 & 0.0077 & 0.0964 & 0.326 \\
\hline \multirow{10}{*}{$\mathrm{HF}$} & $\begin{array}{l}\text { p__Firmicutes; c_Clostridia; o_Clostridiales; } \\
\text { f_Ruminococcaceae; g_Oscillospira }\end{array}$ & 408513 & 16 & 22.125 & 39.141 & 159 & 1 & 158 & 0.496 & 0.0037 & 0.0556 & 0.693 \\
\hline & p__Firmicutes; c__Clostridia; o__Clostridiales & 356590 & 16 & 0.375 & 0.696 & 2 & 0 & 2 & 0.485 & 0.0044 & 0.0660 & 0.693 \\
\hline & $\begin{array}{l}\text { p__Firmicutes; c_Clostridia; o__Clostridiales; } \\
\text { f_Lachnospiraceae }\end{array}$ & 355175 & 16 & 0.125 & 0.331 & 1 & 0 & 1 & 0.477 & 0.0050 & 0.0744 & 0.693 \\
\hline & p__Firmicutes; c_Clostridia; o__Clostridiales & 461487 & 16 & 0.188 & 0.527 & 2 & 0 & 2 & 0.469 & 0.0056 & 0.0847 & 0.693 \\
\hline & $\begin{array}{l}\text { p__Firmicutes; c_Clostridia; o__Clostridiales; } \\
\text { f_Lachnospiraceae }\end{array}$ & 355822 & 16 & 0.313 & 0.982 & 4 & 0 & 4 & 0.469 & 0.0056 & 0.0847 & 0.693 \\
\hline & p_Firmicutes; c_Clostridia; o__Clostridiales & 346764 & 20 & 0.750 & 2.437 & 10 & 0 & 10 & 0.469 & 0.0056 & 0.0847 & 0.693 \\
\hline & $\begin{array}{l}\text { p__Firmicutes; c_Clostridia; o__Clostridiales; } \\
\text { f_Ruminococcaceae; g_Ruminococcus }\end{array}$ & 278098 & 20 & 0.563 & 0.788 & 2 & 0 & 2 & 0.468 & 0.0058 & 0.0863 & 0.693 \\
\hline & P_Firmicutes; c_Clostridia; o__Clostridiales & 458550 & 12 & 0.625 & 1.364 & 5 & 0 & 5 & 0.467 & 0.0058 & 0.0873 & 0.693 \\
\hline & $\begin{array}{l}\text { p__Firmicutes; c_Clostridia; o__Clostridiales; } \\
\text { f_Lachnospiraceae }\end{array}$ & 457614 & 16 & 1.375 & 1.798 & 7 & 0 & 7 & 0.466 & 0.0059 & 0.0889 & 0.693 \\
\hline & $\begin{array}{l}\text { p_Firmicutes; c_Clostridia; o__Clostridiales; } \\
\text { f_Lachnospiraceae; g_ Dorea }\end{array}$ & 724472 & 16 & 0.813 & 1.424 & 4 & 0 & 4 & 0.465 & 0.0060 & 0.0900 & 0.693 \\
\hline
\end{tabular}


Table S5. Statistical analysis of OTU relative abundances in DILC from Reg3 $\gamma^{+/-}$vs. Reg3 $\gamma^{-/-}$mice fed RC or HF diet determined via ANOVA. OTUs exhibiting Bonferroni P-values less than 0.05 are shown. Related to Figures 5, S5.

\begin{tabular}{|c|c|c|c|c|c|c|c|c|}
\hline Taxonomy & OTU ID & $\begin{array}{l}\text { Test- } \\
\text { stat }\end{array}$ & $\begin{array}{c}\text { FDR } \\
\text { P-value }\end{array}$ & $\begin{array}{l}\text { Bonferroni } \\
\text { P-value }\end{array}$ & $\begin{array}{l}R e g 3 \gamma^{+/-} R C \\
\text { mean } \\
\text { relative } \\
\text { abundance }\end{array}$ & $\begin{array}{l}\operatorname{Reg} 3 \gamma^{+/-} \mathrm{HF} \\
\text { mean } \\
\text { relative } \\
\text { abundance }\end{array}$ & $\begin{array}{l}\operatorname{Reg} 3 \gamma^{-1-} \mathrm{RC} \\
\text { mean } \\
\text { relative } \\
\text { abundance }\end{array}$ & $\begin{array}{l}R e g 3 \gamma^{-1-} \mathrm{HF} \\
\text { mean } \\
\text { relative } \\
\text { abundance }\end{array}$ \\
\hline $\begin{array}{l}\text { p_Firmicutes; } \mathrm{c} \text { _Clostridia; } \\
\text { o_Clostridiales; } f \quad \text { Clostridiaceae }\end{array}$ & 555945 & 20.247 & 4.39E-07 & 4.39E-07 & 47.04 & 660.68 & 8.67 & 385.55 \\
\hline $\begin{array}{l}\text { p_Firmicutes; c_Bacilli; } \\
\text { o__Lactobacillales; } \\
\text { f_Streptococcaceae; g_Lactococcus }\end{array}$ & 716006 & 16.191 & 8.23E-06 & $1.82 \mathrm{E}-05$ & 50.04 & 1117.48 & 14.08 & 933.09 \\
\hline $\begin{array}{l}\text { p_Firmicutes; c_Clostridia; } \\
\text { o__Clostridiales; } \\
\text { f _ Peptostreptococcaceae }\end{array}$ & 198209 & 15.642 & 8.23E-06 & 3.08E-05 & 0.17 & 5.84 & 0.17 & 3.82 \\
\hline $\begin{array}{l}\text { p_Firmicutes; c_Clostridia; } \\
\text { o__Clostridiales; } \\
\text { f_Peptostreptococcaceae }\end{array}$ & 180516 & 15.497 & 8.23E-06 & 3.54E-05 & 0.48 & 6.6 & 0.17 & 3.14 \\
\hline $\begin{array}{l}\text { p_Firmicutes; } \text { c_Clostridia; } \\
\text { o } \quad \text { Clostridiales; } f \quad \text { Clostridiaceae }\end{array}$ & 191803 & 15.342 & $8.23 \mathrm{E}-06$ & $4.12 \mathrm{E}-05$ & 0.13 & 1.8 & 0 & 0.45 \\
\hline $\begin{array}{l}\text { p_Firmicutes; c_Bacilli; } \\
\text { o__Lactobacillales; } \\
\text { f_Streptococcaceae; g__Lactococcus }\end{array}$ & 4468805 & 14.900 & 1.06E-05 & 6.34E-05 & 0.26 & 4.92 & 0 & 4.73 \\
\hline $\begin{array}{l}\text { p_Firmicutes; c_Clostridia; } \\
\text { o_Clostridiales }\end{array}$ & 248126 & 14.315 & $1.61 \mathrm{E}-05$ & 0.00011 & 0.04 & 2 & 0 & 1 \\
\hline $\begin{array}{l}\text { p_Firmicutes; c_Bacilli; } \\
\text { o__Lactobacillales; } \\
\text { f__Streptococcaceae; g__Lactococcus }\end{array}$ & 513080 & 14.065 & 1.64E-05 & 0.00014 & 0.26 & 6.96 & 0.17 & 5.55 \\
\hline $\begin{array}{l}\text { P__ Proteobacteria; } \\
\text { c_Betaproteobacteria; } \\
\text { o__Burkholderiales; f__Alcaligenaceae; } \\
\text { g__Sutterella }\end{array}$ & 359809 & 14.047 & 1.64E-05 & 0.00015 & 12.52 & 0.68 & 32.79 & 3.95 \\
\hline $\begin{array}{l}\text { p__ Firmicutes; } c \text { Clostridia; } \\
\text { o } \quad \text { Clostridiales; } f \quad \text { Clostridiaceae }\end{array}$ & 199268 & 13.512 & $2.52 \mathrm{E}-05$ & 0.00025 & 0.04 & 1.56 & 0.04 & 0.86 \\
\hline $\begin{array}{l}\text { p__Firmicutes; c_Clostridia; } \\
\text { o_Clostridiales; } \\
\text { f Peptostreptococcaceae }\end{array}$ & 347714 & 13.172 & 3.10E-05 & 0.00036 & 0.13 & 1.68 & 0 & 1.09 \\
\hline $\begin{array}{l}\text { p_Firmicutes; c_Bacilli; } \\
\text { o__Lactobacillales; } \\
\text { f__Streptococcaceae; g__Lactococcus }\end{array}$ & 571744 & 13.068 & 3.10E-05 & 0.00040 & 0.13 & 2.08 & 0 & 2.27 \\
\hline $\begin{array}{l}\text { p_Firmicutes; c_Bacilli; } \\
\text { o__Lactobacillales; } \\
\text { f_Streptococcaceae; g_L Lactococcus }\end{array}$ & 1523543 & 13.050 & 3.10E-05 & 0.00040 & 0 & 2.48 & 0 & 2.41 \\
\hline $\begin{array}{l}\text { p__Firmicutes; c_Clostridia; } \\
\text { o__Clostridiales; } \\
\text { f_Peptostreptococcaceae }\end{array}$ & 514988 & 12.659 & 4.02E-05 & 0.00060 & 0.09 & 2.4 & 0 & 1.41 \\
\hline $\begin{array}{l}\text { p_Bacteroidetes; c__Bacteroidia; } \\
\text { o__Bacteroidales; f_S } 24-7\end{array}$ & 270984 & 12.658 & 4.02E-05 & 0.00060 & 14.74 & 1.28 & 27.13 & 4.09 \\
\hline $\begin{array}{l}\text { p_Bacteroidetes; c__Bacteroidia; } \\
\text { o__Bacteroidales; f_S } 24-7\end{array}$ & 416078 & 12.443 & 4.71E-05 & 0.00075 & 36.30 & 1 & 41.17 & 7.36 \\
\hline $\begin{array}{l}\text { p_Bacteroidetes; c__ Bacteroidia; } \\
\text { o_Bacteroidales; f } \quad \text { S24-7 }\end{array}$ & 465480 & 12.118 & 6.07E-05 & 0.00105 & 0.57 & 0 & 2.04 & 0.09 \\
\hline $\begin{array}{l}\text { p_Firmicutes; c_Clostridia; } \\
\text { o__Clostridiales; } \\
\text { f_Peptostreptococcaceae }\end{array}$ & 178364 & 12.053 & 6.07E-05 & 0.00112 & 0.17 & 1.52 & 0 & 0.64 \\
\hline $\begin{array}{l}\text { p_Firmicutes; c_Bacilli; } \\
\text { o__Lactobacillales; } \\
\text { f_Streptococcaceae; g Lactococcus }\end{array}$ & 586387 & 12.033 & 6.07E-05 & 0.00115 & 0.17 & 3.08 & 0 & 2.55 \\
\hline $\begin{array}{l}\text { p__Bacteroidetes; c_ Bacteroidia; } \\
\text { o__Bacteroidales; } f \text { S } 24-7\end{array}$ & 355746 & 11.715 & 8.03E-05 & 0.00161 & 45.87 & 2.52 & 61.96 & 8.18 \\
\hline $\begin{array}{l}\text { p_Firmicutes; c_Clostridia; } \\
\text { o__Clostridiales; } \\
\text { f_Peptostreptococcaceae }\end{array}$ & 322840 & 11.517 & $9.42 \mathrm{E}-05$ & 0.00198 & 0.26 & 2.68 & 0 & 1.5 \\
\hline $\begin{array}{l}\text { p_Bacteroidetes; c__Bacteroidia; } \\
\text { o__Bacteroidales; f_S24-7 }\end{array}$ & 315430 & 11.258 & 0.0001183 & 0.00260 & 18.61 & 1.04 & 30.21 & 6.23 \\
\hline $\begin{array}{l}\text { p_Firmicutes; c_Bacilli; } \\
\text { o__Lactobacillales; } \\
\text { f_Streptococcaceae; g Lactococcus }\end{array}$ & 345575 & 11.116 & 0.0001316 & 0.00303 & 0.17 & 2.44 & 0 & 2.86 \\
\hline $\begin{array}{l}\text { p_Firmicutes; c_Clostridia; } \\
\text { o__Clostridiales; f_Clostridiaceae }\end{array}$ & 272964 & 10.653 & 0.0002068 & 0.00496 & 0.13 & 1.16 & 0 & 1.05 \\
\hline $\begin{array}{l}\text { p_Firmicutes; c_Clostridia; } \\
\text { o_Clostridiales; } \\
\text { f_Peptostreptococcaceae }\end{array}$ & 2658058 & 10.583 & 0.0002143 & 0.00536 & 0.04 & 1.44 & 0.08 & 0.73 \\
\hline
\end{tabular}


bioRxiv preprint doi: https://doi.org/10.1101/2020.06.17.130393; this version posted June 18, 2020. The copyright holder for this preprint (which was not certified by peer review) is the author/funder. All rights reserved. No reuse allowed without permission.

\begin{tabular}{|c|c|c|c|c|c|c|c|c|}
\hline $\begin{array}{l}\text { p__Bacteroidetes; c__Bacteroidia; } \\
\text { o__Bacteroidales; f_S } 24-7\end{array}$ & 421792 & 10.427 & 0.0002438 & 0.00634 & 89.91 & 2.2 & 106.79 & 16.41 \\
\hline $\begin{array}{l}\text { p_Firmicutes; c_Bacilli; } \\
\text { o__Lactobacillales; } \\
\text { f__Streptococcaceae; g__Lactococcus }\end{array}$ & 316321 & 10.330 & 0.0002606 & 0.00704 & 0.13 & 2.84 & 0.04 & 2.32 \\
\hline $\begin{array}{l}\text { p_Firmicutes; c_Bacilli; } \\
\text { o_Lactobacillales; } \\
\text { f_Lactobacillaceae; g__Lactobacillus }\end{array}$ & 604966 & 10.285 & 0.0002637 & 0.00739 & 10.91 & 0.56 & 10.96 & 2 \\
\hline $\begin{array}{l}\text { P_Firmicutes; c_Bacilli; } \\
\text { o__Lactobacillales; } \\
\text { f_Lactobacillaceae; g__Lactobacillus; } \\
\text { s_reuteri }\end{array}$ & 692154 & 10.208 & 0.0002678 & 0.00803 & 15.13 & 0.52 & 18 & 2 \\
\hline $\begin{array}{l}\text { p___Bacteroidetes; c___Bacteroidia; } \\
\text { o__Bacteroidales; f_S } 24-7\end{array}$ & 453896 & 10.208 & 0.0002678 & 0.00804 & 32.91 & 2.96 & 57.42 & 9.09 \\
\hline $\begin{array}{l}\text { p_Firmicutes; c_Bacilli; } \\
\text { o__Lactobacillales; } \\
\text { f_Streptococcaceae; g__Lactococcus }\end{array}$ & 288680 & 9.598 & 0.0005047 & 0.015647 & 0 & 2.2 & 0 & 1.86 \\
\hline $\begin{array}{l}\text { p_Firmicutes; c_Clostridia; } \\
\text { o__Clostridiales; } \\
\text { f_Peptostreptococcaceae }\end{array}$ & 4380137 & 9.291 & 0.0006861 & 0.02196 & 0 & 0.8 & 0 & 0.23 \\
\hline $\begin{array}{l}\text { p_Firmicutes; c_Bacilli; } \\
\text { o__Lactobacillales; } \\
\text { f__Lactobacillaceae; g__Lactobacillus; } \\
\text { s__reuteri }\end{array}$ & 588197 & 9.229 & 0.0007129 & 0.02353 & 4.04 & 0.52 & 5.54 & 0.86 \\
\hline $\begin{array}{l}\text { P_Bacteroidetes; c__Bacteroidia; } \\
\text { o__Bacteroidales; f_S } 24-7\end{array}$ & 195919 & 9.164 & 0.0007435 & 0.02528 & 4.39 & 2.92 & 19 & 6.14 \\
\hline $\begin{array}{l}\text { p_Firmicutes; c_Bacilli; } \\
\text { o__Lactobacillales; } \\
\text { f_Lactobacillaceae; g__Lactobacillus }\end{array}$ & 1107027 & 8.845 & 0.0010308 & 0.03608 & 530.17 & 134.76 & 101.54 & 161.55 \\
\hline $\begin{array}{l}\text { p_Firmicutes; } \mathrm{c} \quad \text { Clostridia; } \\
\text { o__Clostridiales; } \mathrm{f} \quad \text { Clostridiaceae }\end{array}$ & 189407 & 8.606 & 0.0012965 & 0.04715 & 0.22 & 1.4 & 0 & 0.82 \\
\hline $\begin{array}{l}\text { p__Bacteroidetes; c _ Bacteroidia; } \\
\text { o__Bacteroidales; } f \quad S 24-7\end{array}$ & 331720 & 8.591 & 0.0012965 & 0.04797 & 0.74 & 0 & 1.38 & 0.23 \\
\hline
\end{tabular}


bioRxiv preprint doi: https://doi.org/10.1101/2020.06.17.130393; this version posted June 18, 2020. The copyright holder for this preprint (which was not certified by peer review) is the author/funder. All rights reserved. No reuse allowed without permission.

Table S6. eJTK OTU rhythmicity in DILC from RC and HF-fed Reg $3 \gamma^{+/-}$and $R e g 3 \gamma^{-/}$mice. Related to Figures $5,6,55$

\begin{tabular}{|c|c|c|c|c|c|c|c|c|c|c|c|c|}
\hline Group & Taxonomy & OTU_ID & Phase & Mean & Std_Dev & $\operatorname{Max}$ & $\begin{array}{c}\mathrm{Mi} \\
\mathrm{n}\end{array}$ & $\operatorname{Max}_{\bar{p}}$ & Tau & $\mathbf{P}$ & $\begin{array}{c}\text { Gamma } \\
P\end{array}$ & $\begin{array}{c}\text { Gamma } \\
\text { BH }\end{array}$ \\
\hline & \multicolumn{12}{|c|}{$\mathrm{p}<0.05$} \\
\hline \multirow{23}{*}{$\begin{array}{c}\mathrm{RC}- \\
\operatorname{Reg} 3 \gamma^{+/-}\end{array}$} & $\begin{array}{l}\text { p_Firmicutes; c_Bacilli; o_Lactobacillales; } \\
\text { f _ Streptococcaceae; g Lactococcus }\end{array}$ & 716006 & 12 & 50.043 & 221.377 & 1088 & 0 & 1088 & 0.625 & 0.0000 & 0.0002 & 0.099 \\
\hline & $\begin{array}{l}\text { p_Firmicutes; c_Bacilli; o Lactobacillales; } \\
\text { f_Streptococcaceae; g_Streptococcus }\end{array}$ & 1082539 & 12 & 0.522 & 1.137 & 5 & 0 & 5 & 0.566 & 0.0001 & 0.0012 & 0.212 \\
\hline & P_Cyanobacteria; c Chloroplast; o Streptophyta & 153978 & 12 & 2.696 & 5.303 & 21 & 0 & 21 & 0.555 & 0.0001 & 0.0016 & 0.212 \\
\hline & $\begin{array}{l}\text { p__Bacteroidetes; C__Bacteroidia; o__Bacteroidales; } \\
\text { f_S24-7 }\end{array}$ & 331720 & 20 & 0.739 & 1.293 & 5 & 0 & 5 & 0.541 & 0.0002 & 0.0023 & 0.212 \\
\hline & $\begin{array}{l}\text { p_Firmicutes; c_Clostridia; o_Clostridiales; } \\
\text { f_Clostridiaceae; g_Candidatus Arthromitus }\end{array}$ & 425767 & 20 & 6.609 & 12.744 & 59 & 0 & 59 & 0.538 & 0.0002 & 0.0024 & 0.212 \\
\hline & $\begin{array}{l}\text { p_Firmicutes; c Bacilli; o Lactobacillales; } \\
\text { f_Lactobacillaceae; } g_{\text {L_Lactobacillus; }} \mathrm{L}\end{array}$ & 269125 & 12 & 0.957 & 1.429 & 5 & 0 & 5 & 0.512 & 0.0003 & 0.0047 & 0.344 \\
\hline & $\begin{array}{l}\text { p_Bacteroidetes; c_Bacteroidia; o__Bacteroidales; } \\
\text { f_Rikenellaceae; } \mathrm{g} \text {; s }\end{array}$ & 264240 & 20 & 1.130 & 2.939 & 14 & 0 & 14 & 0.480 & 0.0007 & 0.0100 & 0.503 \\
\hline & $\begin{array}{l}\text { p_Actinobacteria; c_Actinobacteria; o } \text { Aifidobacteriales; } \\
\text { f B Bifidobacteriaceae; g_Bifidobacterium }\end{array}$ & 519290 & 12 & 0.522 & 0.827 & 3 & 0 & 3 & 0.479 & 0.0007 & 0.0102 & 0.503 \\
\hline & $\begin{array}{l}\text { p_Bacteroidetes; C_Bacteroidia; O_Bacteroidales; } \\
\text { f_S24-7 }\end{array}$ & 192906 & 20 & 0.348 & 0.560 & 2 & 0 & 2 & 0.479 & 0.0007 & 0.0103 & 0.503 \\
\hline & p_ Firmicutes; c C Clostridia; o Clostridiales & 351859 & 16 & 0.174 & 0.480 & 2 & 0 & 2 & 0.472 & 0.0008 & 0.0121 & 0.532 \\
\hline & P_Bacteroidetes; c_Bacteroidia; o_Bacteroidales & 801260 & 20 & 0.478 & 1.137 & 5 & 0 & 5 & 0.444 & 0.0015 & 0.0227 & 0.603 \\
\hline & $\begin{array}{l}\text { p__Firmicutes; c_Bacilli; o_Lactobacillales; } \\
\text { f_Lactobacillaceae; g_Lactobacillus }\end{array}$ & 135956 & 12 & 1.739 & 2.436 & 11 & 0 & 11 & 0.440 & 0.0016 & 0.0244 & 0.603 \\
\hline & p_ Firmicutes; c C Clostridia; o _ Clostridiales & 342786 & 20 & 0.261 & 0.845 & 4 & 0 & 4 & 0.429 & 0.0021 & 0.0311 & 0.603 \\
\hline & P_Firmicutes; c_Clostridia; o_ Clostridiales & 275139 & 12 & 0.957 & 3.689 & 18 & 0 & 18 & 0.426 & 0.0022 & 0.0334 & 0.603 \\
\hline & $\begin{array}{l}\text { P_Deferribacteres; c_Deferribacteres; } \\
\text { o_Deferribacterales; f_Deferribacteraceae; } \\
\text { g_Mucispirillum; s schaedleri }\end{array}$ & 1136443 & 12 & 3.957 & 16.897 & 83 & 0 & 83 & 0.420 & 0.0025 & 0.0372 & 0.603 \\
\hline & $\begin{array}{l}\text { P_Proteobacteria; c Alphaproteobacteria; } \\
\text { o_ Rhizobiales; } f \text { Brucellaceae; g Ochrobactrum }\end{array}$ & 817783 & 16 & 0.087 & 0.282 & 1 & 0 & 1 & 0.417 & 0.0027 & 0.0399 & 0.603 \\
\hline & $\begin{array}{l}\text { p_Actinobacteria; c_Actinobacteria; o Actinomycetales; } \\
\text { f Mycobacteriaceae; } g \text { _ Mycobacterium }\end{array}$ & 711803 & 16 & 0.087 & 0.282 & 1 & 0 & 1 & 0.417 & 0.0027 & 0.0399 & 0.603 \\
\hline & p__Firmicutes; c_Clostridia; o__Clostridiales & 831409 & 12 & 0.087 & 0.282 & 1 & 0 & 1 & 0.417 & 0.0027 & 0.0399 & 0.603 \\
\hline & $\begin{array}{l}\text { p_Firmicutes; c_Bacilli; o Bacillales; } \\
\text { f_Staphylococcaceae; g Staphylococcus; s_sciuri }\end{array}$ & 1084865 & 12 & 0.957 & 1.706 & 6 & 0 & 6 & 0.413 & 0.0029 & 0.0432 & 0.603 \\
\hline & $\begin{array}{l}\text { p_Bacteroidetes; C_Bacteroidia; O_Bacteroidales; } \\
\text { f_S } 24-7\end{array}$ & 348821 & 20 & 0.478 & 1.137 & 4 & 0 & 4 & 0.413 & 0.0029 & 0.0434 & 0.603 \\
\hline & P__Firmicutes; c_Clostridia; o__Clostridiales & 1108453 & 12 & 0.130 & 0.448 & 2 & 0 & 2 & 0.412 & 0.0029 & 0.0441 & 0.603 \\
\hline & $\begin{array}{l}\text { p_Firmicutes; c_Clostridia; o_Clostridiales; } \\
\text { f_Ruminococcaceae }\end{array}$ & 349459 & 12 & 0.217 & 0.832 & 4 & 0 & 4 & 0.412 & 0.0029 & 0.0441 & 0.603 \\
\hline & $\begin{array}{l}\text { p_Firmicutes; c_Clostridia; o_Clostridiales; } \\
\text { f_Ruminococcaceae }\end{array}$ & 336691 & 12 & 0.261 & 0.845 & 4 & 0 & 4 & 0.412 & 0.0030 & 0.0444 & 0.603 \\
\hline \multirow{14}{*}{$\begin{array}{c}\mathrm{HF}- \\
\operatorname{Reg}_{3 Y^{+/-}}\end{array}$} & $\begin{array}{l}\text { P__Bacteroidetes; C__Bacteroidia; O__Bacteroidales; } \\
\text { f_S } 24-7\end{array}$ & 338258 & 16 & 0.920 & 1.853 & 6 & 0 & 6 & 0.512 & 0.0002 & 0.0025 & 0.628 \\
\hline & P_TM7; c_TM7-3; o_CW040; f_F16 & 401717 & 20 & 0.400 & 1.020 & 4 & 0 & 4 & 0.497 & 0.0002 & 0.0037 & 0.628 \\
\hline & $\begin{array}{l}\text { p__Bacteroidetes; C_Bacteroidia; o__Bacteroidales; } \\
\text { f_S } 24-7\end{array}$ & 195919 & 16 & 2.920 & 8.849 & 43 & 0 & 43 & 0.456 & 0.0007 & 0.0105 & 0.628 \\
\hline & $\begin{array}{l}\text { P_Proteobacteria; c_Alphaproteobacteria; } \\
\text { o_Rhizobiales; f_Brucellaceae; g__Ochrobactrum }\end{array}$ & 256276 & 20 & 0.280 & 0.826 & 4 & 0 & 4 & 0.452 & 0.0008 & 0.0115 & 0.628 \\
\hline & $\begin{array}{l}\text { p_Firmicutes; c_Clostridia; o_Clostridiales; } \\
\text { f_Clostridiaceae }\end{array}$ & 555945 & 12 & $\begin{array}{c}660.68 \\
0\end{array}$ & 533.638 & 1777 & 0 & 1777 & 0.444 & 0.0009 & 0.0140 & 0.628 \\
\hline & $\begin{array}{l}\text { P_Bacteroidetes; C_Bacteroidia; O_Bacteroidales; } \\
\text { f_S24-7 }\end{array}$ & 270984 & 16 & 1.280 & 2.069 & 8 & 0 & 8 & 0.436 & 0.0011 & 0.0168 & 0.628 \\
\hline & $\begin{array}{l}\text { p_Firmicutes; c_Clostridia; o_Clostridiales; } \\
\text { f_Clostridiaceae }\end{array}$ & 297143 & 0 & 0.920 & 0.977 & 3 & 0 & 3 & 0.421 & 0.0016 & 0.0240 & 0.628 \\
\hline & $\begin{array}{l}\text { P_Bacteroidetes; C_Bacteroidia; O_Bacteroidales; } \\
\text { f_S24-7 }\end{array}$ & 315430 & 20 & 1.040 & 1.865 & 7 & 0 & 7 & 0.421 & 0.0016 & 0.0241 & 0.628 \\
\hline & $\begin{array}{l}\text { P__Bacteroidetes; C__Bacteroidia; o__Bacteroidales; } \\
\text { f_S } 24-7\end{array}$ & 389282 & 4 & 0.240 & 0.650 & 3 & 0 & 3 & 0.406 & 0.0022 & 0.0337 & 0.628 \\
\hline & P__Firmicutes; $\mathrm{C} \_$Clostridia; o_Clostridiales & 415491 & 20 & 0.640 & 1.694 & 8 & 0 & 8 & 0.404 & 0.0023 & 0.0349 & 0.628 \\
\hline & p_Firmicutes; c Clostridia; o_Clostridiales & 259870 & 20 & 0.200 & 0.632 & 3 & 0 & 3 & 0.391 & 0.0031 & 0.0461 & 0.628 \\
\hline & $\begin{array}{l}\text { p__Firmicutes; c Bacilli; o Lactobacillales; } \\
\text { f Streptococcaceae; g_Streptococcus }\end{array}$ & 661259 & 20 & 15.240 & 14.922 & 50 & 0 & 50 & 0.390 & 0.0032 & 0.0475 & 0.628 \\
\hline & $\begin{array}{l}\text { p_Firmicutes; c_Clostridia; o Clostridiales; } \\
\text { f_Ruminococcaceae; g_Oscillospira }\end{array}$ & 452014 & 20 & 0.120 & 0.325 & 1 & 0 & 1 & 0.389 & 0.0032 & 0.0478 & 0.628 \\
\hline & $\begin{array}{l}\text { p_Bacteroidetes; c_Bacteroidia; O_Bacteroidales; } \\
\text { f_S } 24-7\end{array}$ & 339017 & 20 & 0.520 & 1.836 & 9 & 0 & 9 & 0.388 & 0.0033 & 0.0489 & 0.628 \\
\hline \multirow{10}{*}{$\begin{array}{c}\mathrm{RC}- \\
\mathrm{Reg}_{3} \gamma^{-1}\end{array}$} & $\begin{array}{l}\text { P__Bacteroidetes; C_Bacteroidia; O_Bacteroidales; } \\
\text { f_S24-7 }\end{array}$ & 421792 & 20 & $\begin{array}{c}106.79 \\
2\end{array}$ & 111.521 & 461 & 0 & 461 & 0.513 & 0.0002 & 0.0033 & 0.526 \\
\hline & $\begin{array}{l}\text { p_Bacteroidetes; C_Bacteroidia; o__Bacteroidales; } \\
\text { f_Rikenellaceae }\end{array}$ & 264240 & 12 & 0.542 & 1.322 & 6 & 0 & 6 & 0.511 & 0.0002 & 0.0035 & 0.526 \\
\hline & $\begin{array}{l}\text { p_Firmicutes; c_Bacilli; o Lactobacillales; } \\
\text { f_Streptococcaceae; g_Streptococcus }\end{array}$ & 661259 & 16 & 4.125 & 8.964 & 36 & 0 & 36 & 0.497 & 0.0003 & 0.0050 & 0.526 \\
\hline & $\begin{array}{l}\text { p_Bacteroidetes; c_Bacteroidia; o__Bacteroidales; } \\
\text { f S S24-7 }\end{array}$ & 233587 & 4 & 0.542 & 0.957 & 3 & 0 & 3 & 0.483 & 0.0005 & 0.0070 & 0.526 \\
\hline & $\begin{array}{l}\text { p_Bacteroidetes; c_Bacteroidia; O_Bacteroidales; } \\
\text { f_S } 24-7\end{array}$ & 460953 & 4 & 1.083 & 1.288 & 5 & 0 & 5 & 0.468 & 0.0007 & 0.0101 & 0.526 \\
\hline & $\begin{array}{l}\text { P_Bacteroidetes; c__Bacteroidia; o__Bacteroidales; } \\
\text { f_S24-7 }\end{array}$ & 465480 & 4 & 2.042 & 2.389 & 9 & 0 & 9 & 0.456 & 0.0009 & 0.0135 & 0.526 \\
\hline & $\begin{array}{l}\text { p_Firmicutes; c_Bacilli; o_Lactobacillales; } \\
\text { f_Lactobacillaceae; g_Lactobacillus }\end{array}$ & 128227 & 8 & 0.417 & 0.571 & 2 & 0 & 2 & 0.443 & 0.0012 & 0.0183 & 0.526 \\
\hline & $\begin{array}{l}\text { p_Firmicutes; c Erysipelotrichi; o Erysipelotrichales; } \\
\text { f_Erysipelotrichaceae; g Allobaculum }\end{array}$ & 4379961 & 4 & 1.083 & 1.754 & 7 & 0 & 7 & 0.441 & 0.0013 & 0.0191 & 0.526 \\
\hline & $\begin{array}{l}\text { p_Bacteroidetes; c_Bacteroidia; O_Bacteroidales; } \\
\text { f_S } 24-7\end{array}$ & 348821 & 20 & 0.750 & 0.924 & 3 & 0 & 3 & 0.435 & 0.0014 & 0.0215 & 0.526 \\
\hline & $\begin{array}{l}\text { p_Firmicutes; c_Bacilli; o Lactobacillales; } \\
\text { f_Lactobacillaceae; g_Lactobacillus }\end{array}$ & 266445 & 8 & 8.292 & 11.074 & 51 & 0 & 51 & 0.432 & 0.0015 & 0.0231 & 0.526 \\
\hline
\end{tabular}


bioRxiv preprint doi: https://doi.org/10.1101/2020.06.17.130393; this version posted June 18, 2020. The copyright holder for this preprint (which was not certified by peer review) is the author/funder. All rights reserved. No reuse allowed without permission.

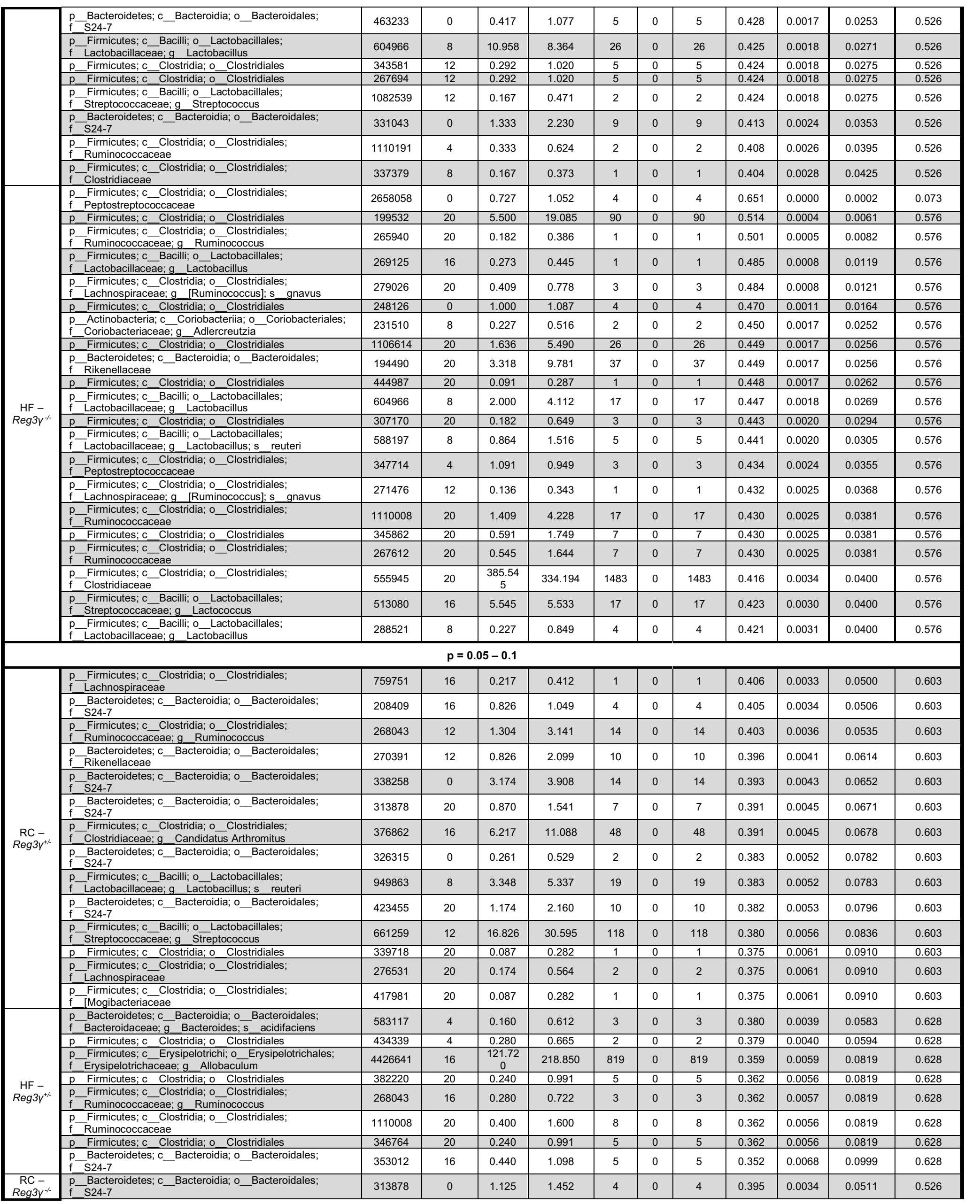


bioRxiv preprint doi: https://doi.org/10.1101/2020.06.17.130393; this version posted June 18, 2020. The copyright holder for this preprint (which was not certified by peer review) is the author/funder. All rights reserved. No reuse allowed without permission.

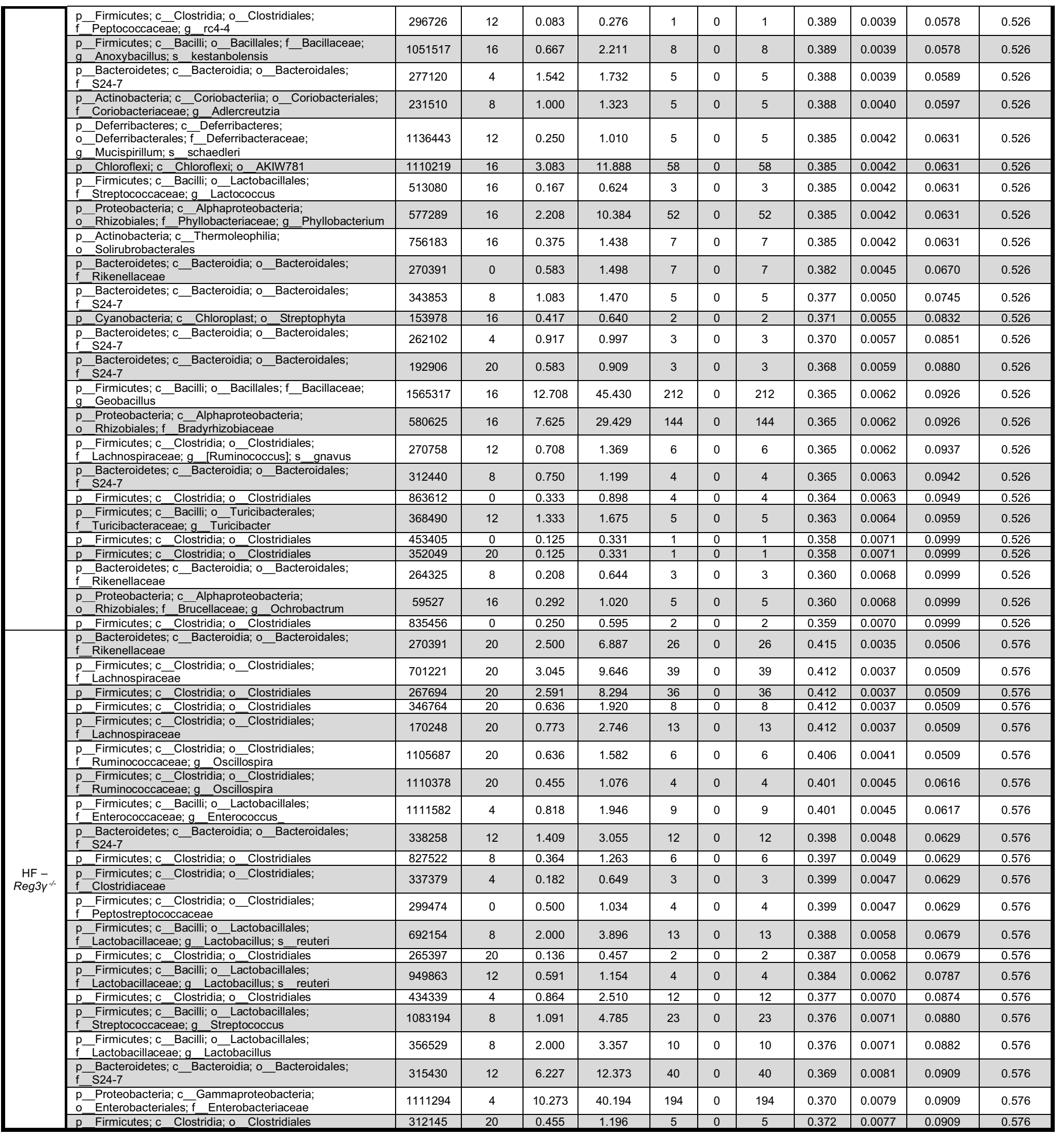


Table S7. eJTK oscillating OTUs in DILC and DIMS at the taxonomic levels of order and family in RC and HFfed $R e g 3 \gamma^{+/-}$and $R e g 3 \gamma^{-/-}$mice. Related to Figure 6.

\begin{tabular}{|c|c|c|c|c|c|c|c|c|c|}
\hline \multirow{3}{*}{ Order } & \multirow{3}{*}{ Family } & \multicolumn{4}{|c|}{ DILC } & \multicolumn{4}{|c|}{ DIMS } \\
\hline & & \multicolumn{2}{|c|}{$\operatorname{Reg} 3 y^{+/-}$} & \multicolumn{2}{|c|}{$\operatorname{Reg} 3 y^{-/-}$} & \multicolumn{2}{|c|}{$\operatorname{Reg} 3 y^{+/-}$} & \multicolumn{2}{|c|}{$\operatorname{Reg} 3 y^{-/-}$} \\
\hline & & RC & HF & $\mathbf{R C}$ & HF & RC & HF & RC & HF \\
\hline \multirow{2}{*}{ Actinomycetales } & Micrococcaceae & $\overline{0}$ & 0 & 0 & 0 & $\overline{0}$ & $\overline{1}$ & 0 & $\overline{0}$ \\
\hline & Mycobacteriaceae & 1 & 0 & 0 & 0 & 0 & 0 & 0 & 0 \\
\hline Bifidobacteriales & Bifidobacteriaceae & 1 & 0 & 0 & 0 & 0 & 1 & 0 & 1 \\
\hline Coriobacteriales & Coriobacteriaceae & 0 & 0 & 0 & 1 & 0 & 0 & 0 & 0 \\
\hline \multirow{4}{*}{ Bacteroidales } & Bacteroidaceae & 0 & 0 & 0 & 0 & 0 & 0 & 1 & 0 \\
\hline & Porphyromonadaceae & 0 & 0 & 0 & 0 & 0 & 1 & 1 & 0 \\
\hline & Rikenellaceae & 1 & 0 & 1 & 1 & 0 & 0 & 1 & 0 \\
\hline & S24-7 & 4 & 6 & 7 & 0 & 7 & 3 & 8 & 6 \\
\hline Deferribacterales & Deferribacteraceae & 1 & 0 & 0 & 0 & 0 & 0 & 0 & 0 \\
\hline Streptophyta & Unassigned Streptophyta & 1 & 0 & 0 & 0 & 0 & 0 & 0 & 0 \\
\hline Bacillales & Staphylococcaceae & 1 & 0 & 0 & 0 & 0 & 1 & 0 & 0 \\
\hline \multirow{3}{*}{ Lactobacillales } & Enterococcaceae & 0 & 0 & 0 & 0 & 0 & 1 & 0 & 0 \\
\hline & Lactobacillaceae* & 2 & 0 & 3 & 4 & 1 & 1 & 3 & 3 \\
\hline & Streptococcaceae & 2 & 1 & 2 & 1 & 0 & 1 & 0 & 1 \\
\hline Turicibacterales & Turicibacteraceae & 0 & 0 & 0 & 0 & 1 & 0 & 0 & 0 \\
\hline \multirow{7}{*}{ Clostridiales } & [Mogibacteriaceae] & 0 & 0 & 0 & 0 & 0 & 0 & 1 & 1 \\
\hline & Clostridiaceae* & 1 & 2 & 1 & 1 & $\mathbf{0}$ & 1 & 1 & 1 \\
\hline & Lachnospiraceae & 0 & 0 & 0 & 2 & 0 & 3 & 6 & 5 \\
\hline & Peptococcaceae & 0 & 0 & 0 & 0 & 0 & 0 & 1 & 0 \\
\hline & Peptostreptococcaceae* & $\mathbf{0}$ & 0 & 0 & 2 & $\mathbf{0}$ & 0 & 2 & 1 \\
\hline & Ruminococcaceae & 2 & 1 & 1 & 3 & 1 & 0 & 6 & 3 \\
\hline & Unassigned Clostridiales & 5 & 2 & 2 & 6 & 1 & 2 & 15 & 8 \\
\hline Erysipelotrichales & Erysipelotrichaceae & 0 & 0 & 1 & 0 & 0 & 1 & 0 & 0 \\
\hline Enterobacteriales & Enterobacteriaceae & 0 & 0 & 0 & 0 & 0 & 1 & 0 & 2 \\
\hline Pseudomonadales & Pseudomonadaceae & 0 & 0 & 0 & 0 & 0 & 1 & 0 & 0 \\
\hline Rhizobiales & Brucellaceae & 1 & 1 & 0 & 0 & 0 & 0 & 3 & 1 \\
\hline \multirow{2}{*}{ Burkholderiales } & Comamonadaceae & 0 & 0 & 0 & 0 & 0 & 0 & 0 & 1 \\
\hline & Oxalobacteraceae & 0 & 0 & 0 & 0 & 1 & 0 & 0 & 0 \\
\hline CW040 & F16 & 0 & 1 & 0 & 0 & 0 & 0 & 1 & 0 \\
\hline
\end{tabular}

*Blue-shaded rows refer to families where relative abundances over a 12:12 LD period are presented in main text Figure 6, panel D. 